\title{
ALGAE AND INVERTEBRATES IN THE WATER COLUMN OF SELECTED PRAIRIE WETLANDS IN THE COTTONWOOD LAKE AREA, STUTSMAN COUNTY, NORTH DAKOTA, 1984
}

By

J. W. LaBaugh and G. A. Swanson

\section{U. S. GEOLOGICAL SURVEY}

Open-File Report 88-451

Prepared in cooperation with the

U. S. FISH AND WILDLIFE SERVICE

NORTHERN PRAIRIE WILDLIFE RESEARCH CENTER 
DEPARTMENT OF THE INTERIOR

DONALD PAUL HODEL, Secretary

U.S. GEOLOGICAL SURVEY

Dallas L. Peck, Director

For additional information write to:

James W. LaBaugh

U.S. Geological Survey

Box 25046, MS 413

Denver Federal Center

Lakewood, CO 80225-0046
Copies of this report can be purchased from:

U. S. Geological Survey Books and Open-File Reports Federal Center, Building 810 Box 25425

Denver, CO 80225 


\section{CONTENTS}

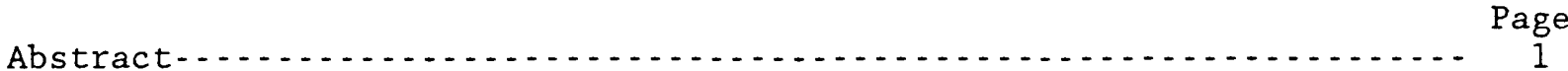

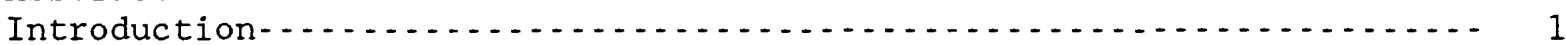

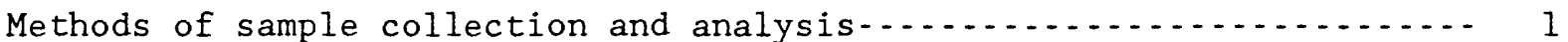

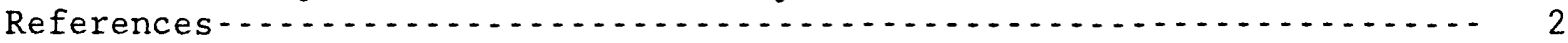

\section{ILLUSTRATIONS}

Figure 1. Map showing location of study area and location of wetlands in which algae and invertebrates were collected...........

2. Diagram showing design for sampling algae and invertebrates

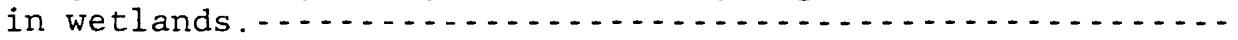

TABLES

Table 1. Algal species and species density in the water column of

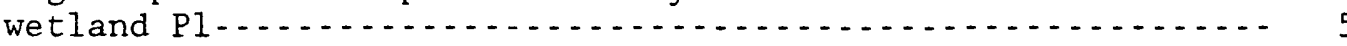

2. Algal species and species density in the water column of wetland P8 ..................................... 23

3. Algal species and species density in the water column of wetland Pl1 .................................... 48

4. Algal species and species density in the water column of

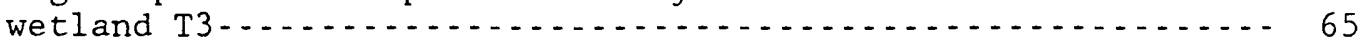

5. Algal species and species density in the water column of

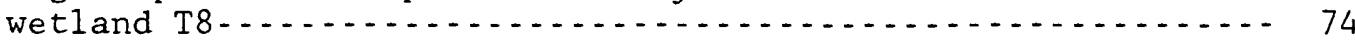

6. Invertebrate species and species density in the water column

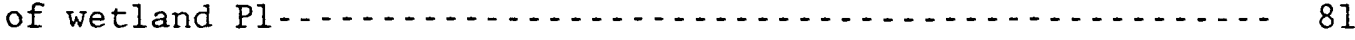

7. Invertebrate species and species density in the water column

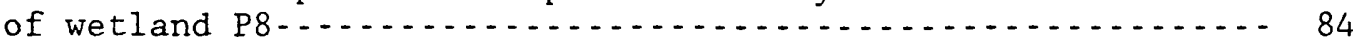

8. Invertebrate species and species density in the water column of wetland P11................................ 90

9. Invertebrate species and species density in the water column

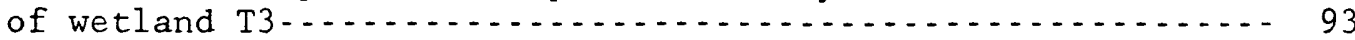

10. Invertebrate species and species density in the water column

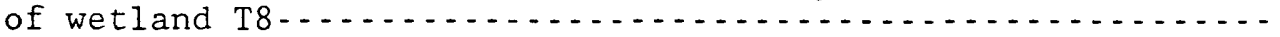

\section{METRIC CONVERSION FACTORS}

Multiply

micrometer

milliliter

liter by

$3.9370079 \times 10^{5}$

0.06102

0.0353
To obtain

inch cubic inch cubic foot 


\title{
ALGAE AND INVERTEBRATES IN THE WATER COLUMN OF SELECTED PRAIRIE WETLANDS IN THE COTTONWOOD LAKE AREA, STUTSMAN COUNTY, NORTH DAKOTA, 1984
}

\author{
by J. W. LaBaugh and G. A. Swanson ${ }^{1}$
}

\begin{abstract}
Studies of hydrological-biogeochemical interactions on selected prairie wetlands in the Cottonwood Lake area, Stutsman County, North Dakota, includes investigations of fluxes of chemical elements closely related to the structure and function of biological communities of these wetlands. Data presented in this report include species identification of algae and invertebrates and the density of each of those species collected in the water column of the wetlands. Samples were collected along three transects in each wetland during the period in 1984 that the wetlands contained water when ice was not present.
\end{abstract}

\section{INTRODUCTION}

Algae and invertebrate data were collected from selected prairie wetlands in the Cottonwood Lake area, Stutsman County, North Dakota (fig. 1 ), as part of a continuing study of the interaction between hydrologic fluxes, chemical fluxes, and the biological communities of these wetlands by the U.S. Geological Survey and the U.S. Fish and Wildlife Service. The rationale for selection of the Cottonwood Lake area for the intensive study of hydrologic, chemical, and biological processes is given by winter and Carr (1980). An interpretive report of the relation between chemical characteristics of wetlands and the local ground-water-flow system is given by LaBaugh and others (1987).

\section{METHODS OF SAMPLE COLLECTION AND ANALYSIS}

Two types of wetlands were selected for study, semipermanent and seasonal. Semipermanent wetlands contained water the entire year and were not covered by ice between late April and late October. Seasonal wetlands contained water from the time snow and ice melted in the wetlands in April until late July when the wetlands were completely dry. Samples were collected from semipermanent wetlands (wetland P1, wetland P8, and wetland P11) as well as from seasonal wetlands (wetland T3 and wetland T8) approximately once a month during the period when the wetlands contained water and were not covered by ice. All samples were collected at a single point along each of three transects in each wetland (fig. 2) by use of a tube water-column sampler that was described by Swanson (1978). Details concerning the location of the transects chosen for sample collection and point of collection within each transect in these wetlands were presented by LaBaugh and others (1987).

1. U. S. Fish and Wildlife Service, Jamestown, North Dakota 
After water from a transect within a wetland was collected in the tube water-column sampler, water for subsequent algal analysis from that transect was put into a 1-liter high-density polyethylene bottle. To this bottle, 10 milliliters of Lugol's solution was added as a preservative. Preserved samples were sent to Chadwick and Associates ${ }^{1}$, Littleton, Colorado, for species identification of algae and ennumeration of algae for species density (cells per milliliter) using an inverted microscope. Results of this analysis are presented in tables 1-5.

Prior to analysis of invertebrate species identification and ennumeration, the volume of water collected from an individual transect within a wetland was measured by use of a l-liter graduated cylinder and then recorded. Water was then poured through a Wisconsin plankton net bucket (mesh size opening 80 micrometers). The sample contained within the bucket was emptied into a 250 milliliter high-density polyethylene bottle. Soda water was added to narcotize the organisms in the bottle prior to the addition of 10 milliliters of 40 percent fomalin as a preservative. Preserved samples were sent to Dr. William Taylor, Michigan State University for species identification of invertebrates and ennumeration of each species. The number of organisms in the sample were divided by the corresponding recorded volume of water for that sample to determine the density of organisms per liter. These results are presented in Tables 6-10.

\section{REFERENCES}

LaBaugh, J.W., Winter, T.C., Adomaitis, V.A., and Swanson, G.A., 1987, Hydrology and chemistry of selected prairie wetlands in the Cottonwood Lake area, Stutsman County, North Dakota, 1979-82: U.S. Geological Survey Professional Paper 1431, 26 p.

Swanson, G.A., 1978, A water column sampler for invertebrates in shallow wetlands: Journal of Wildlife Management, v. 42, p. 670-671.

Winter, T.C., and Carr, M.R., 1980, Hydrologic setting of wetlands in the Cottonwood Lake area, Cottonwood Lake area, Stutsman County, North Dakota: U.S. Geological Survey Water-Resources Investigations 80-99, $42 \mathrm{p}$.

1. use of firm names in this report is for identification purposes only and does not constitute endorsement by the U.S. Geological Survey. 


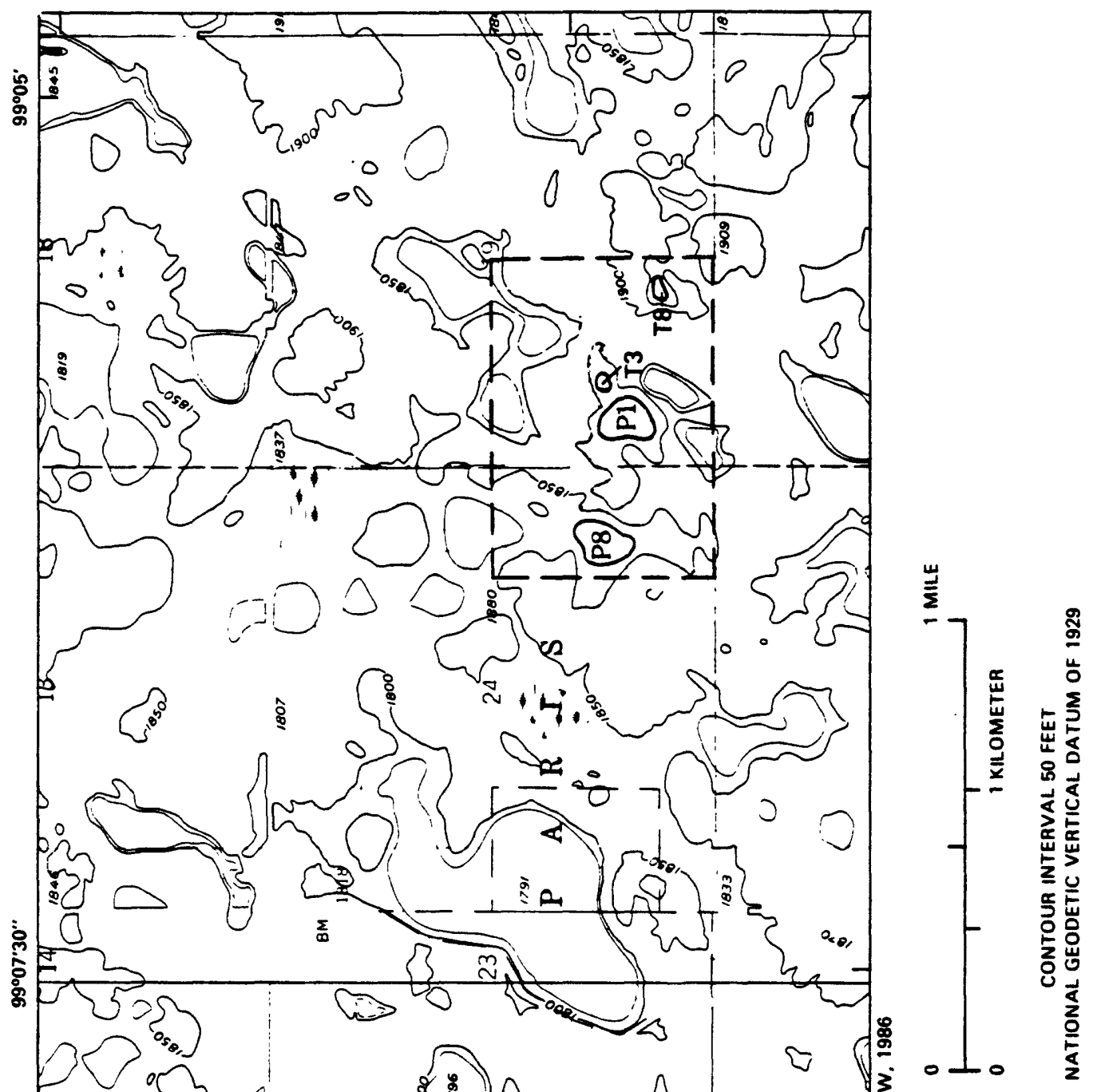

起

$\underbrace{}_{\rightarrow-1}$

范

40

5

○

$+\frac{1}{0}$

0

$\rightarrow$

㹂

告

4.1.

${ }_{0}^{S_{3}}$ sm ams

(3)

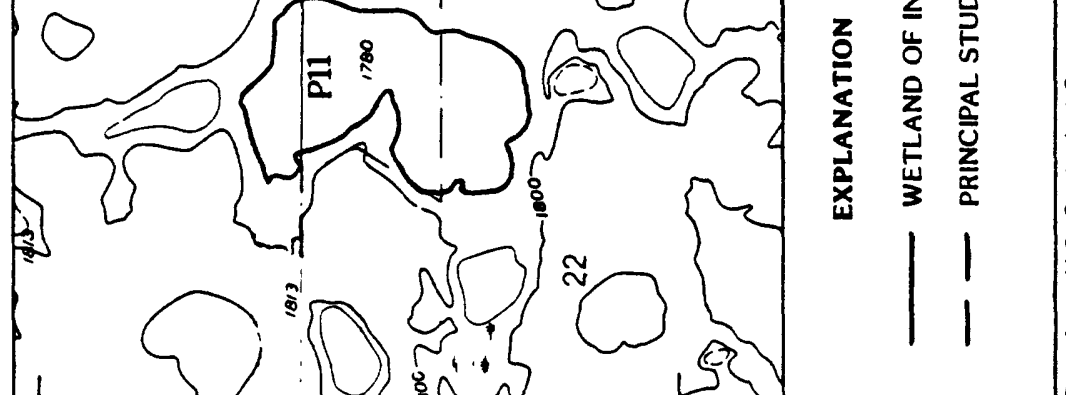

㝘 


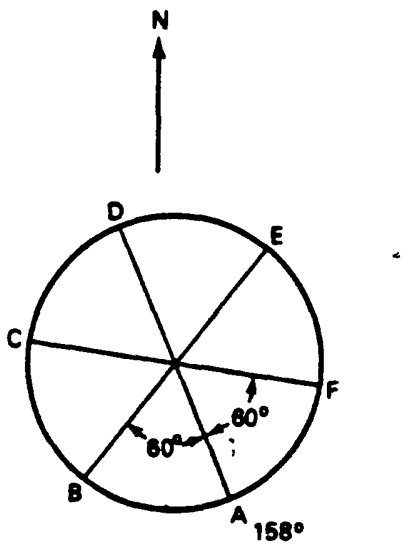

LOCATION OF SAMPLING TRANSECTS

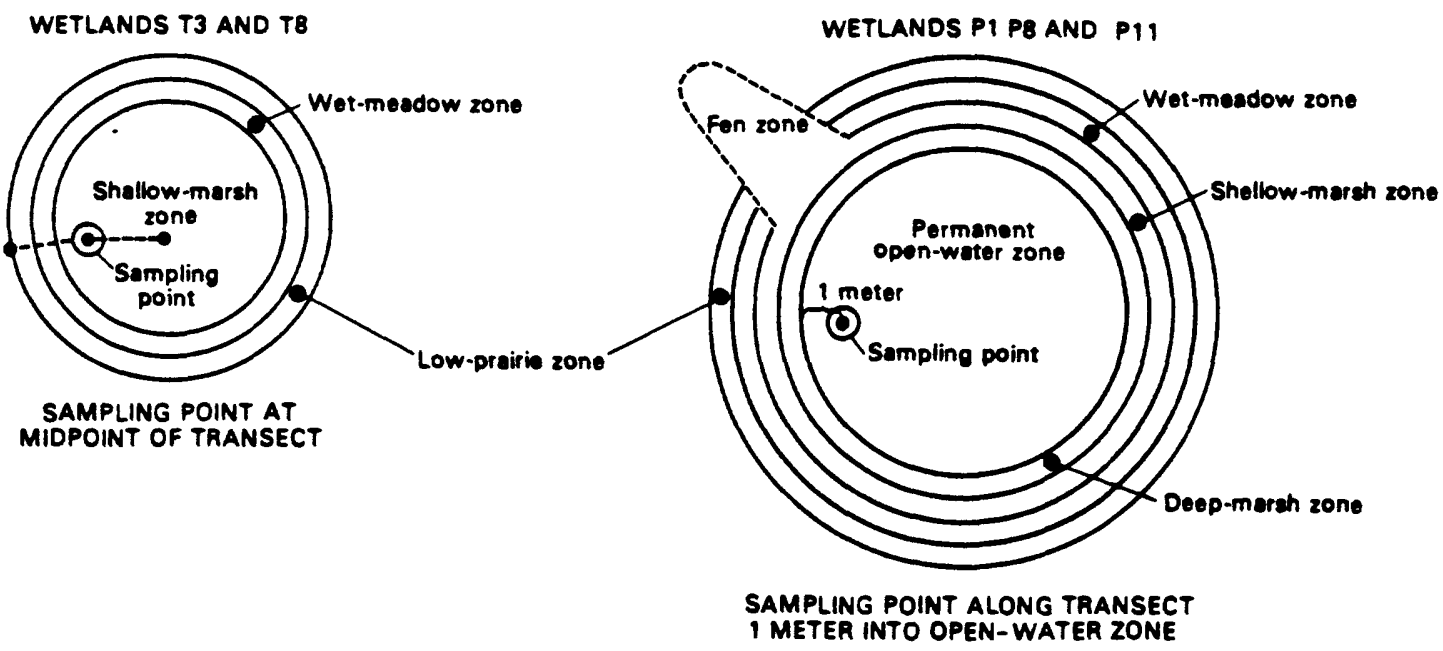

Figure 2.--Design for sampling algae and invertebrates in wetlands. 


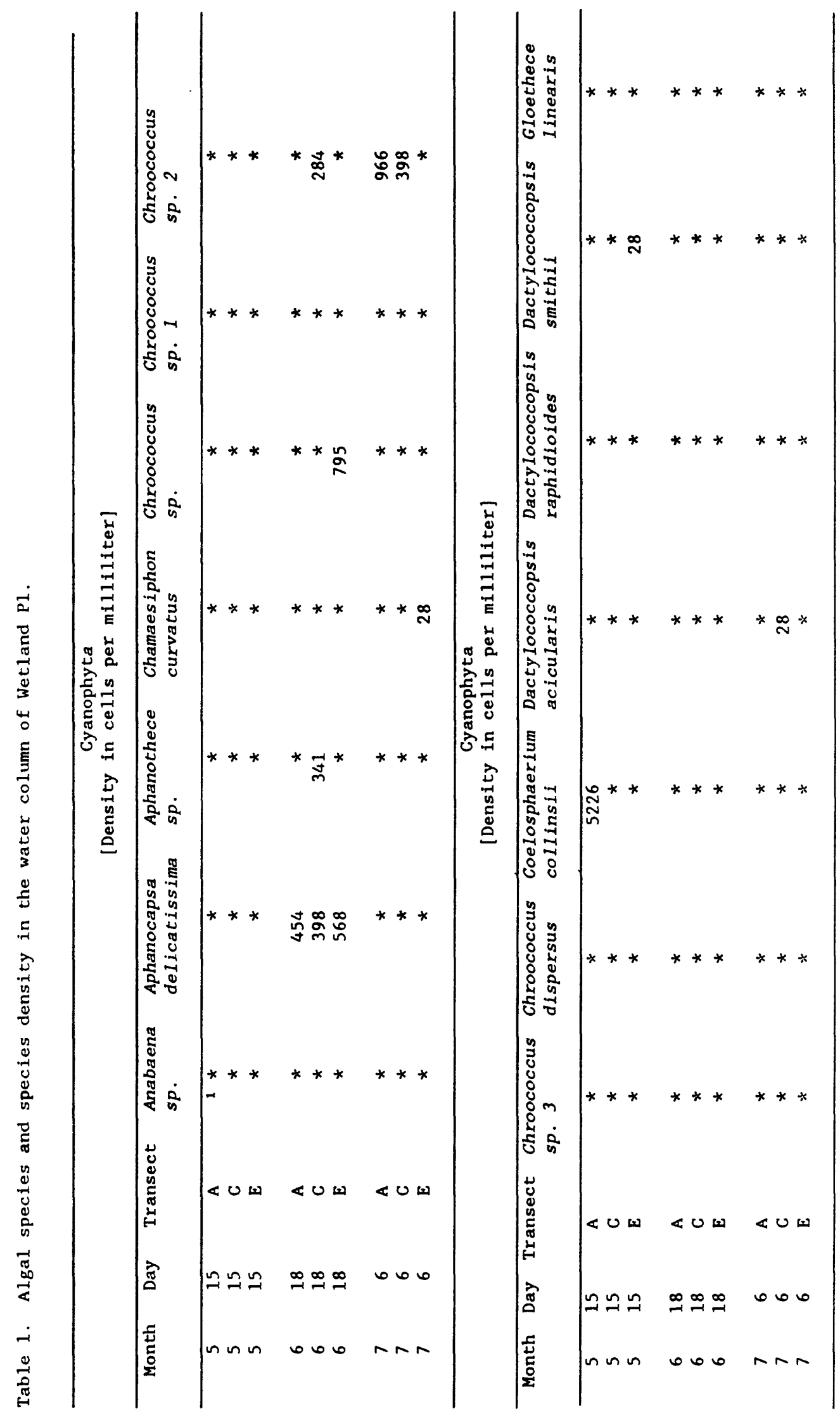




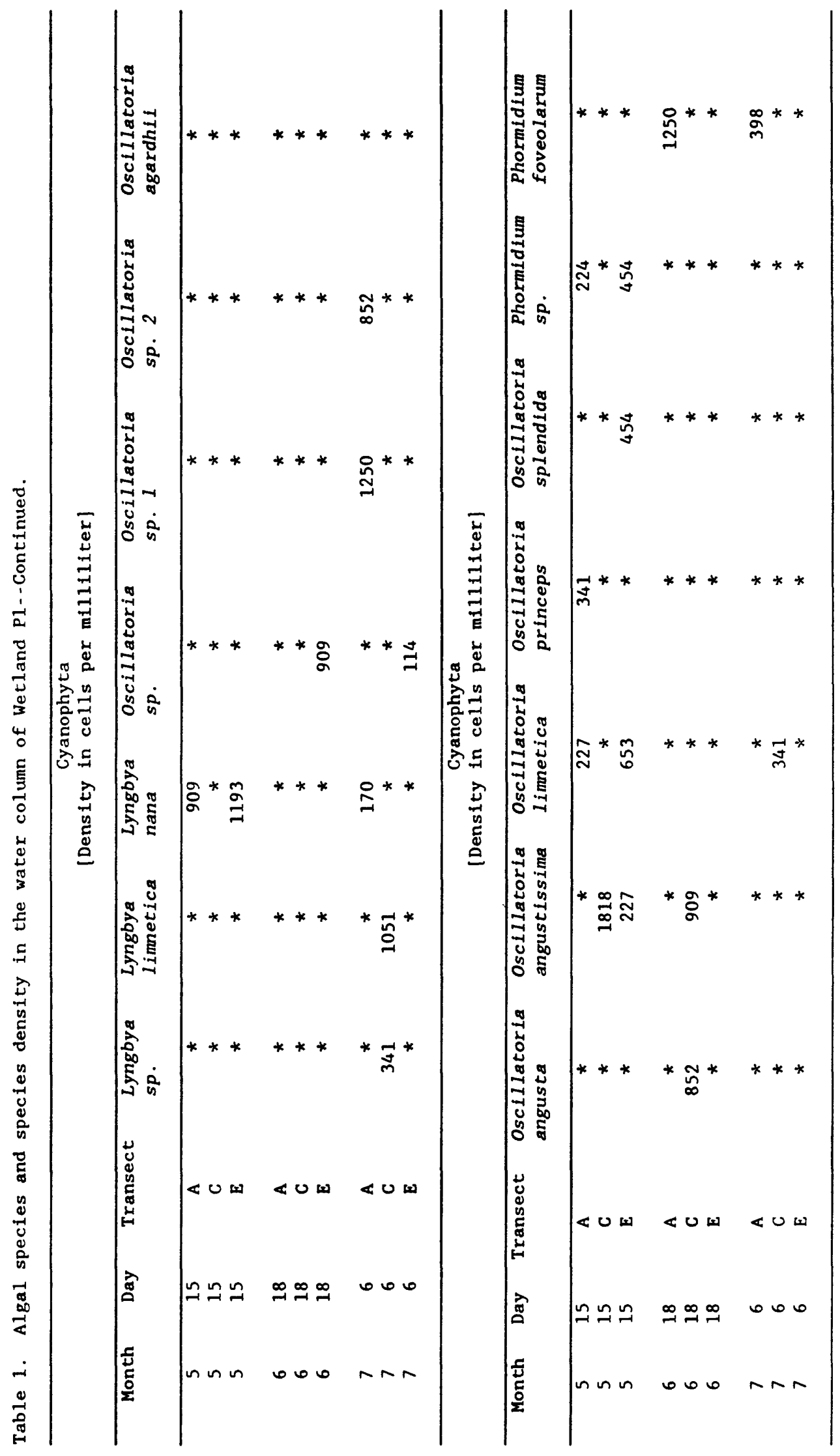




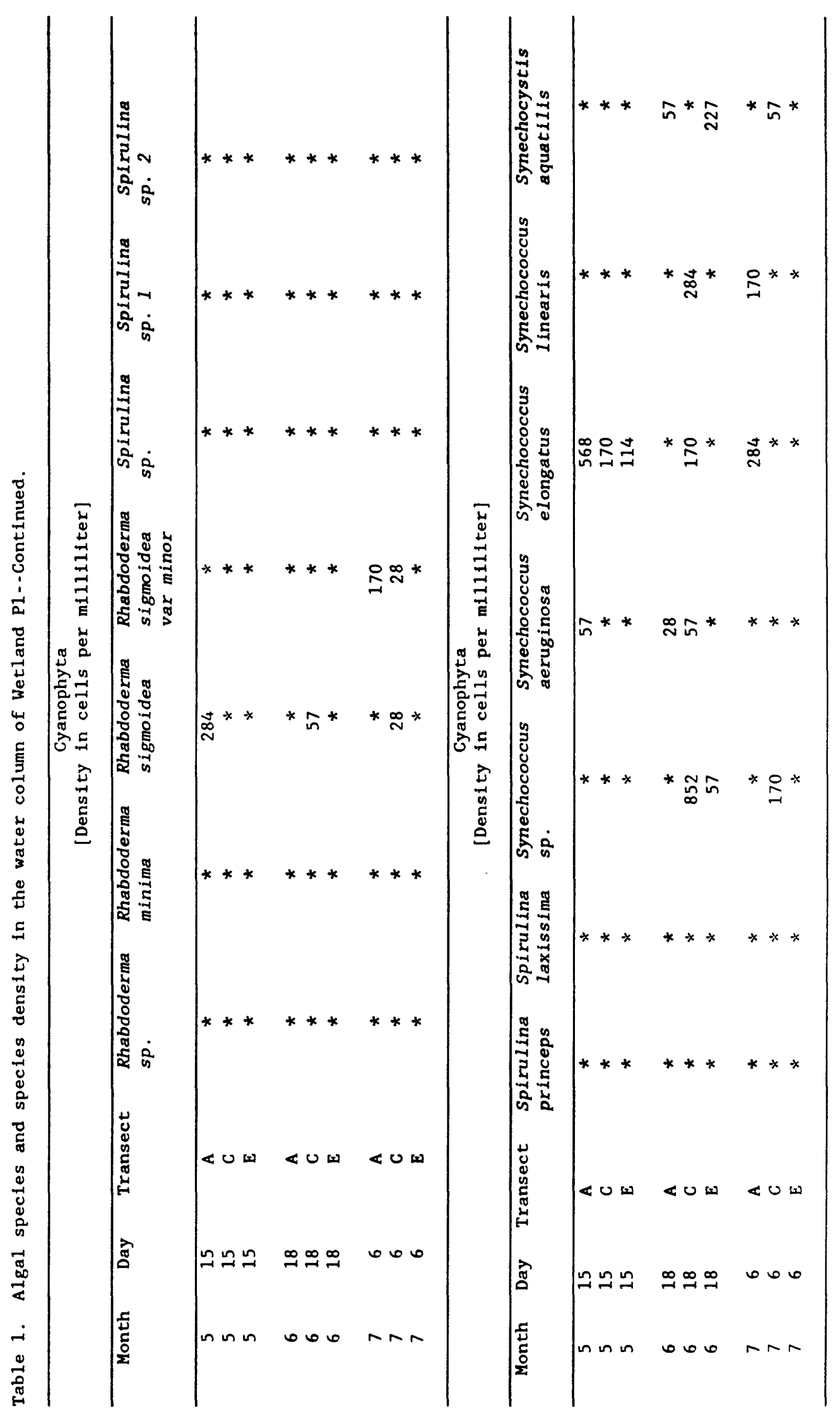




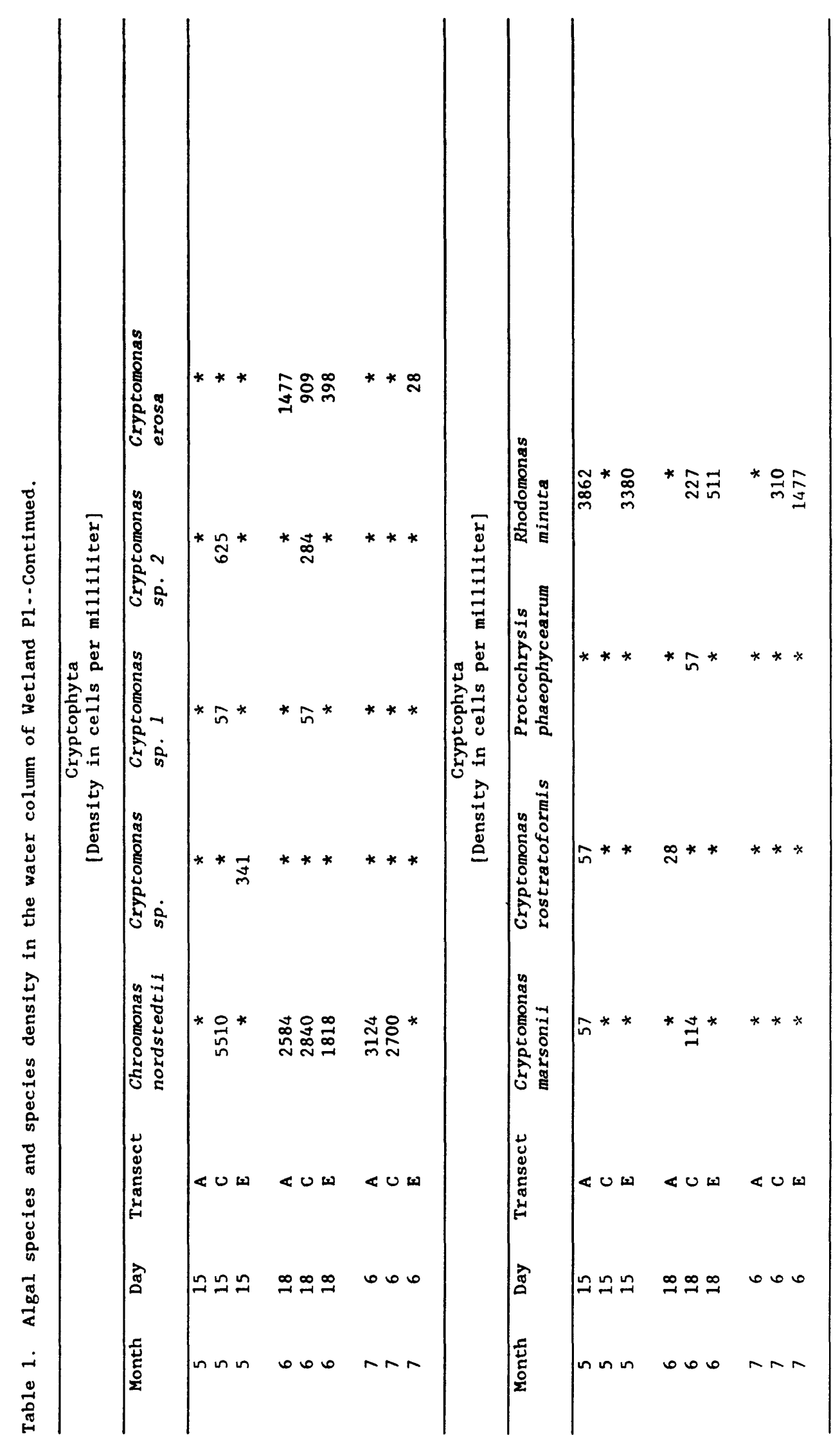




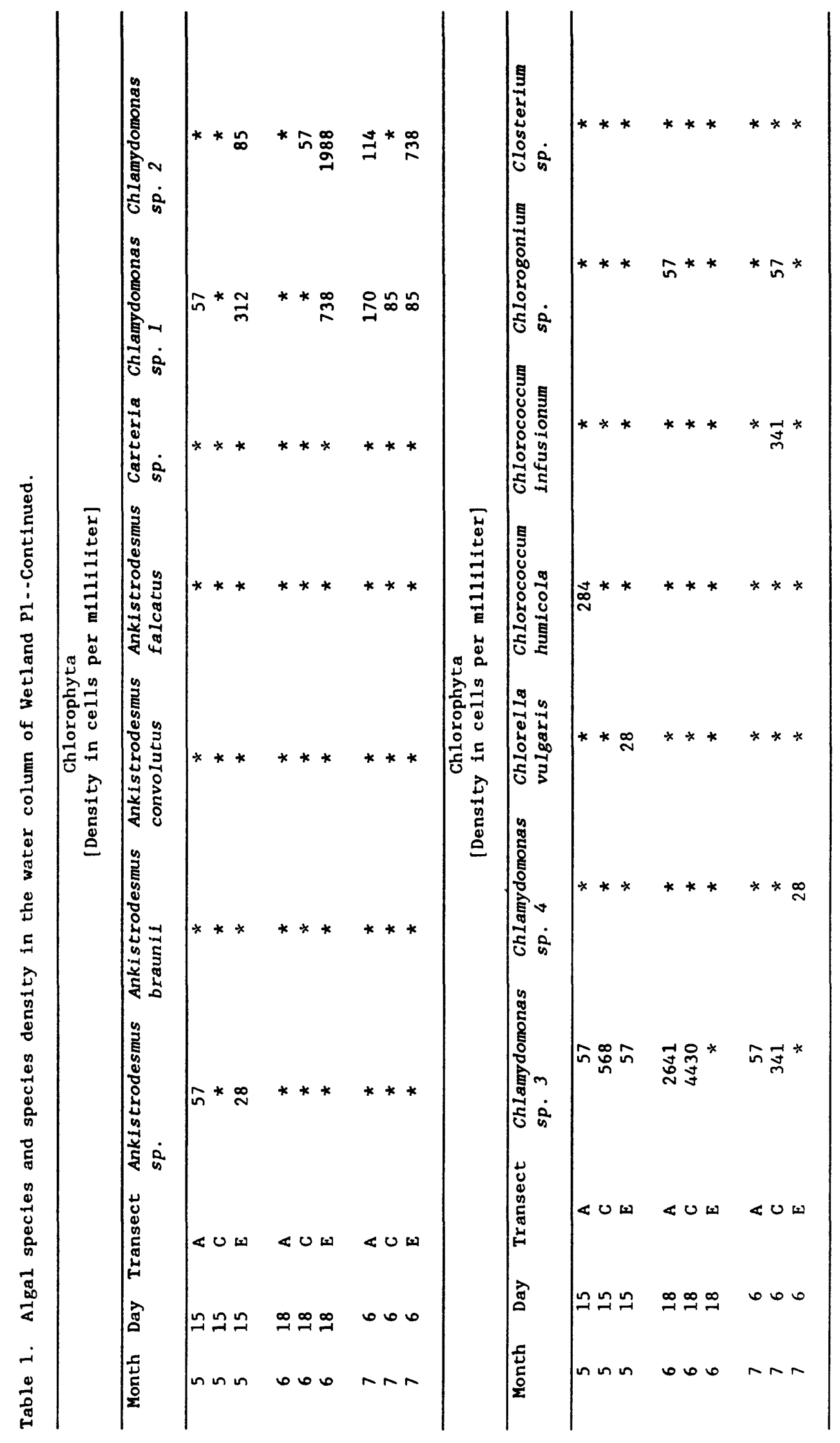




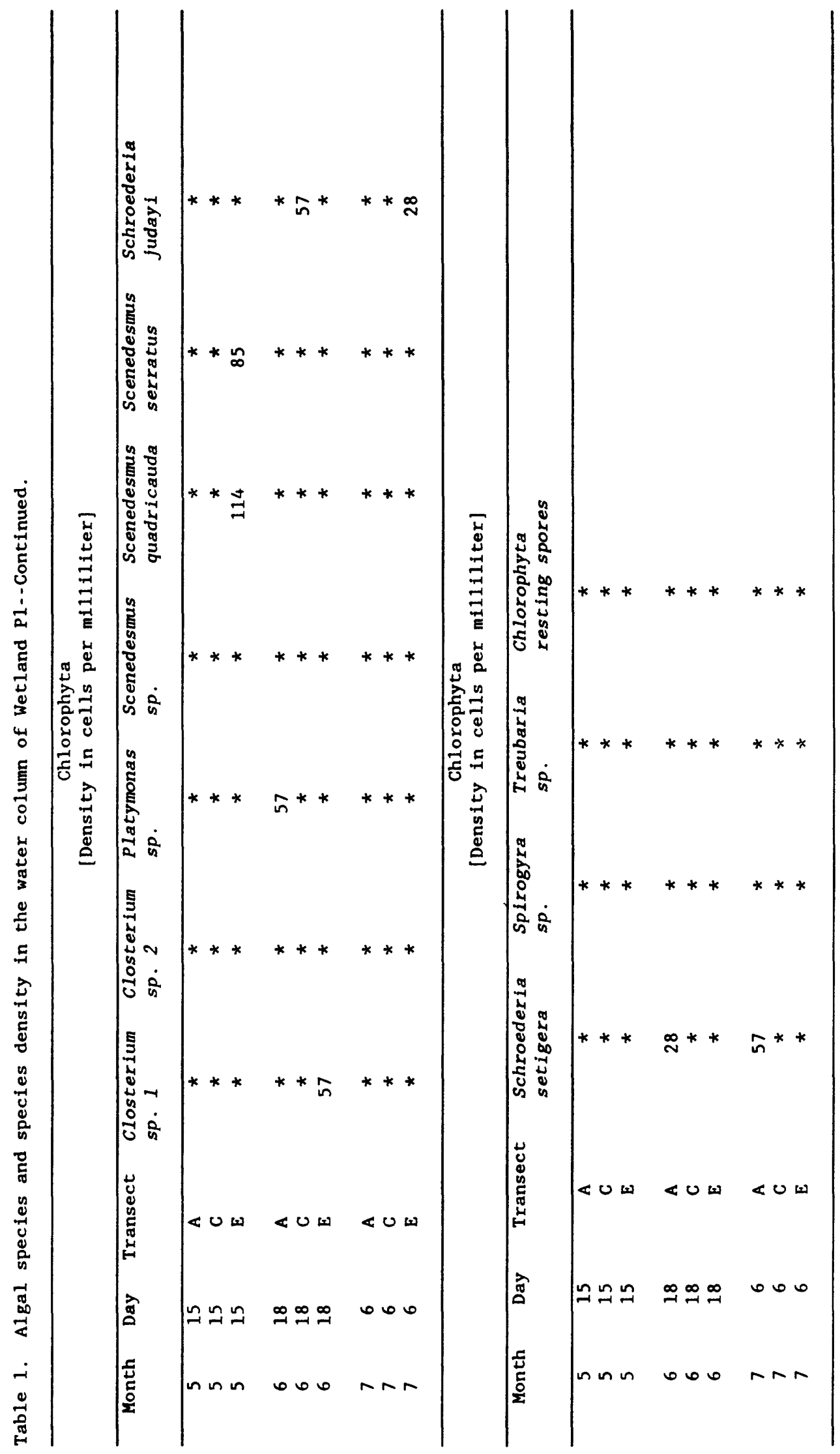








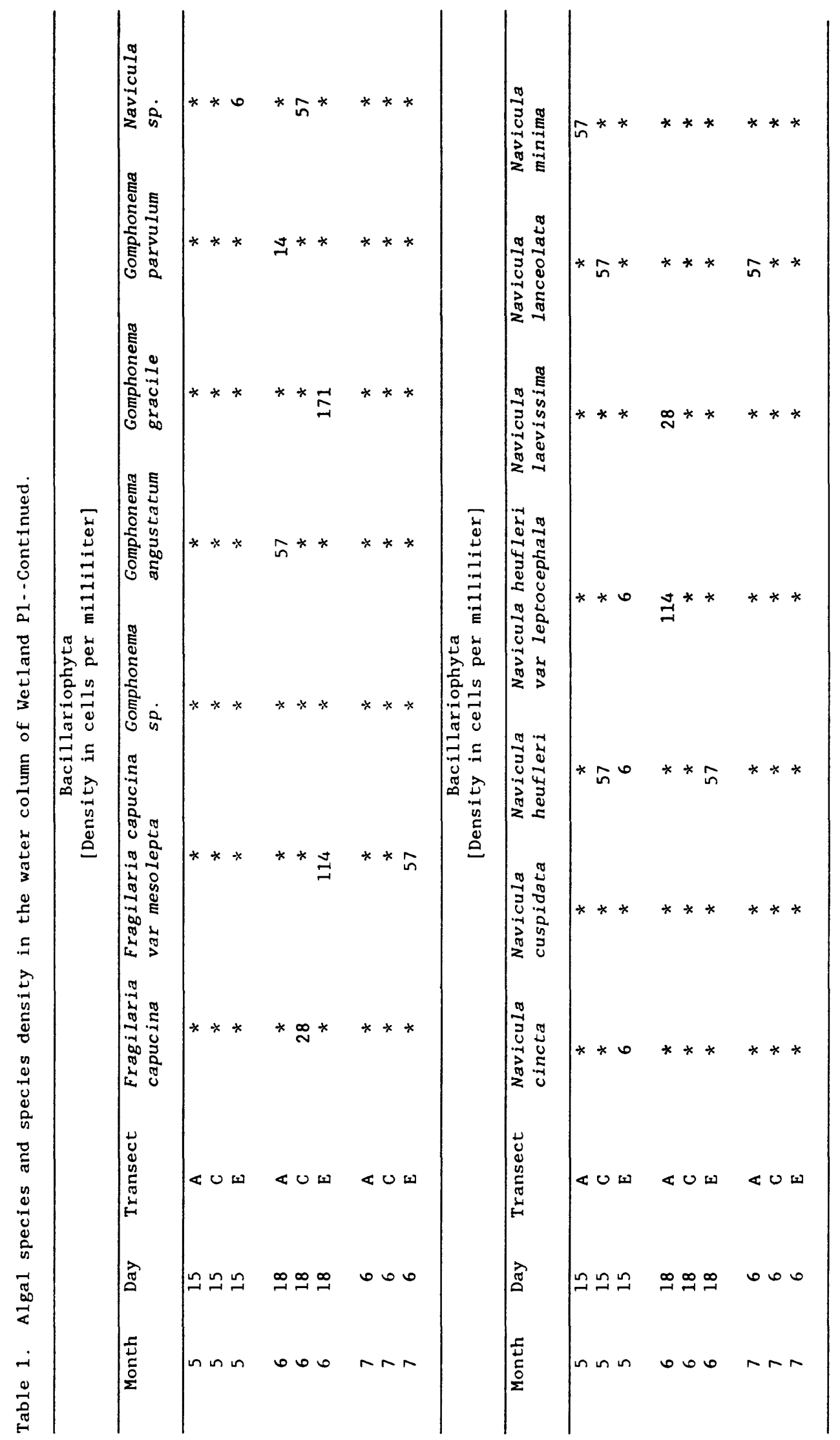


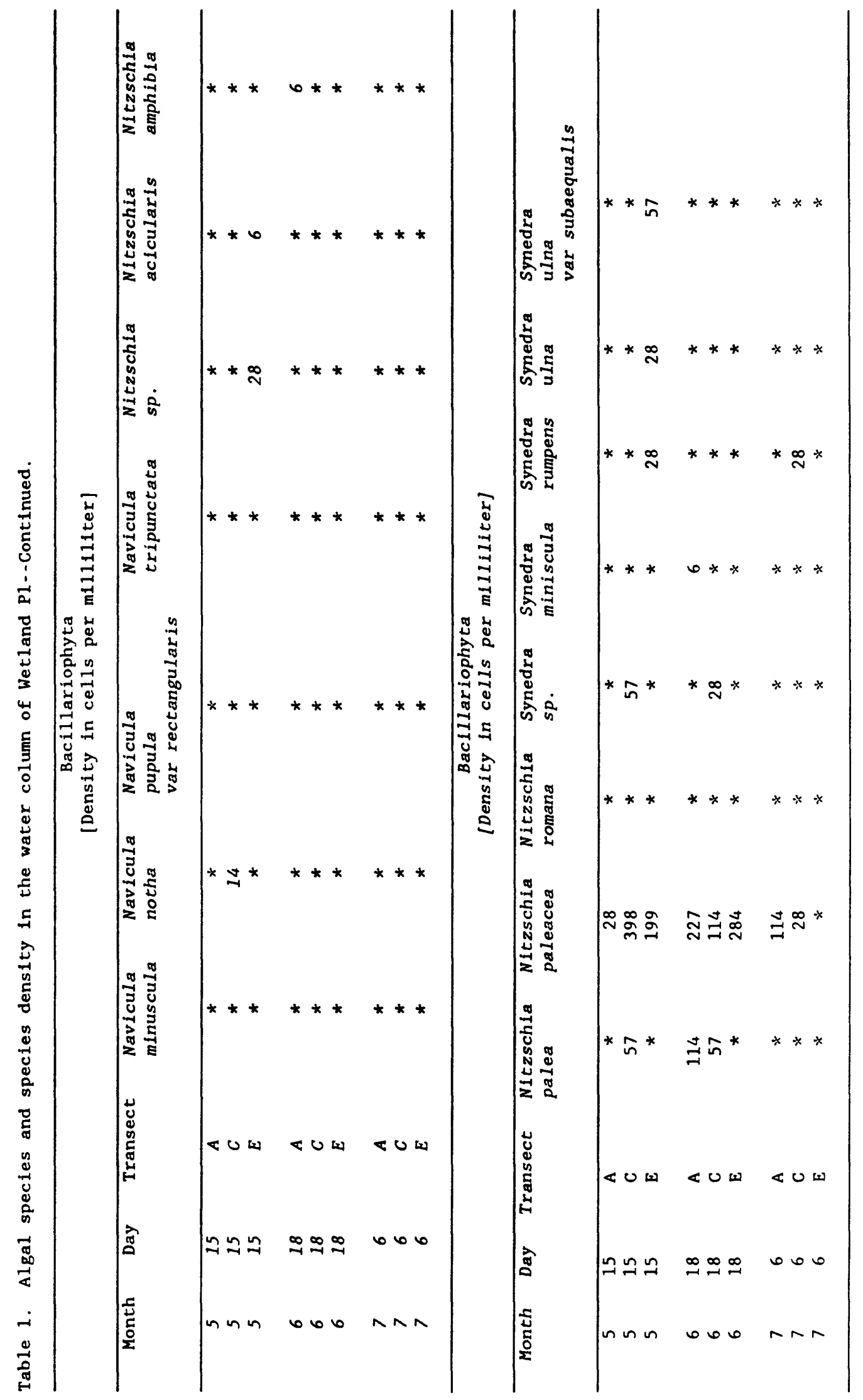









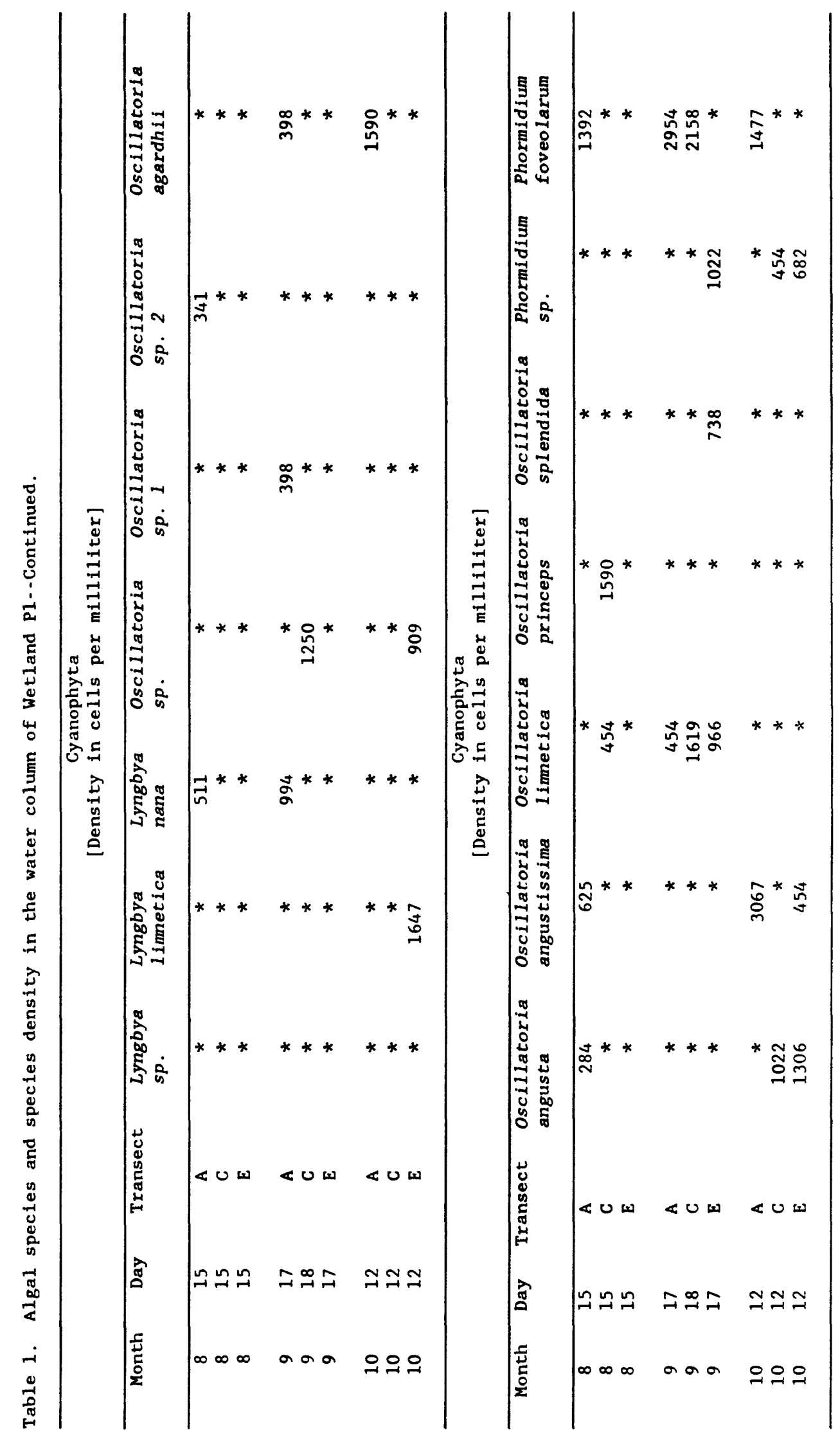




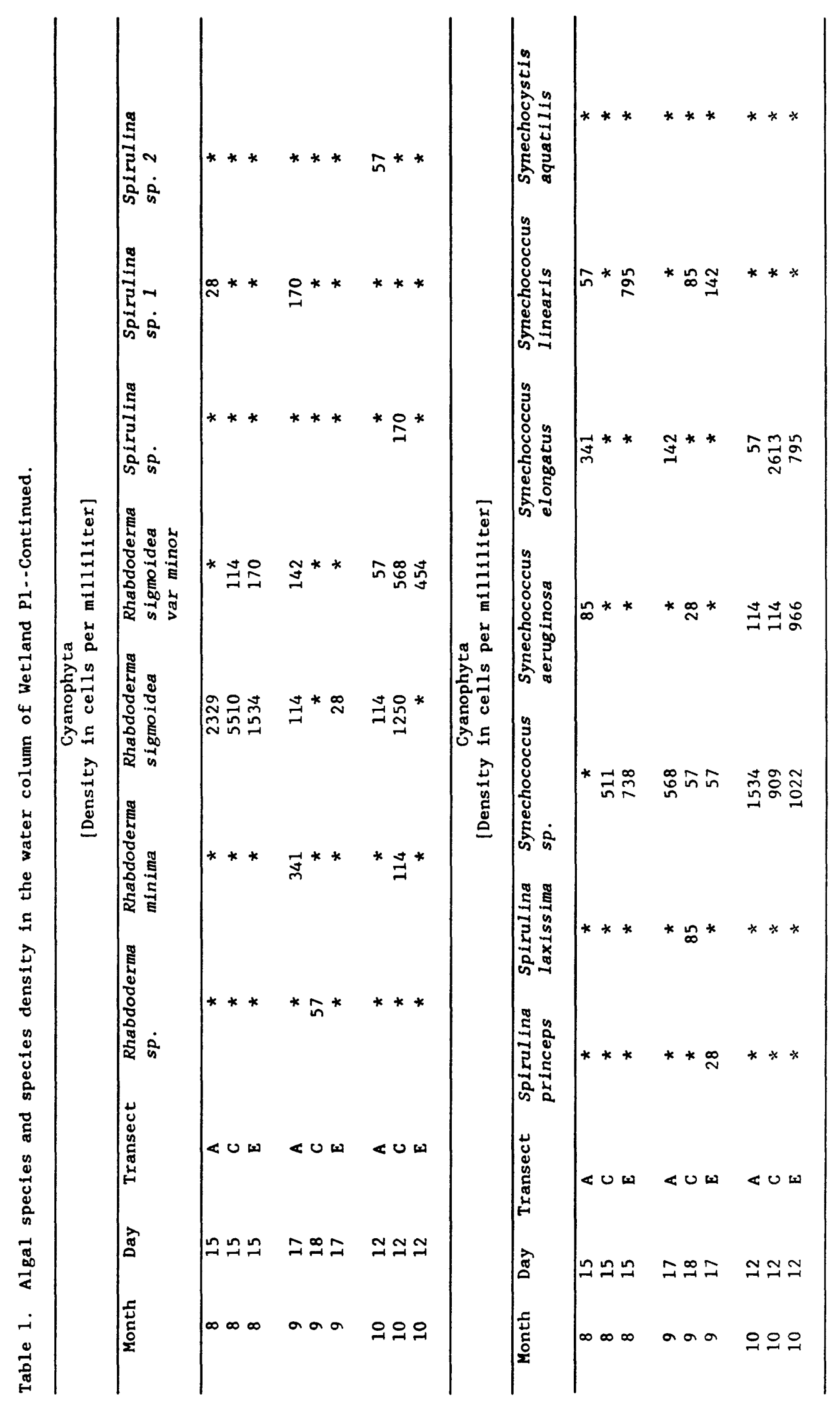




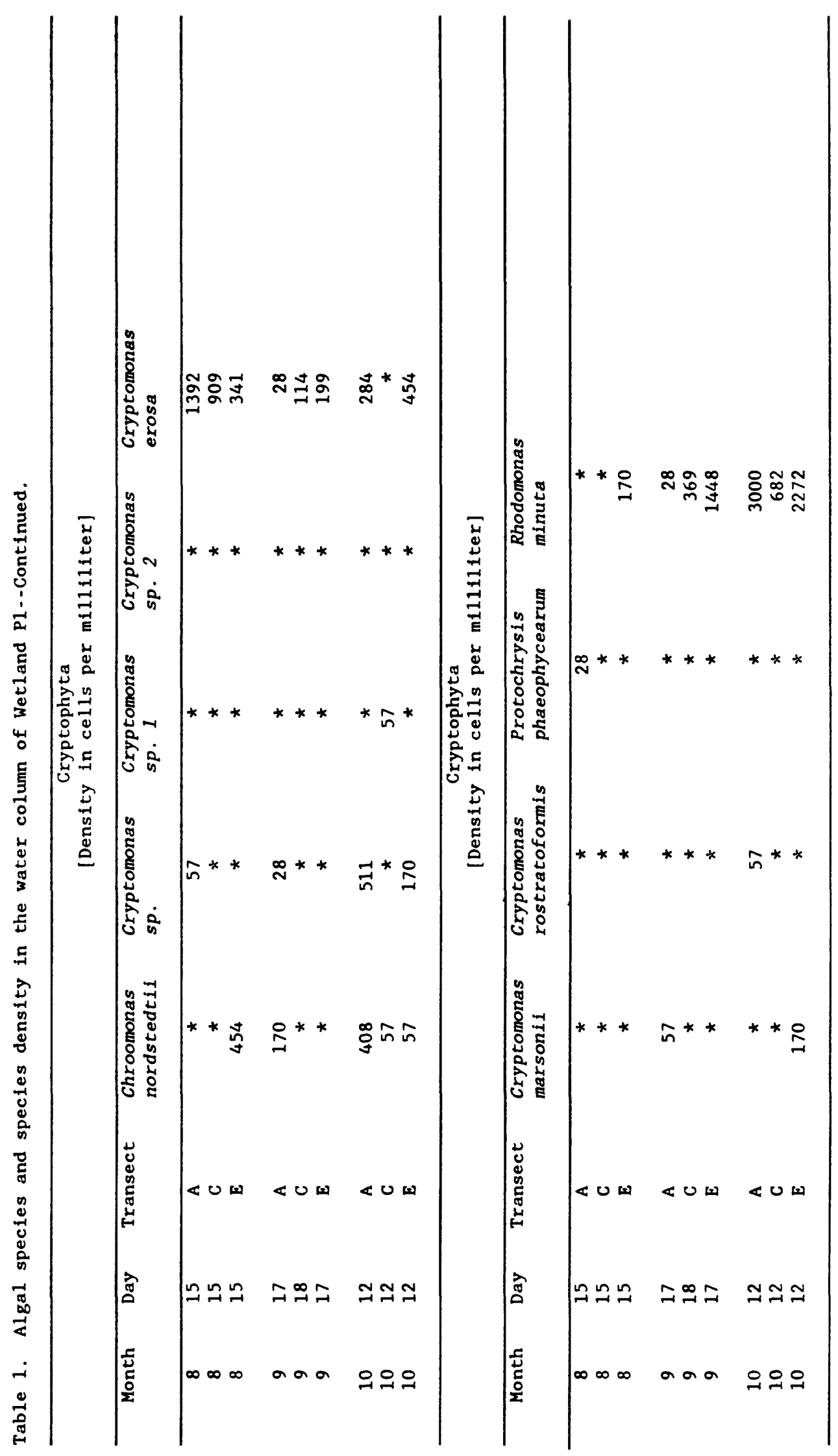














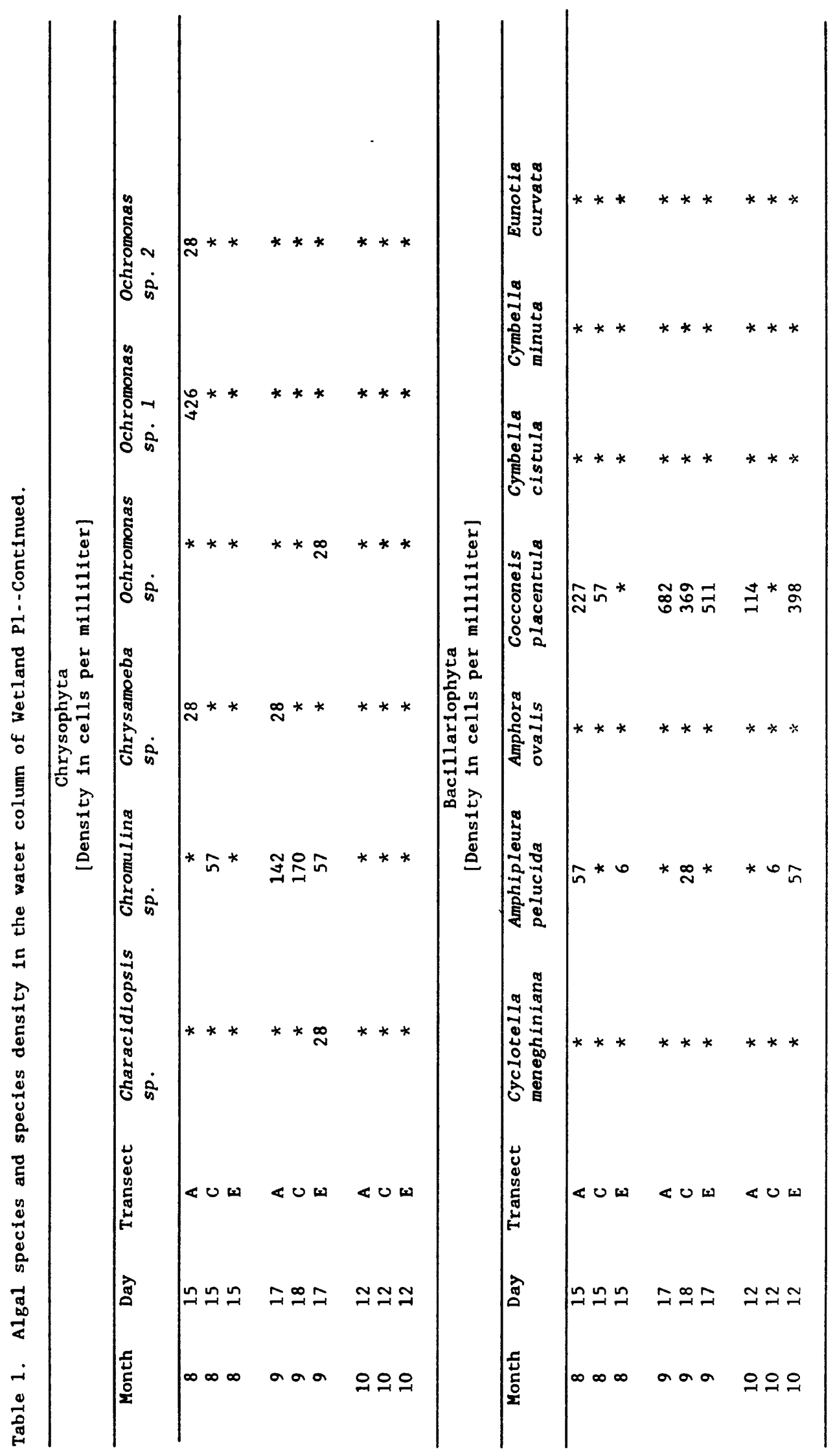




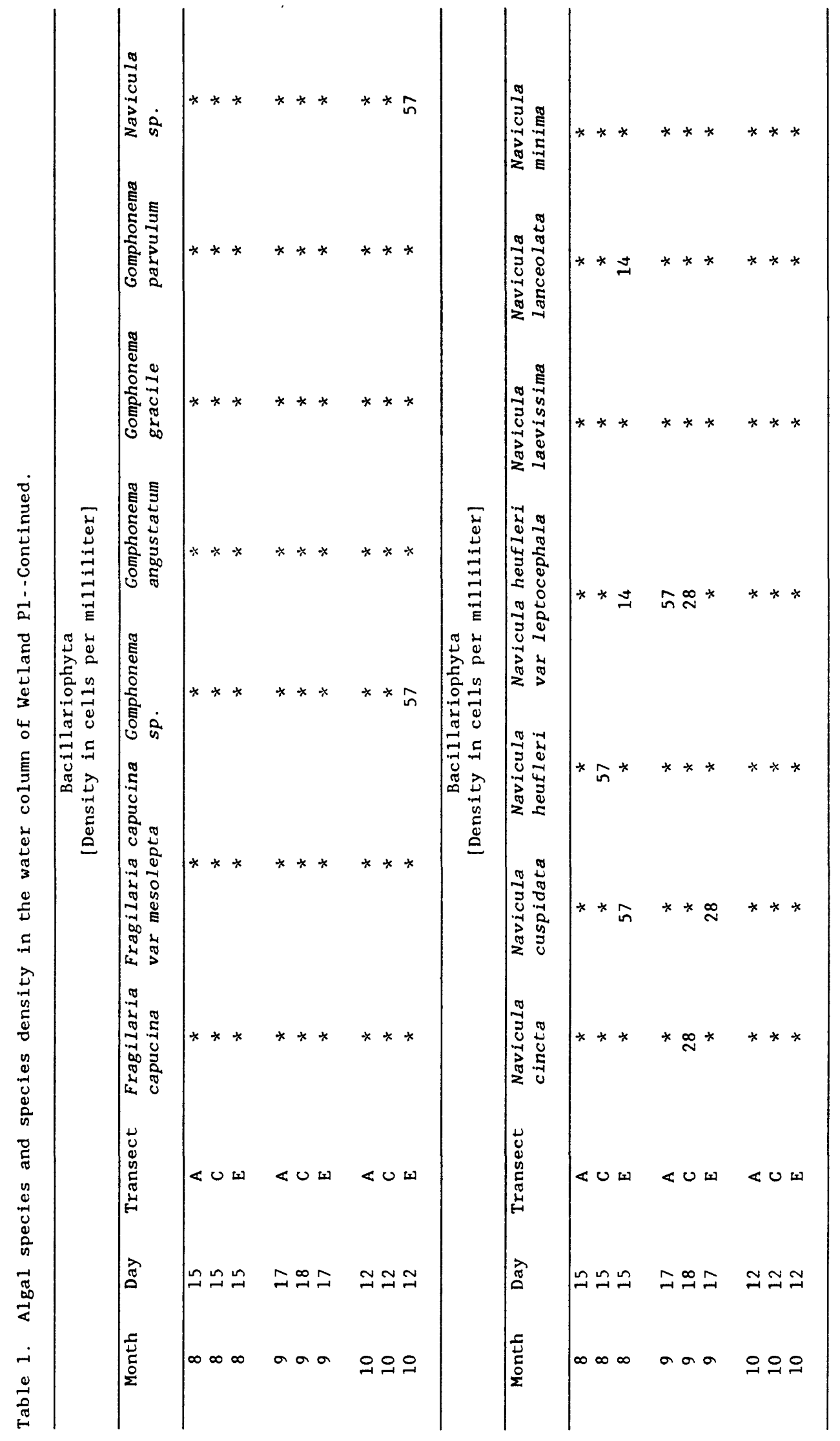









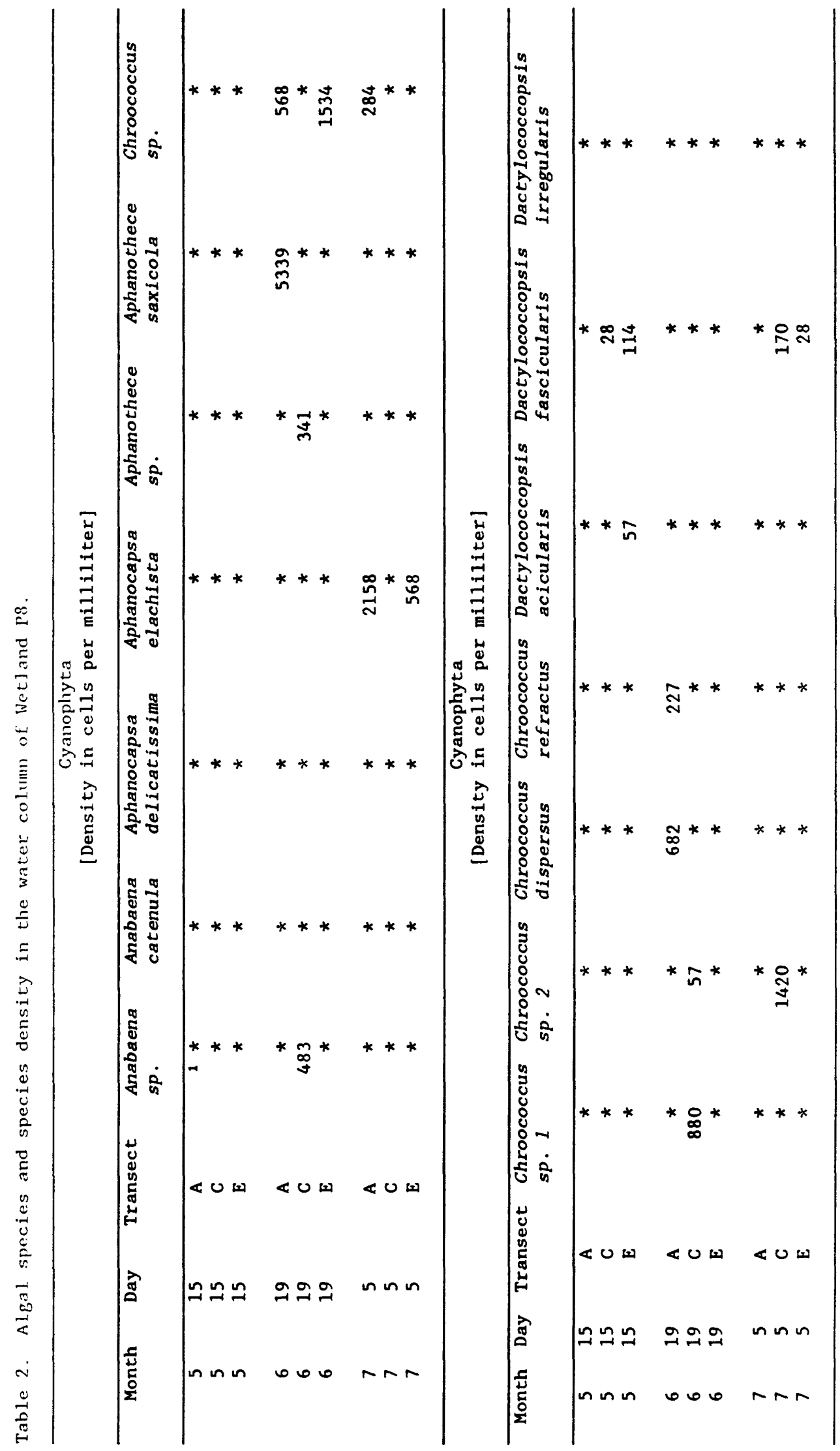




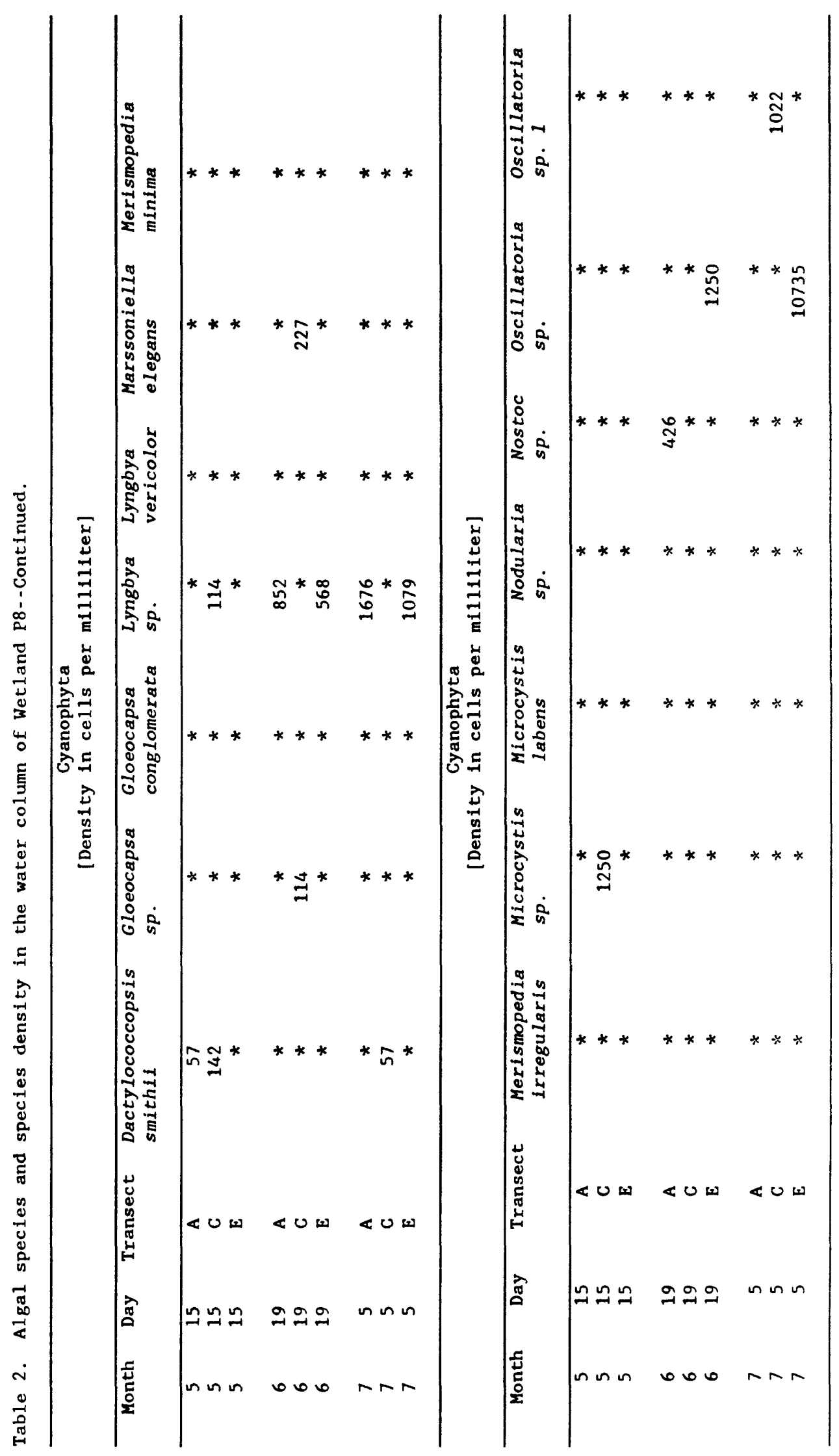




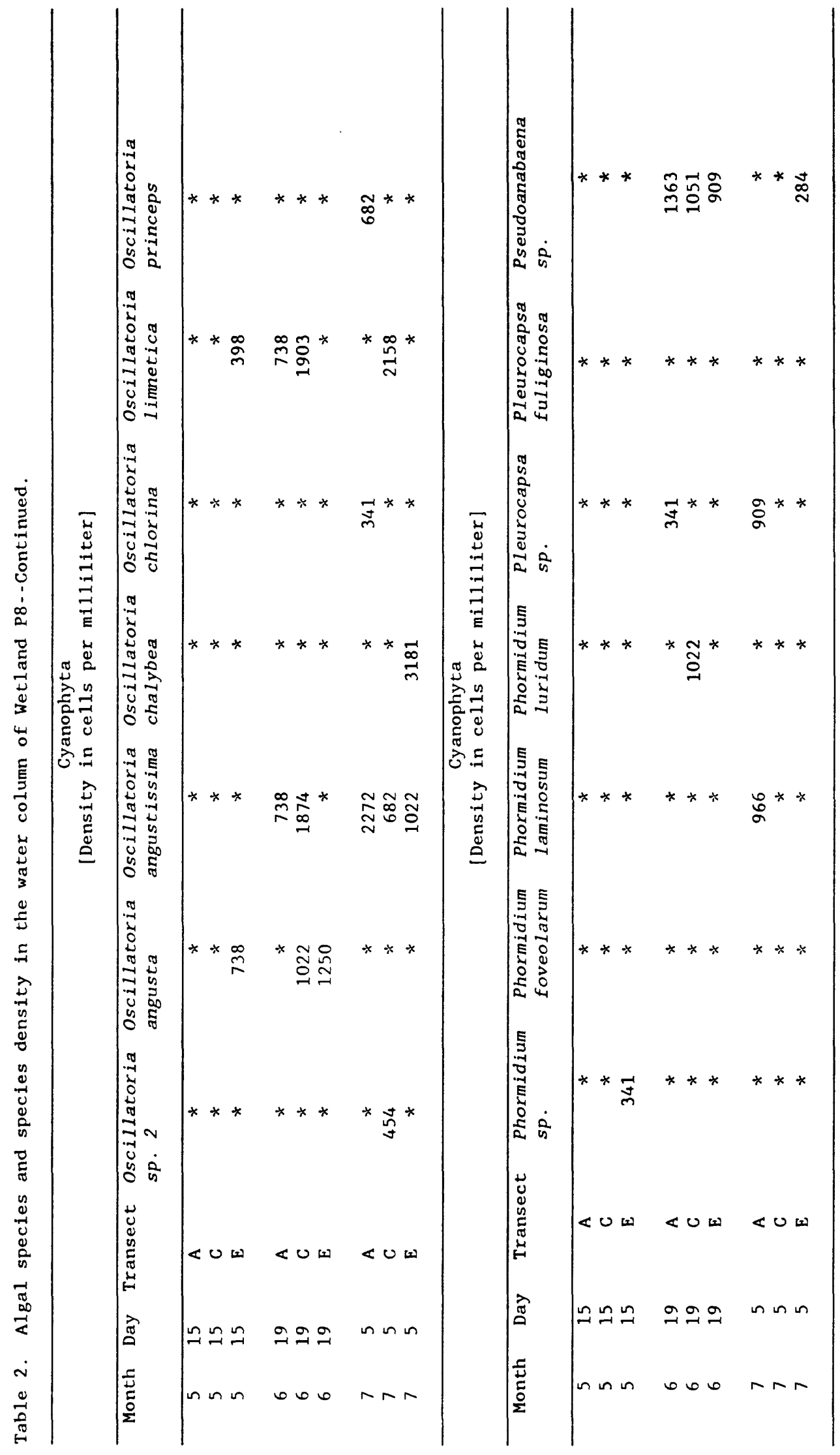




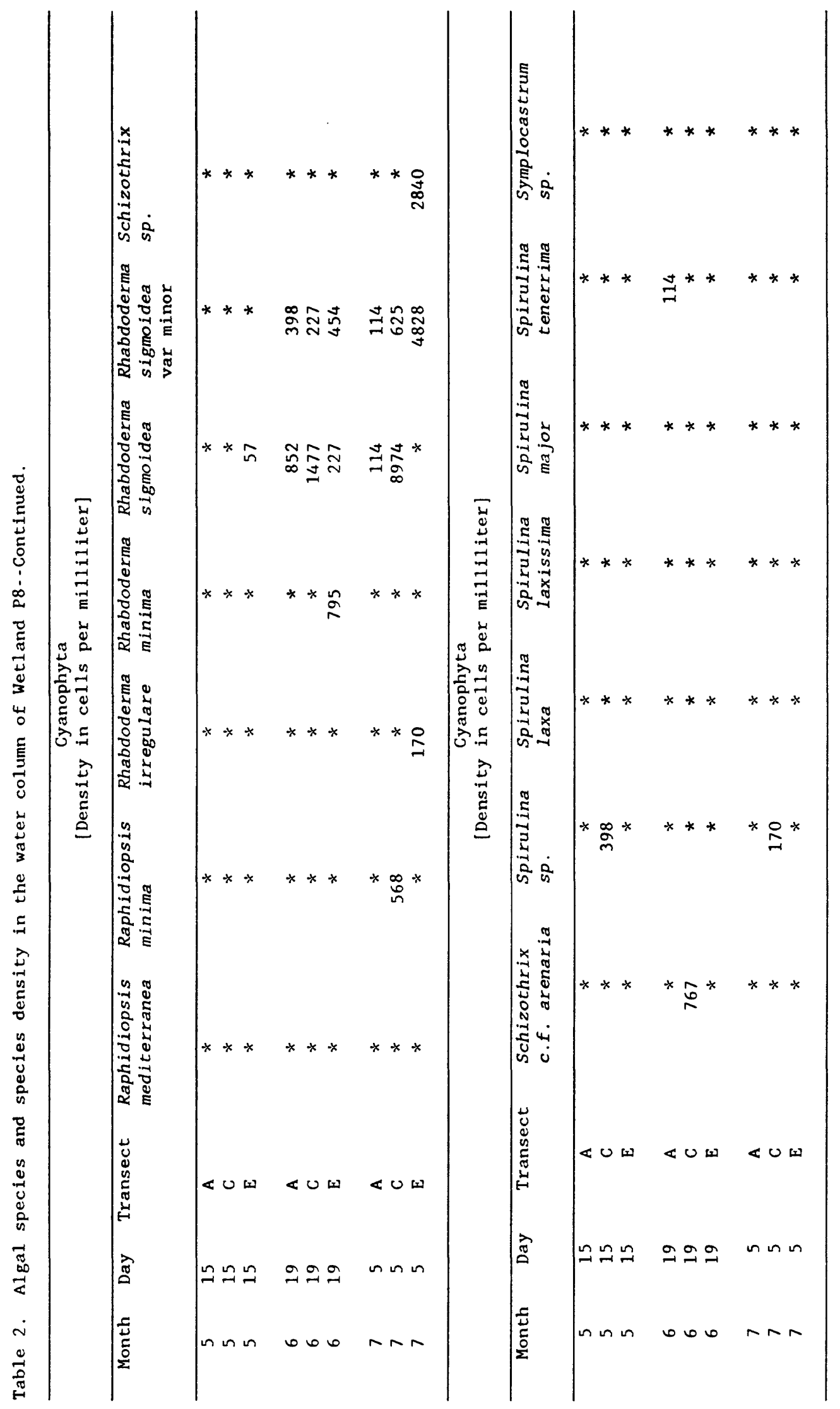




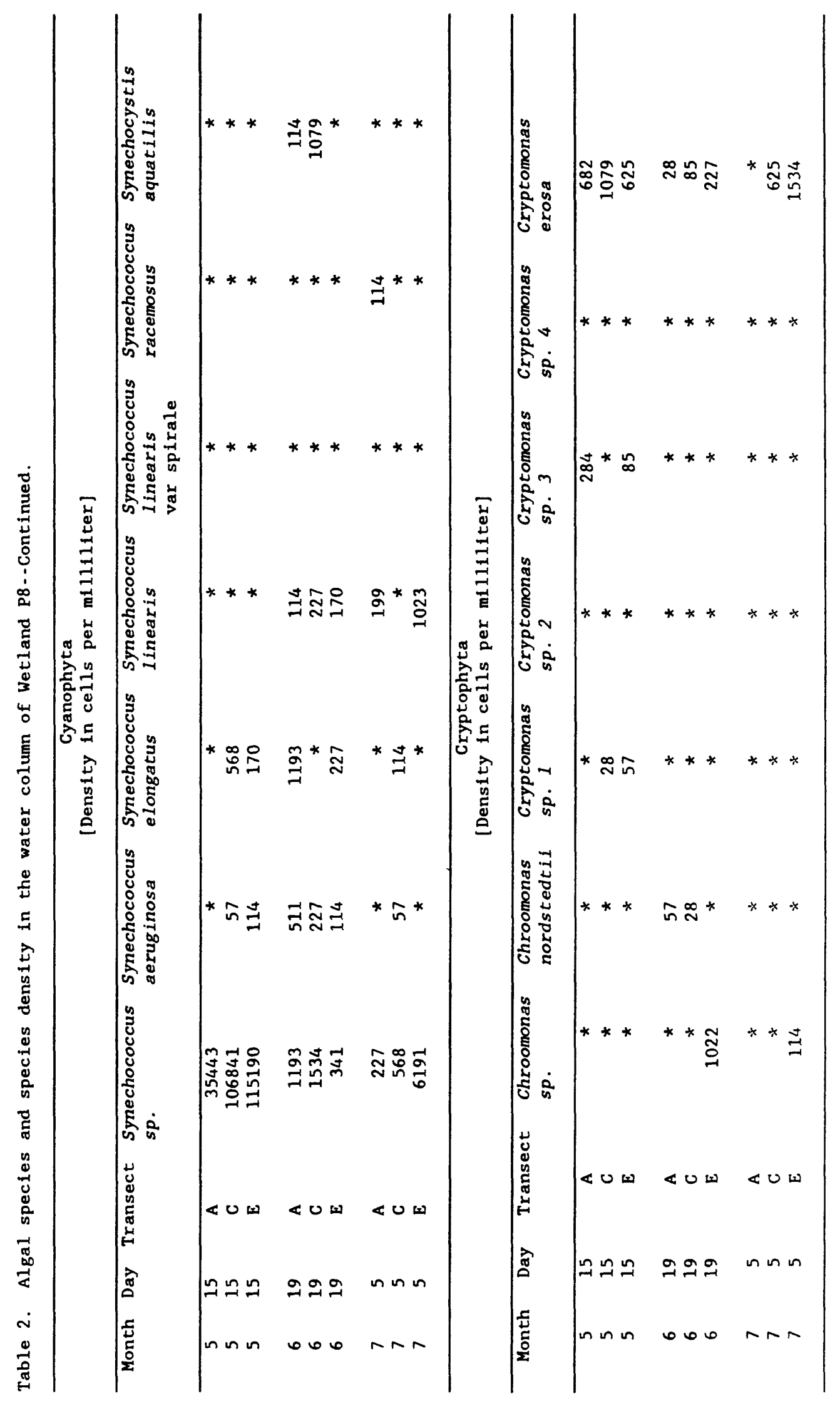




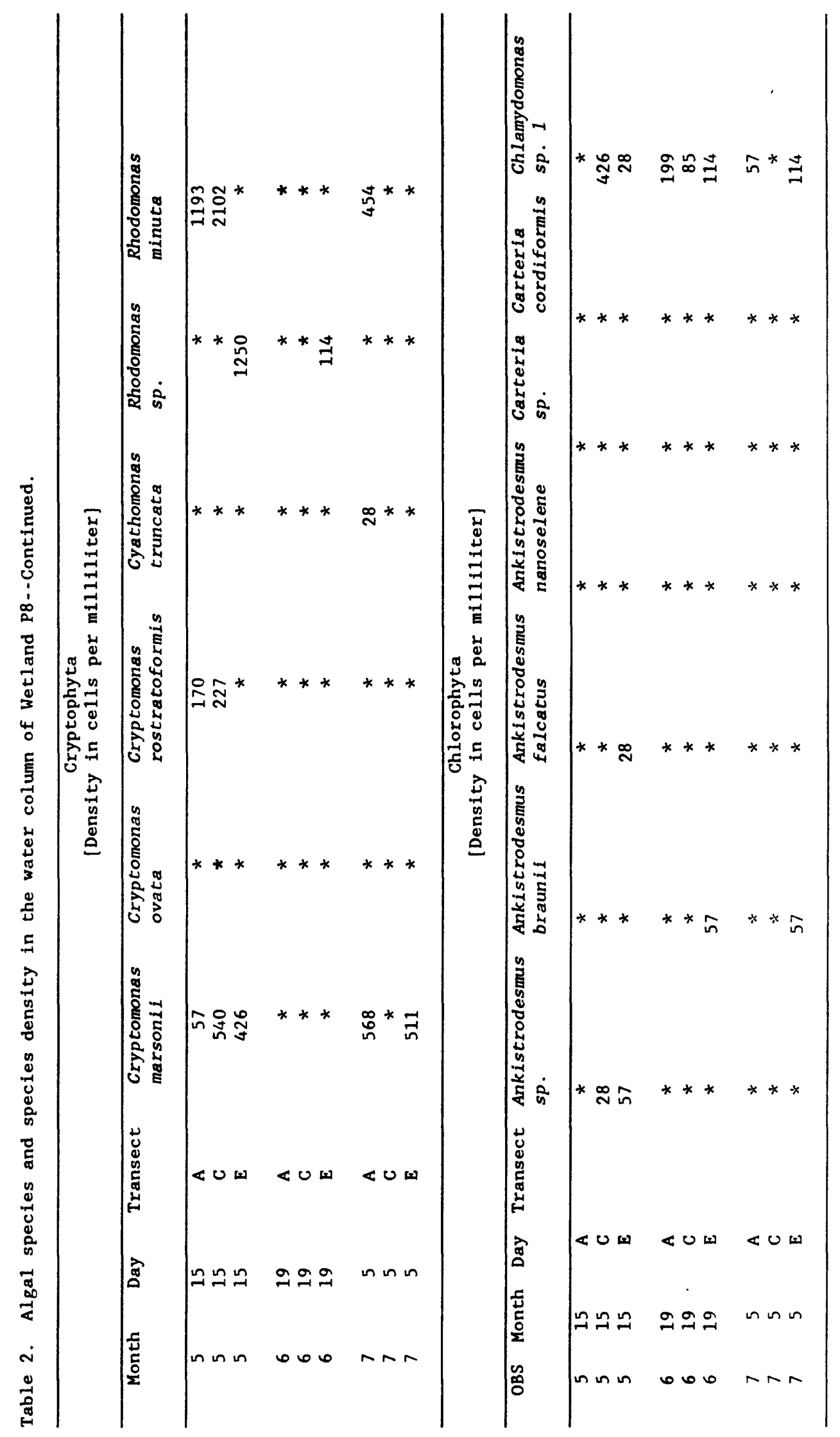




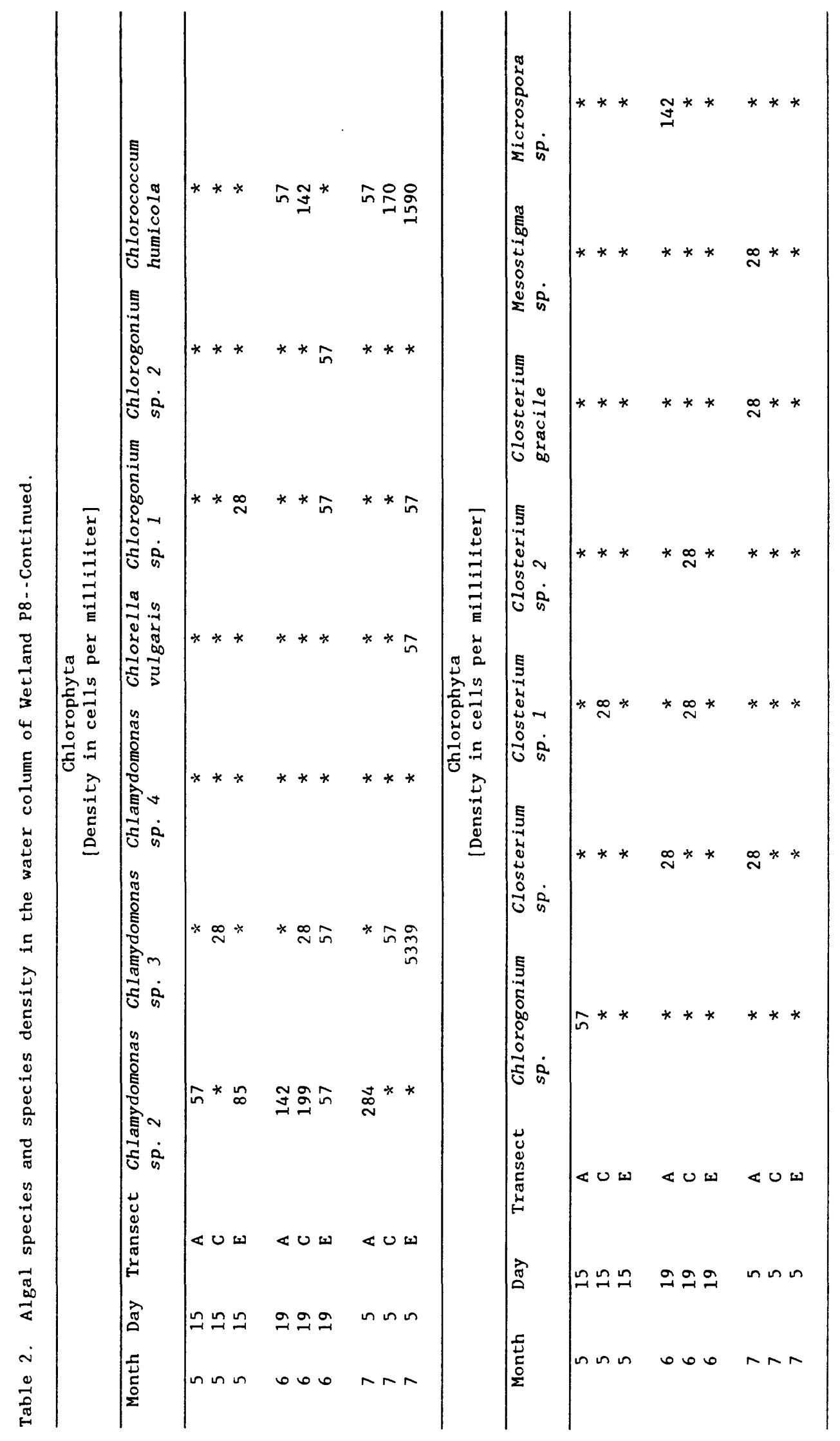




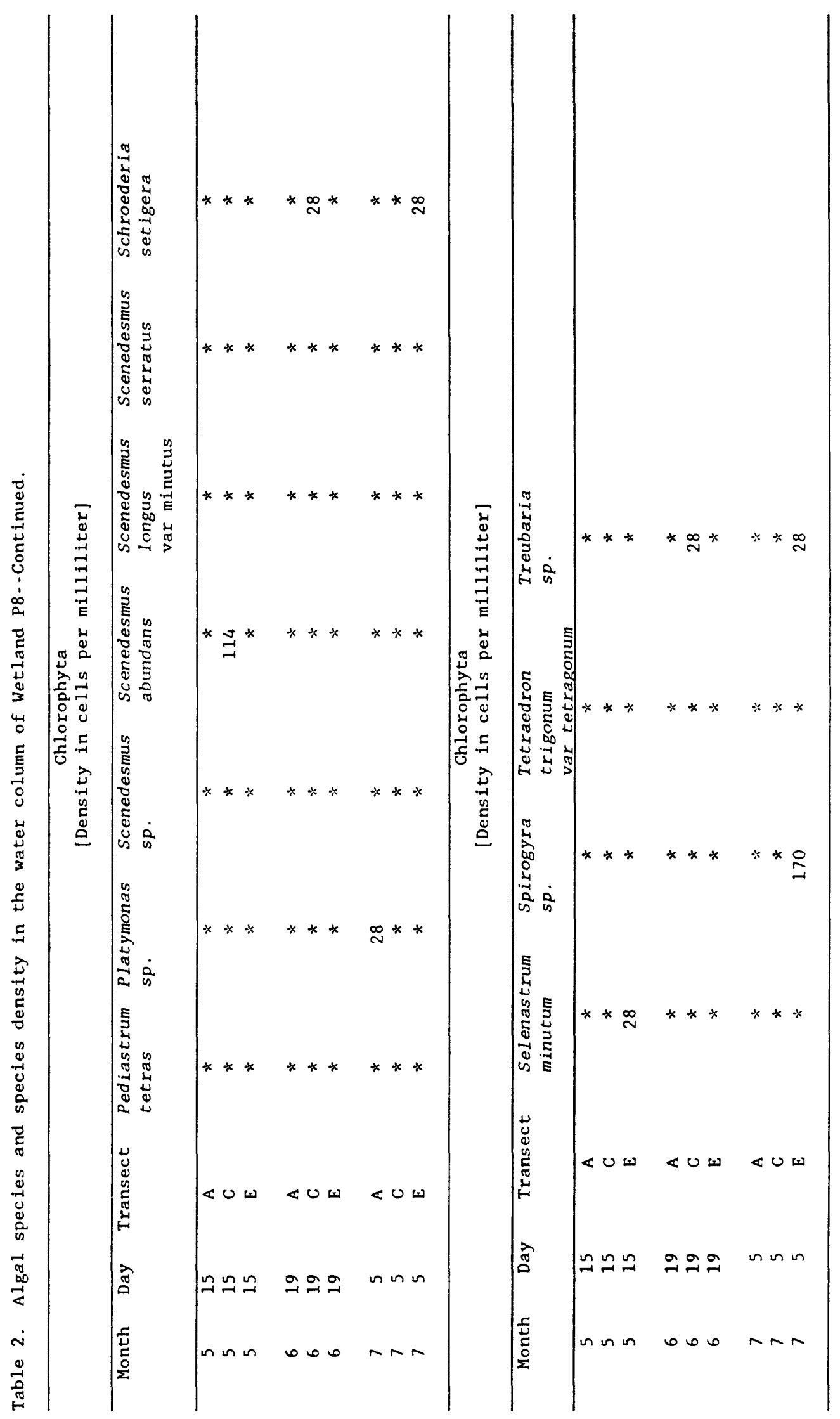




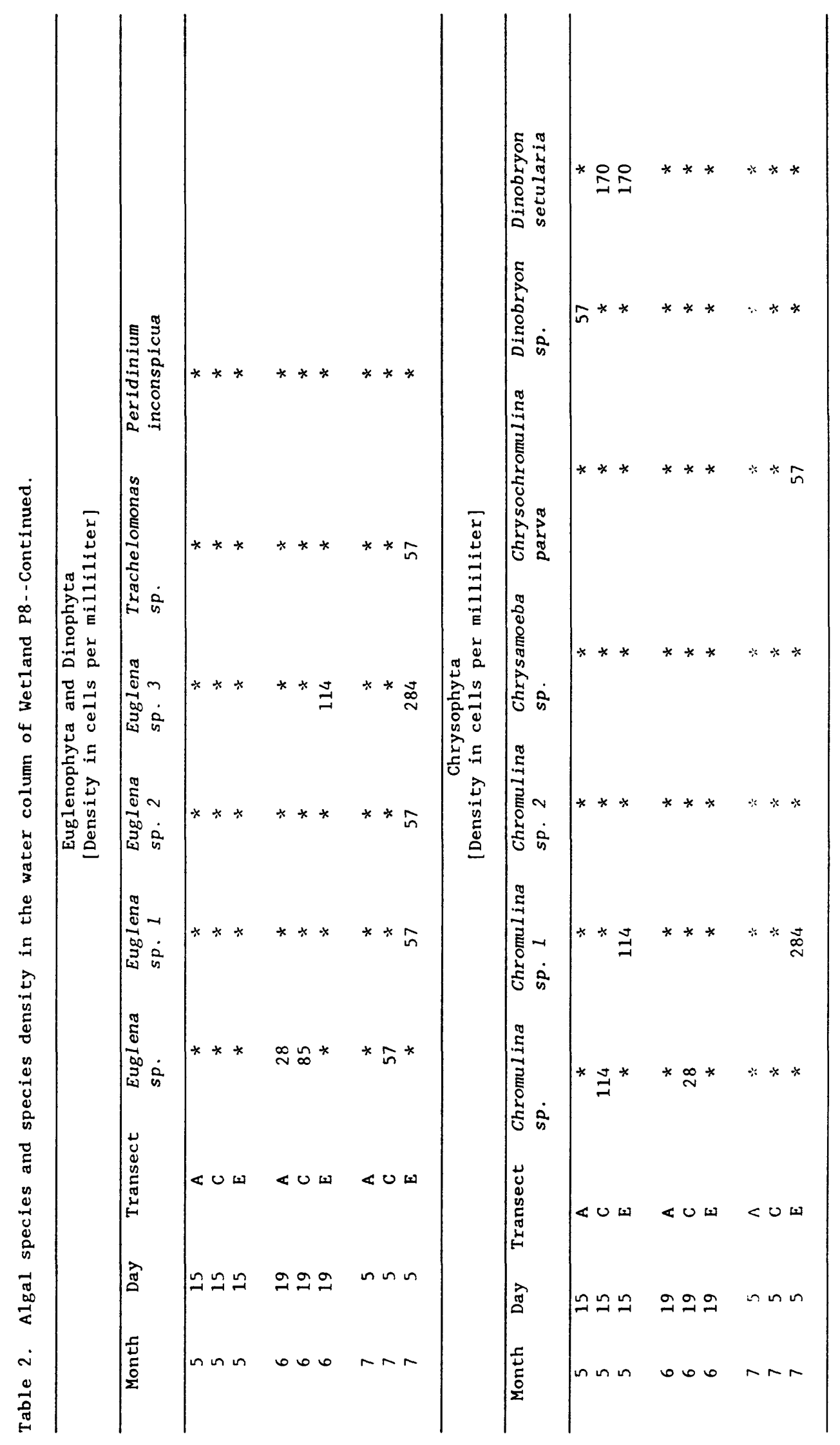




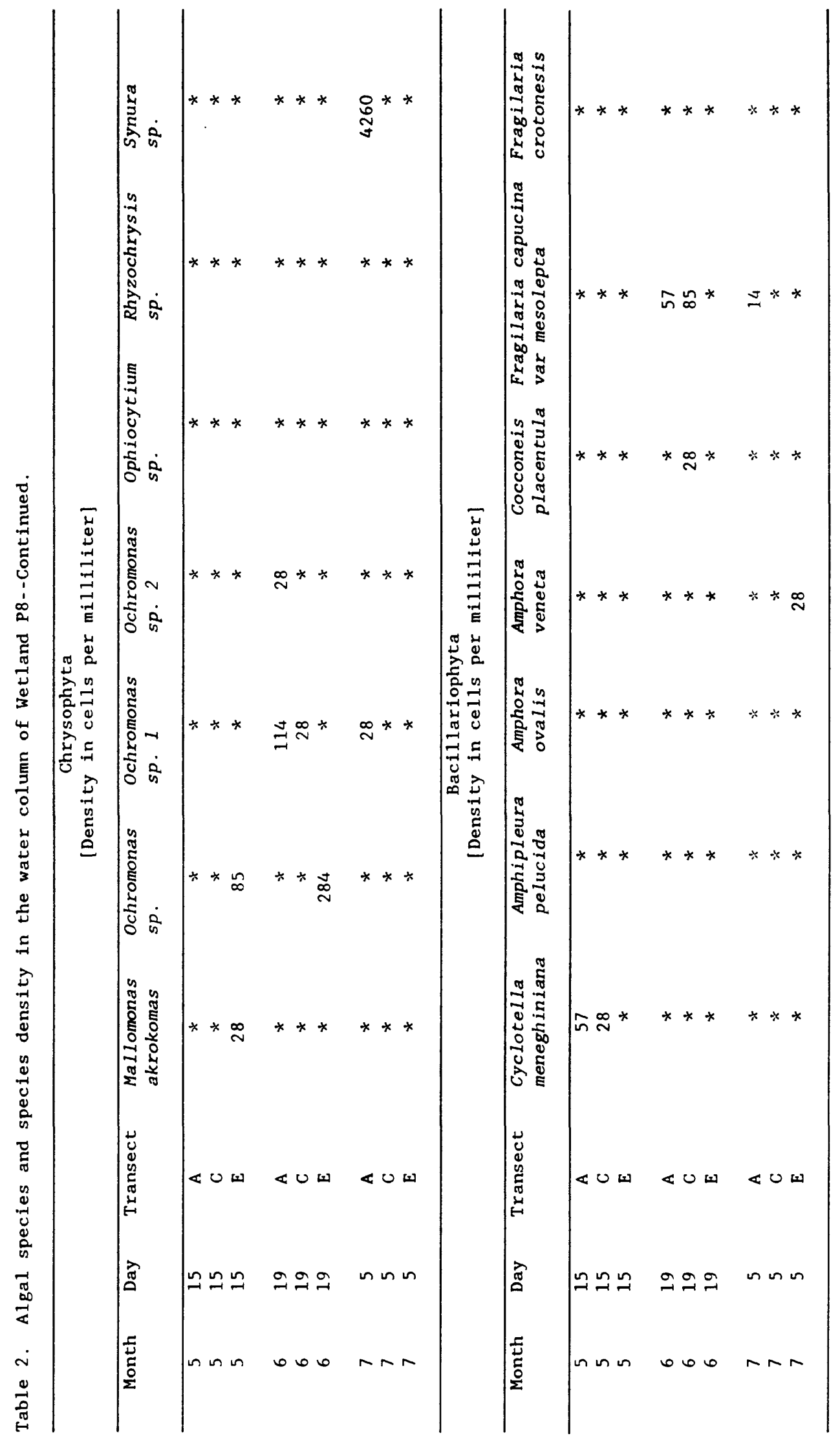




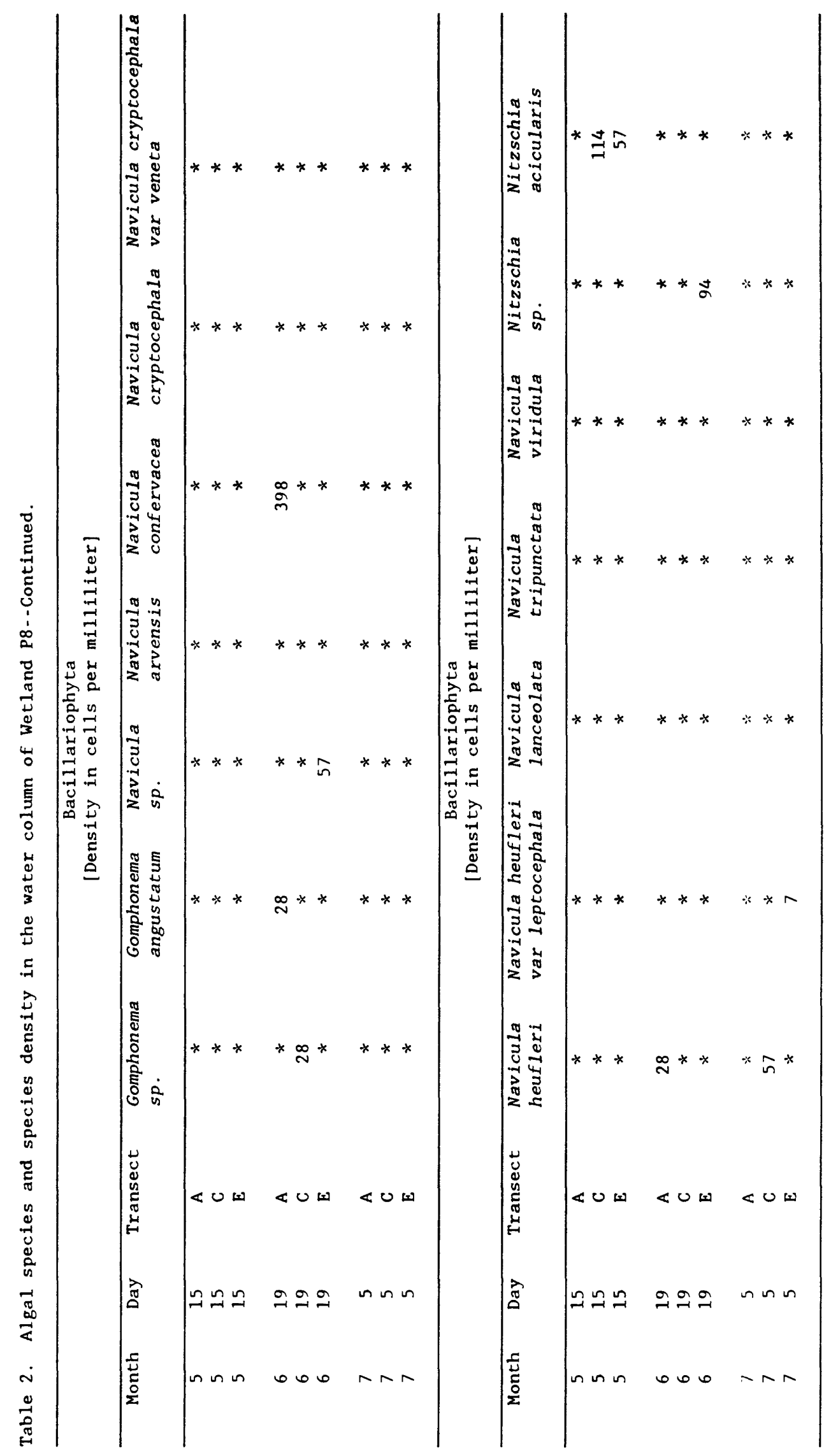




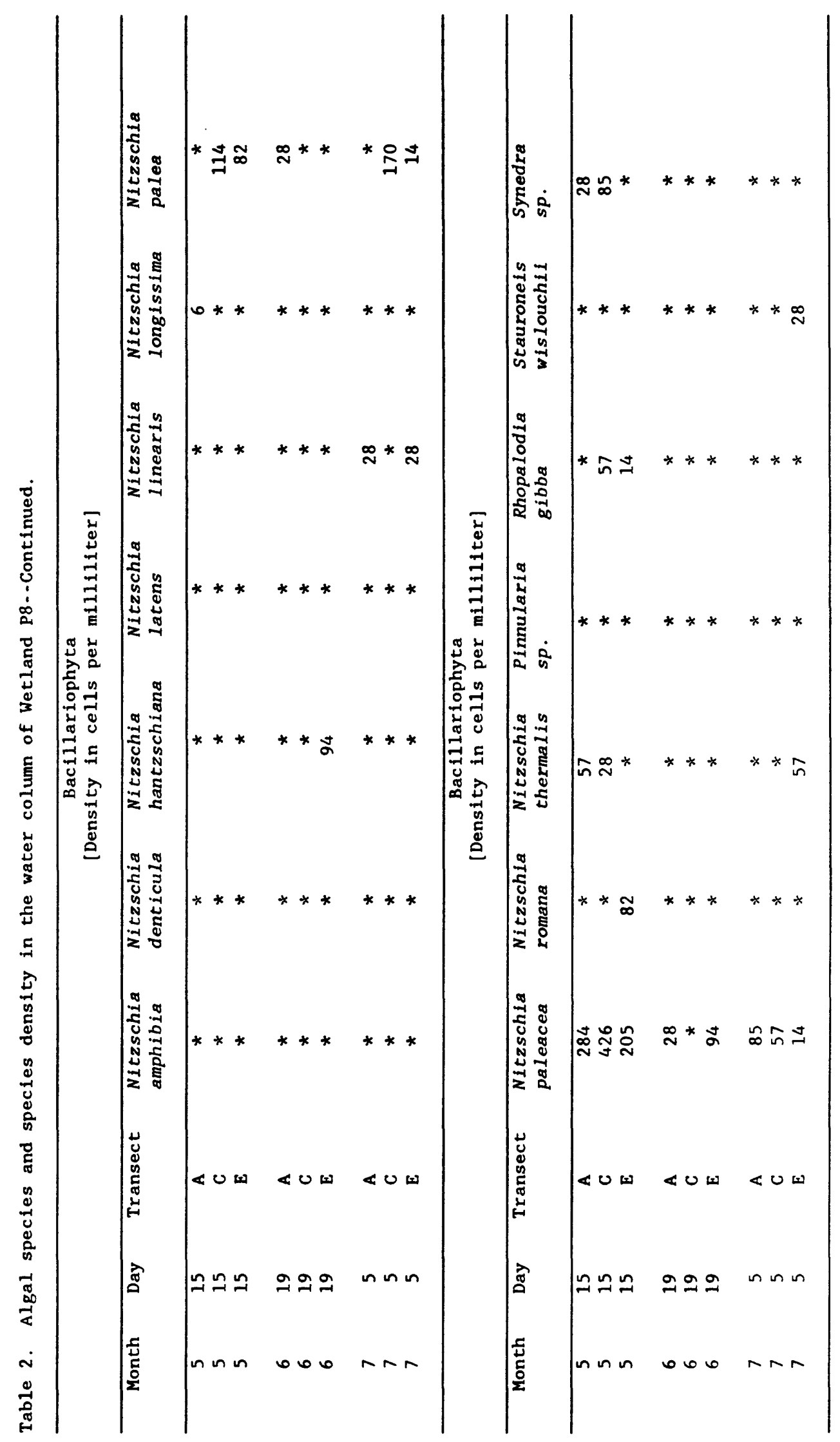




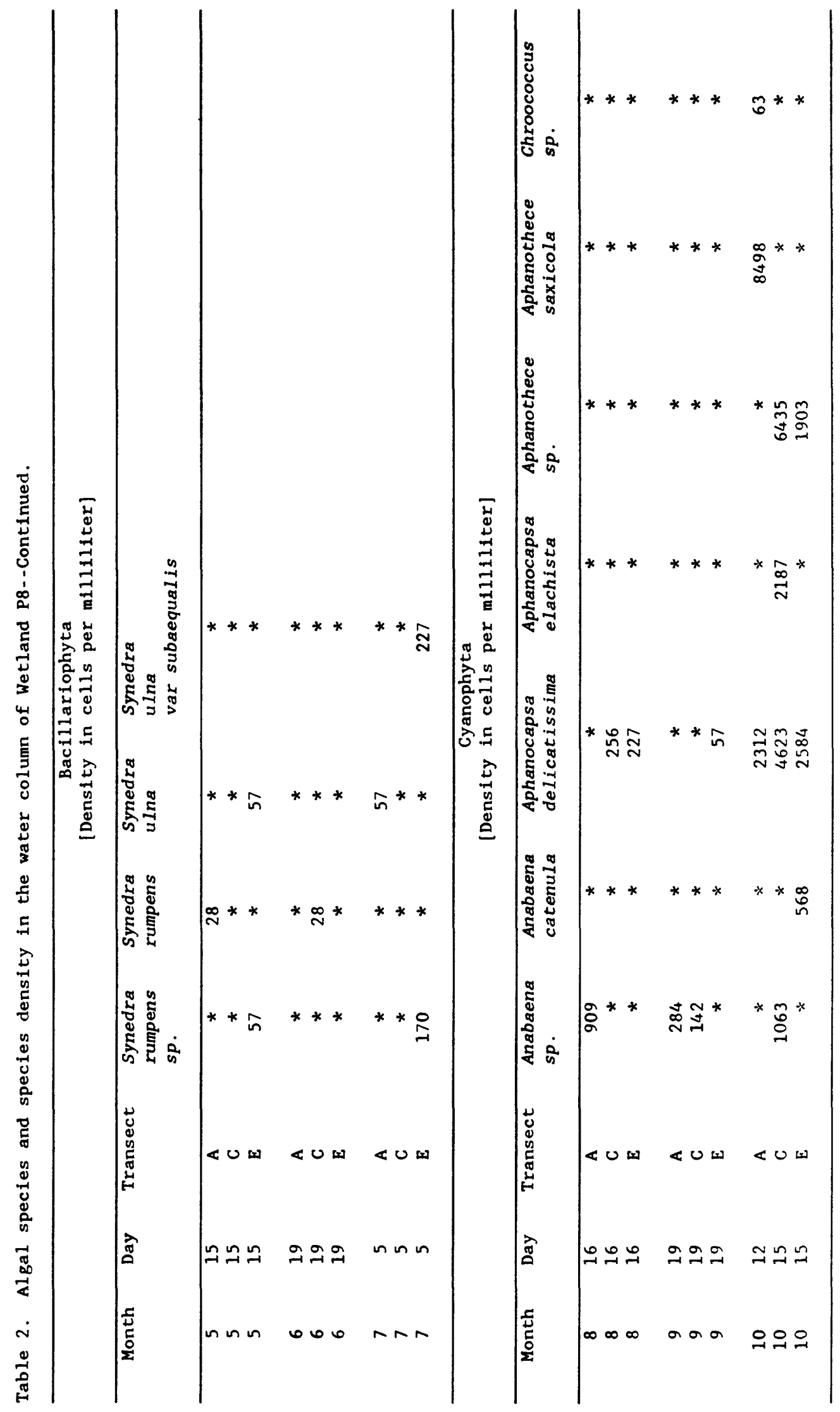




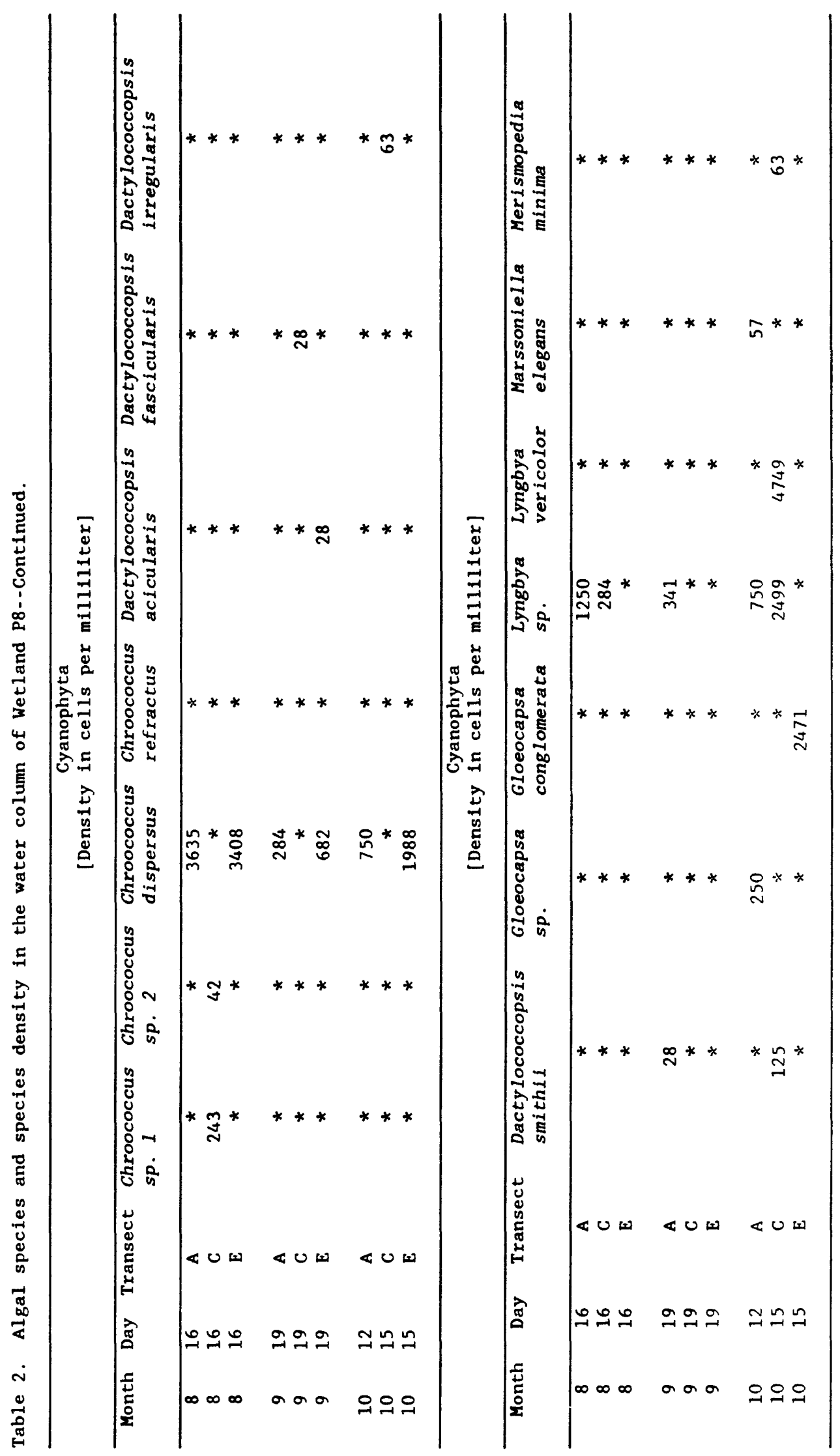




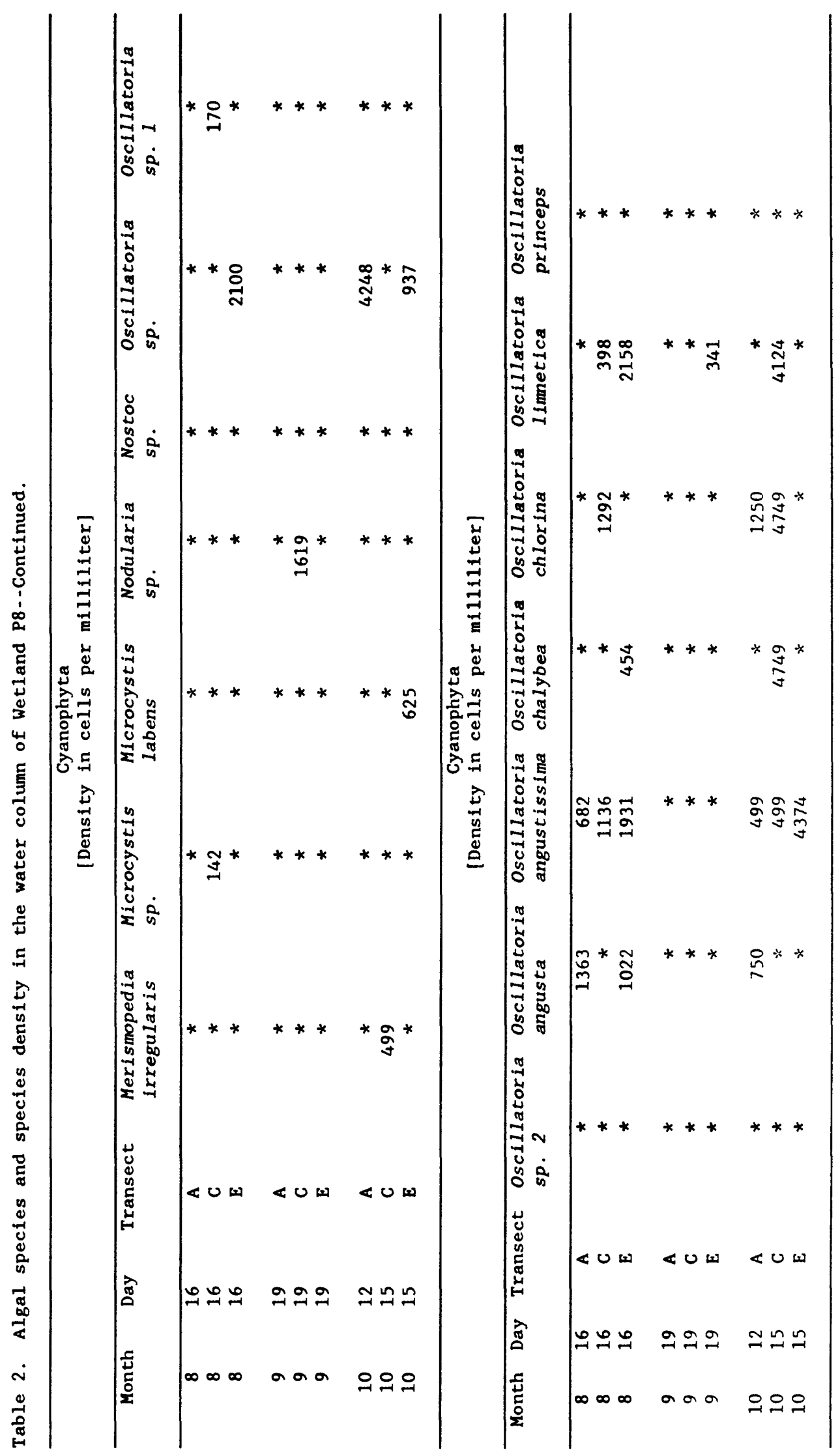




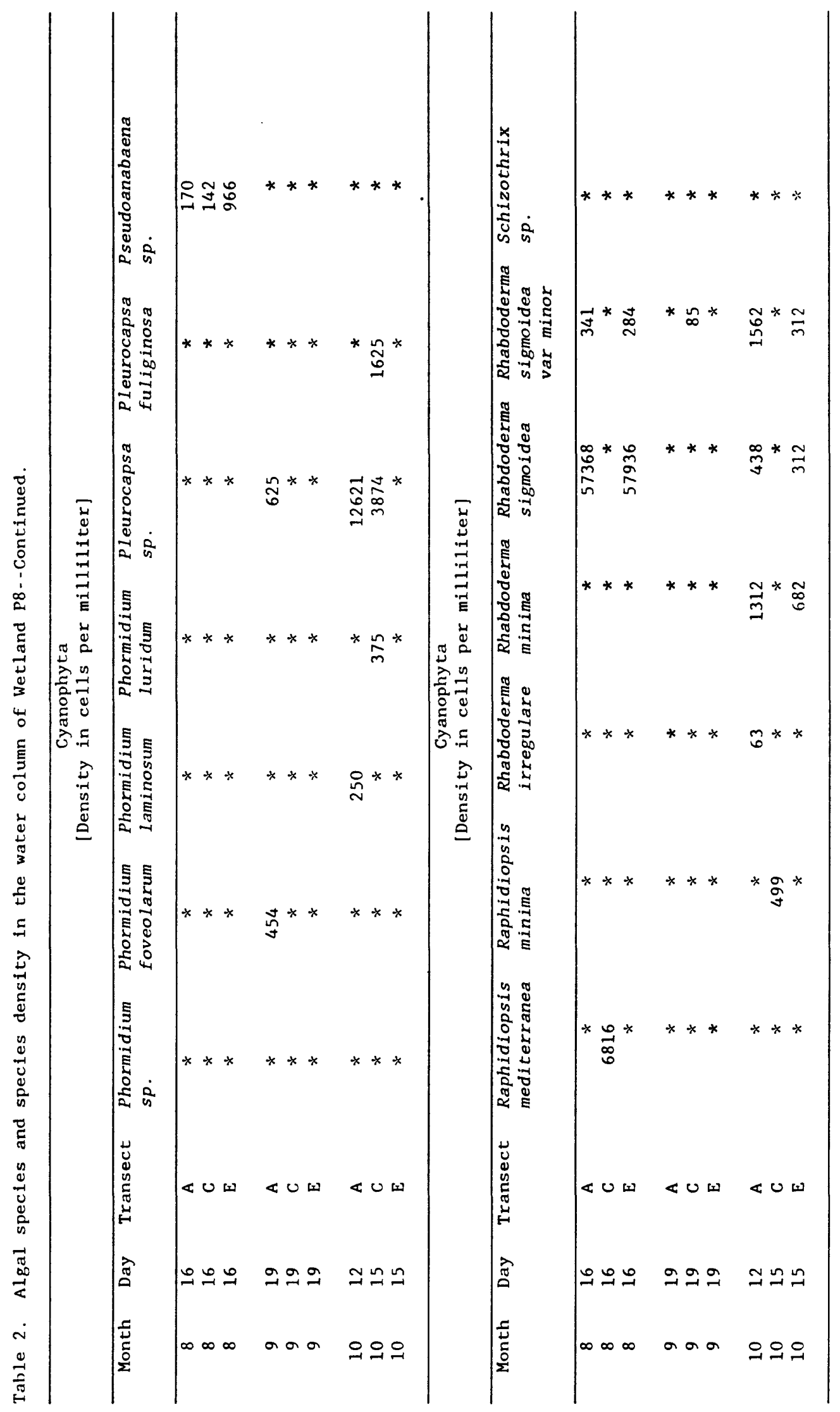




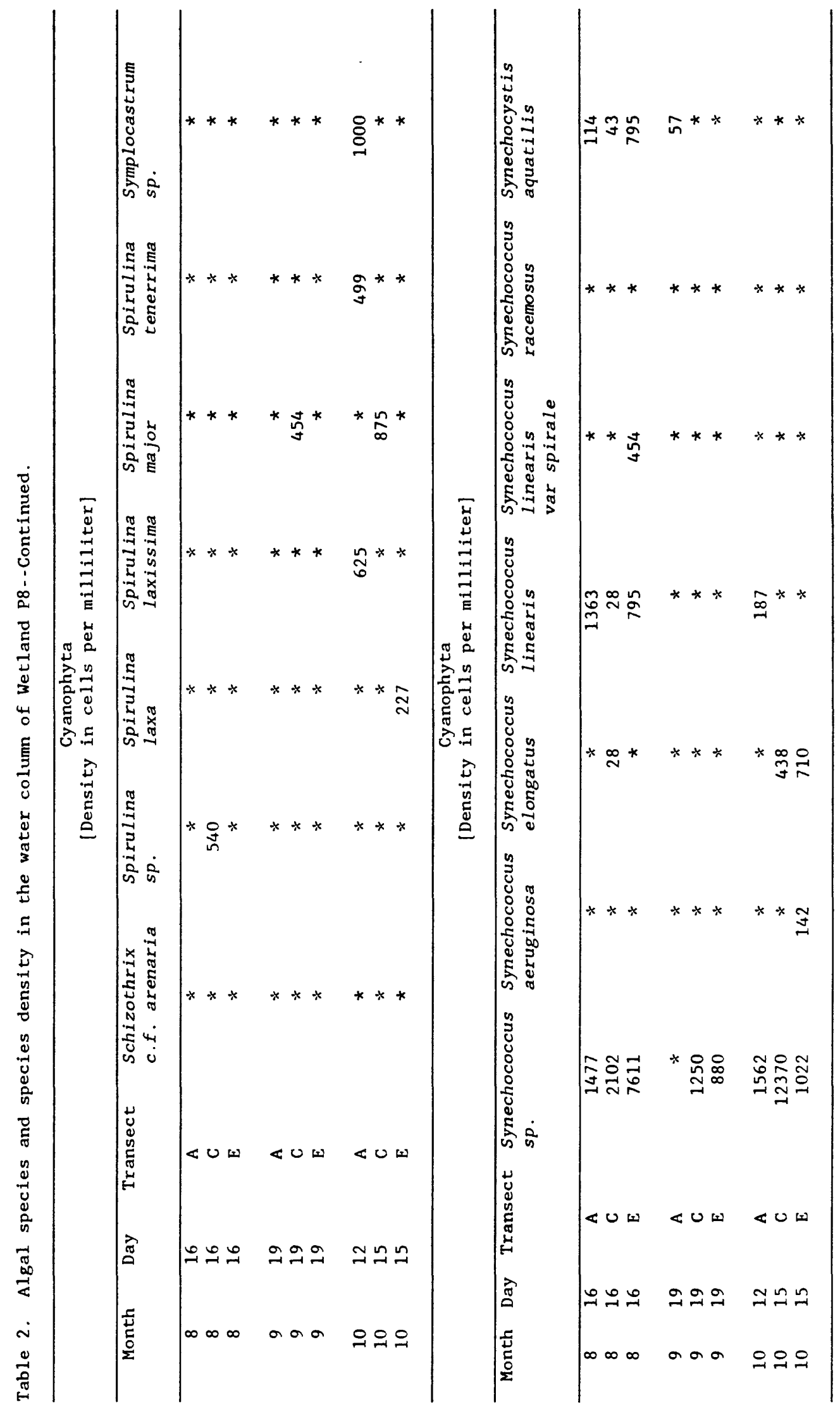




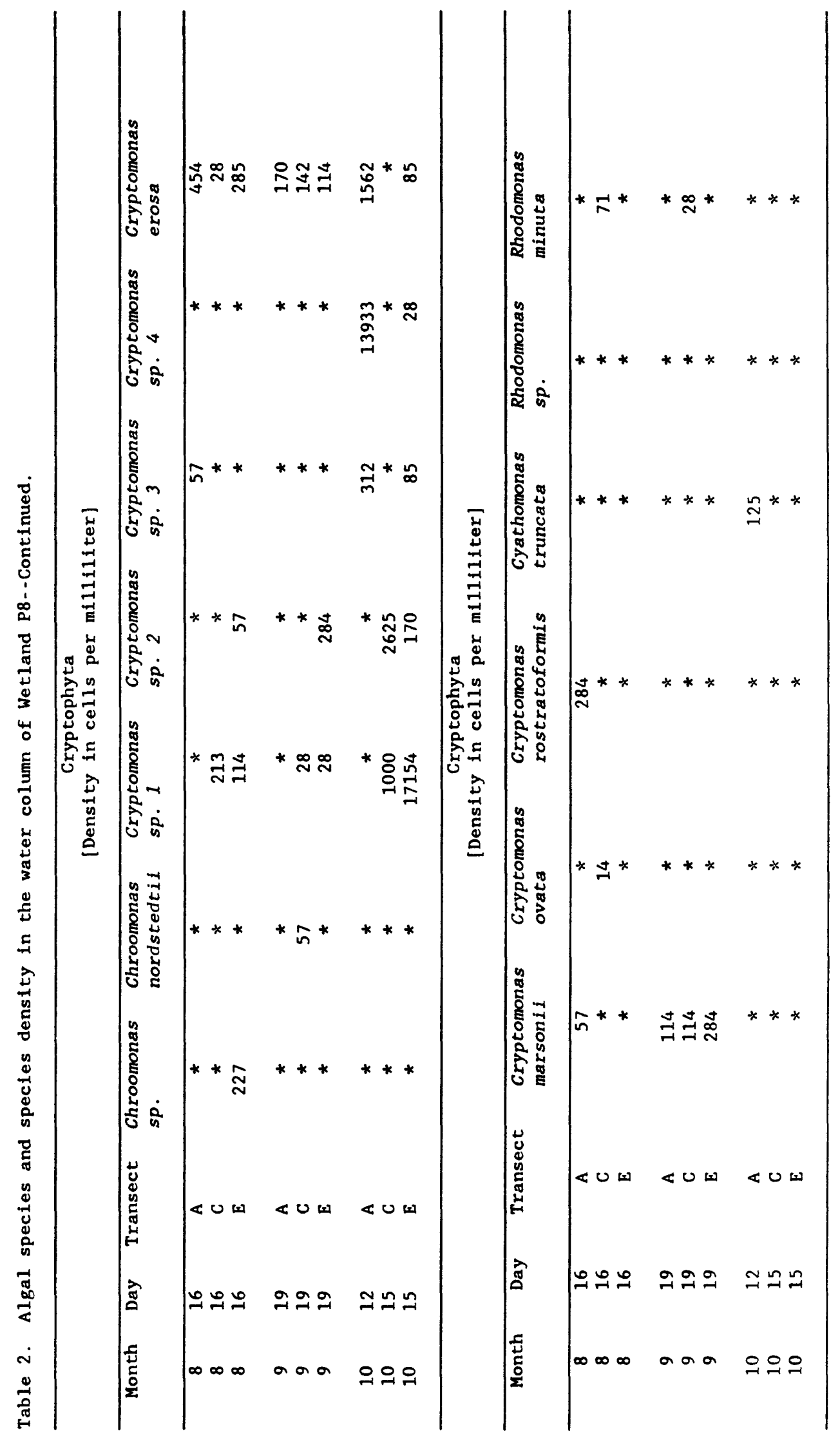




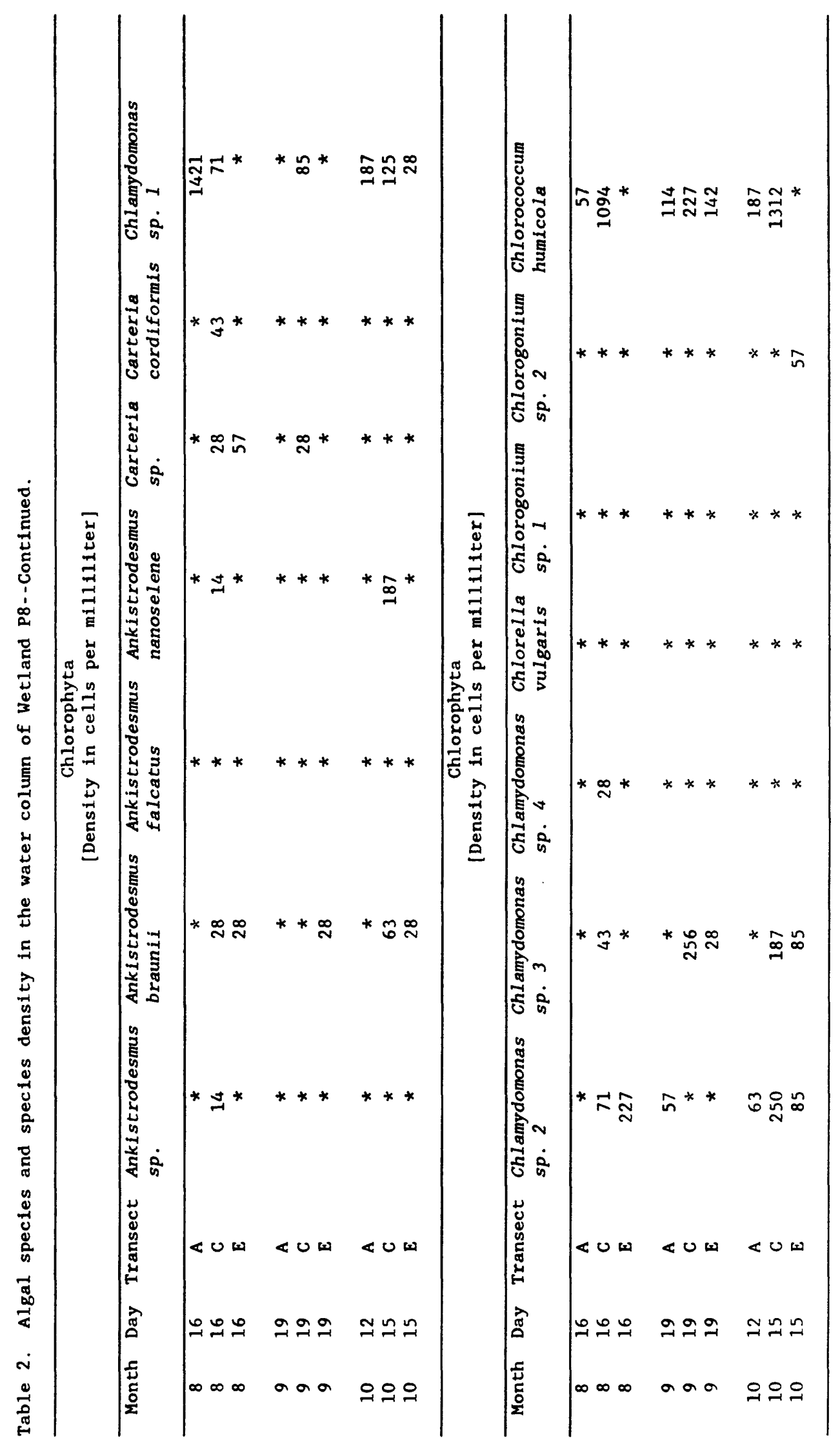




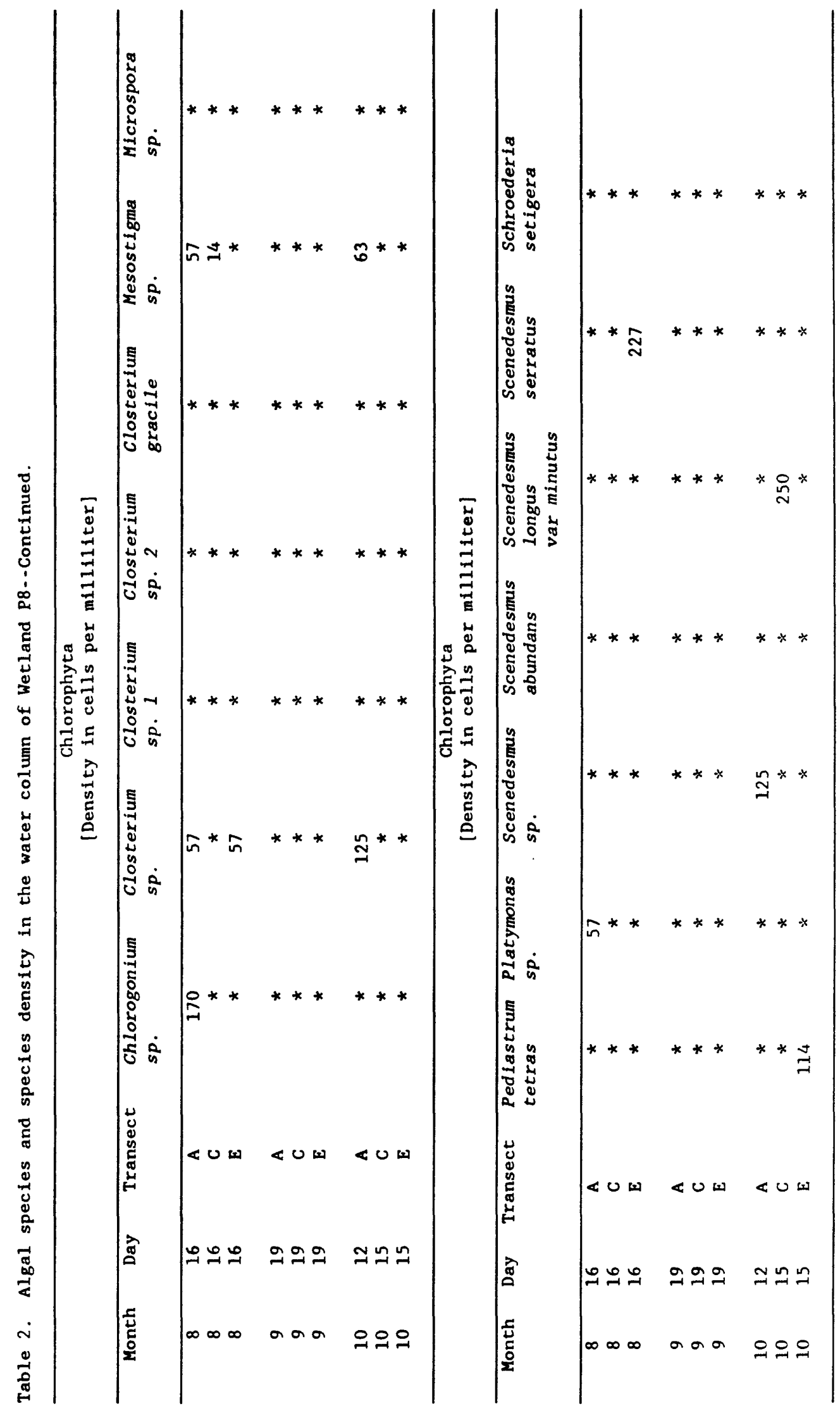




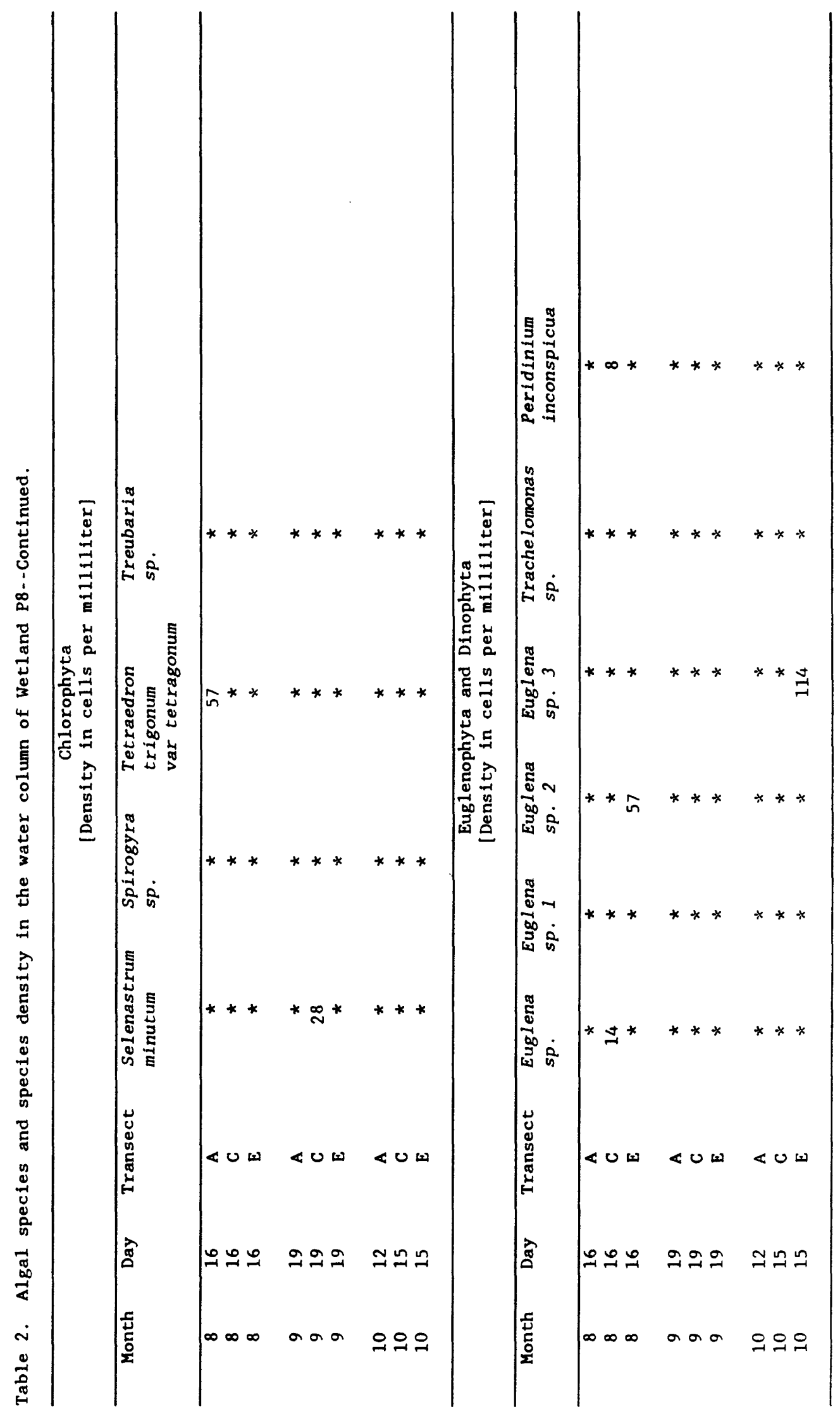




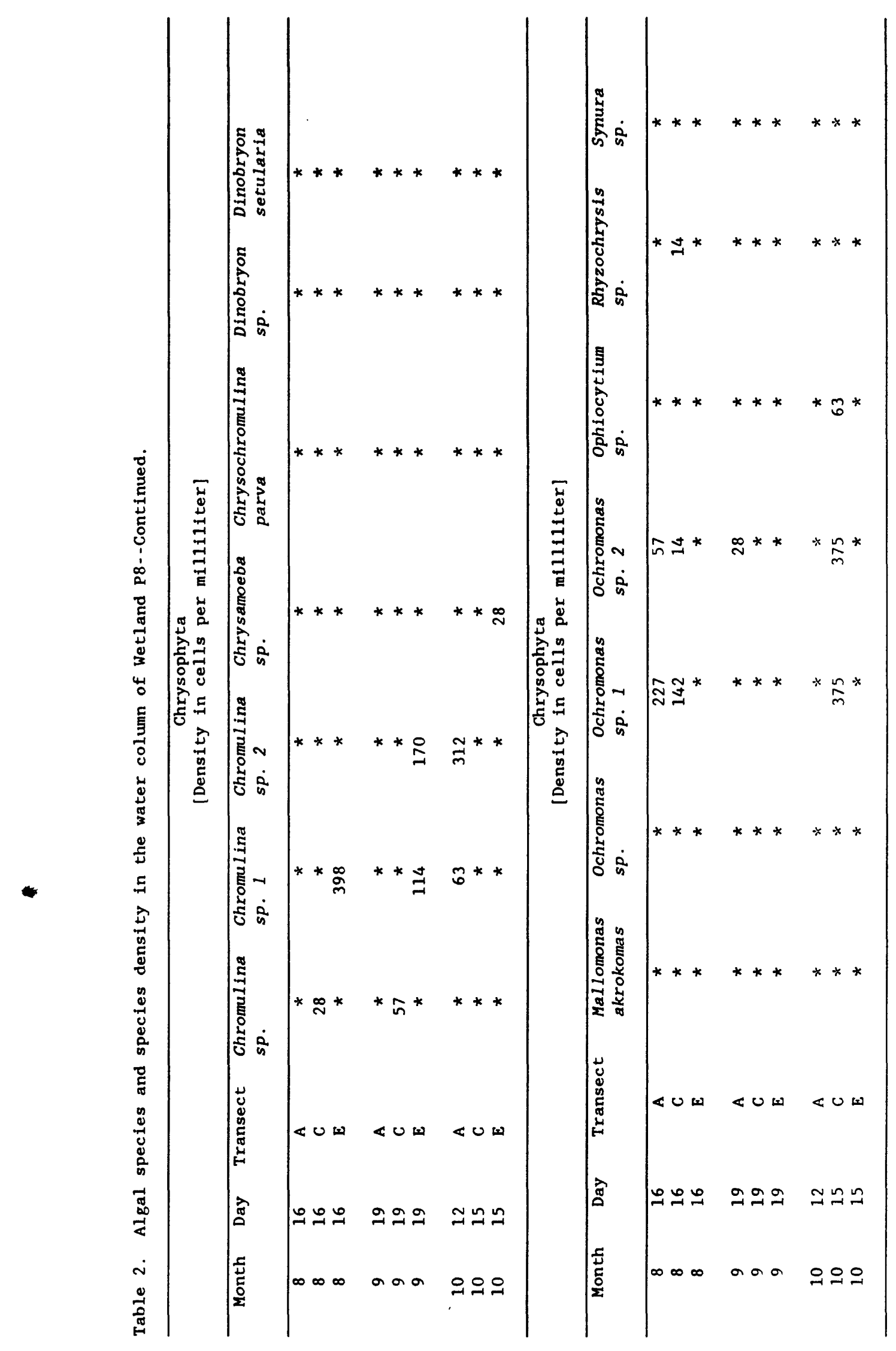




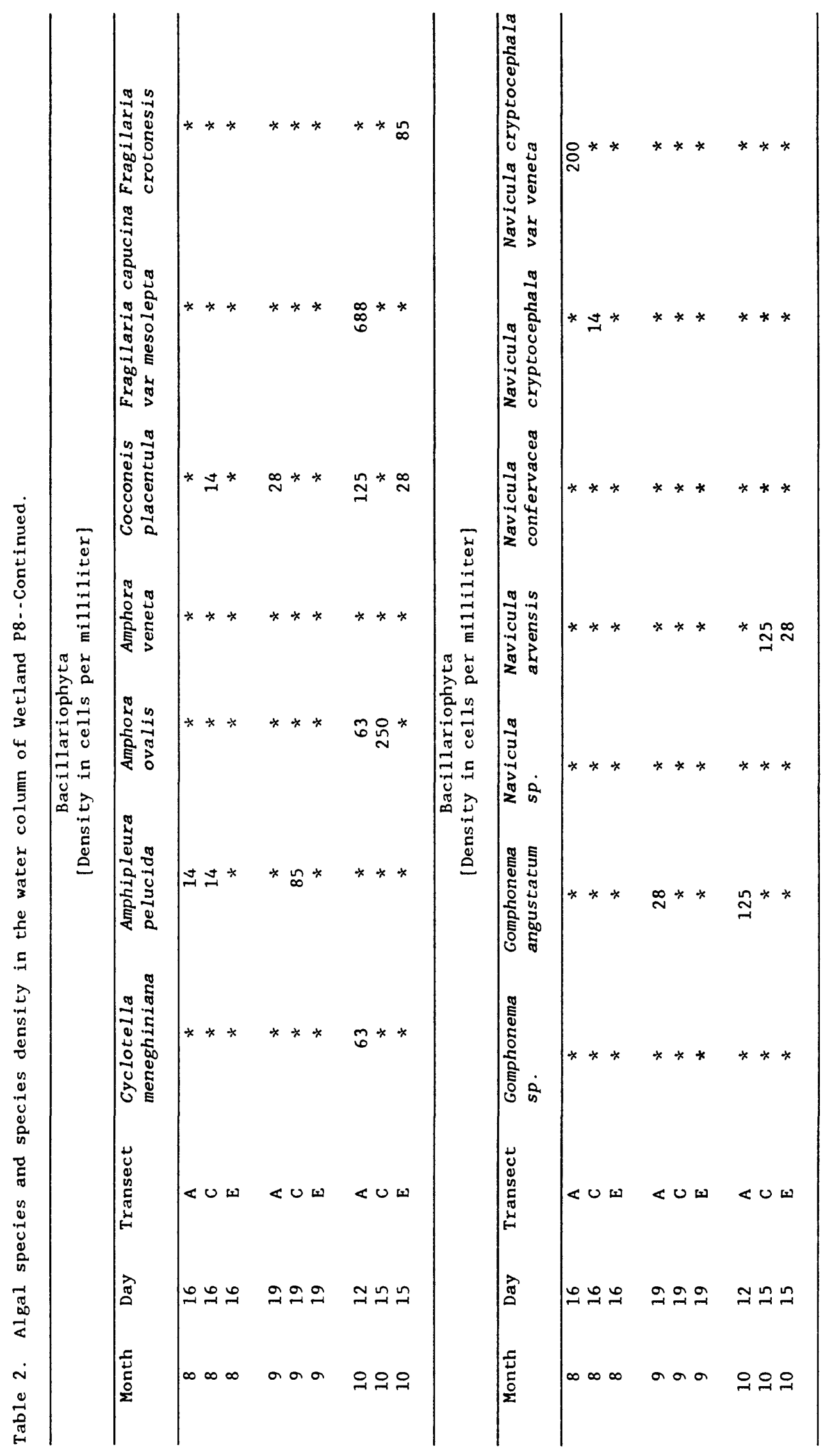









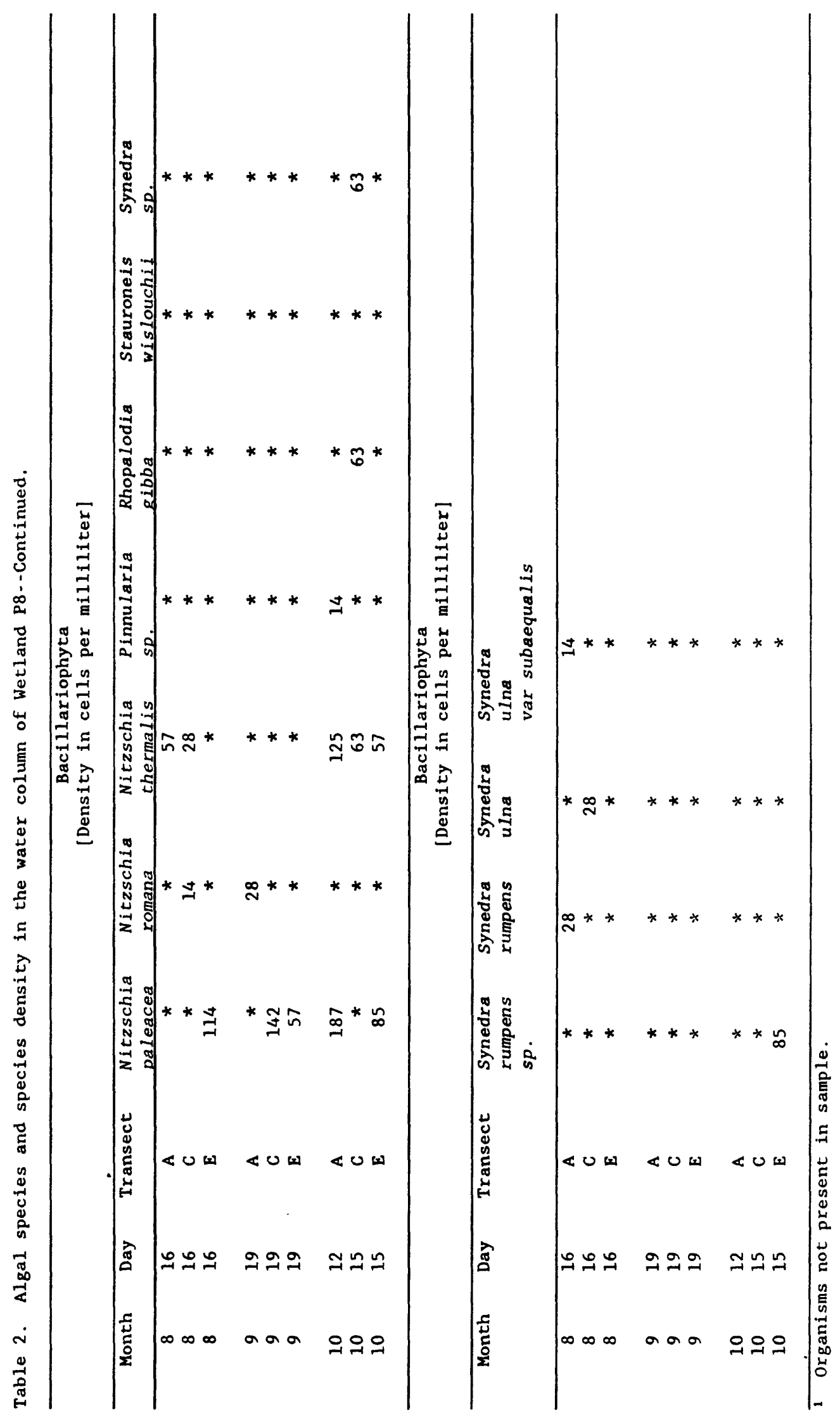




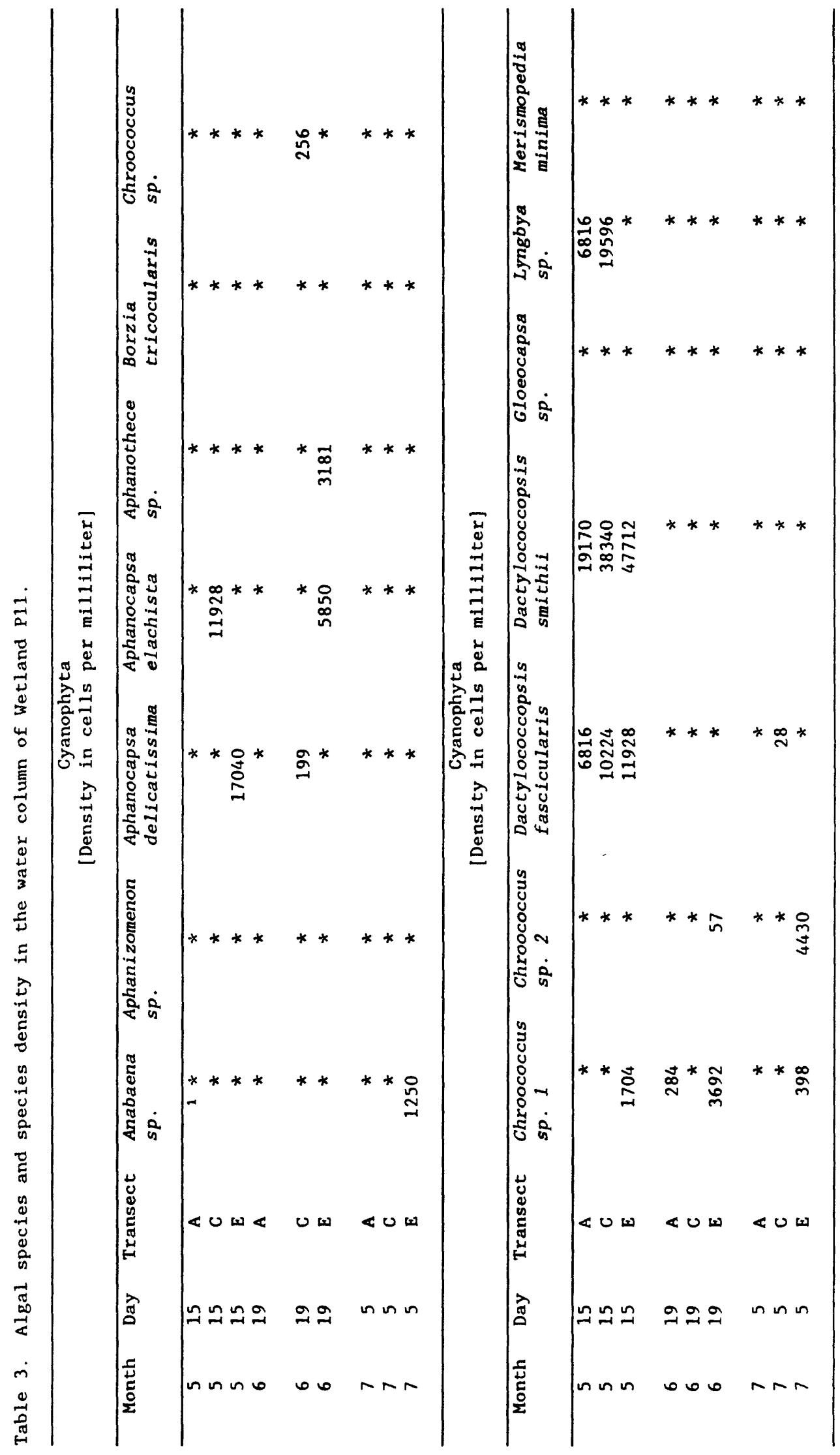




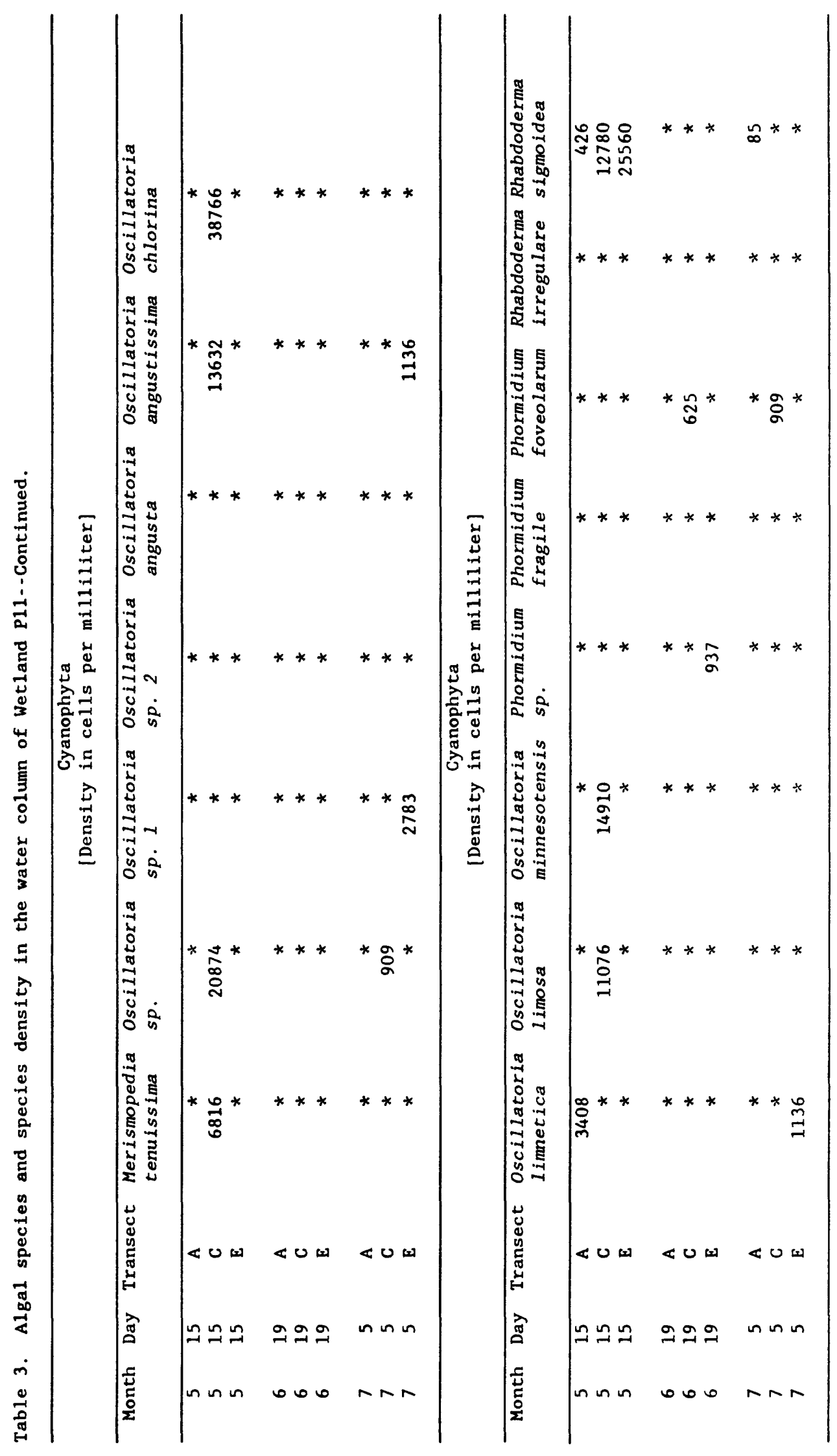




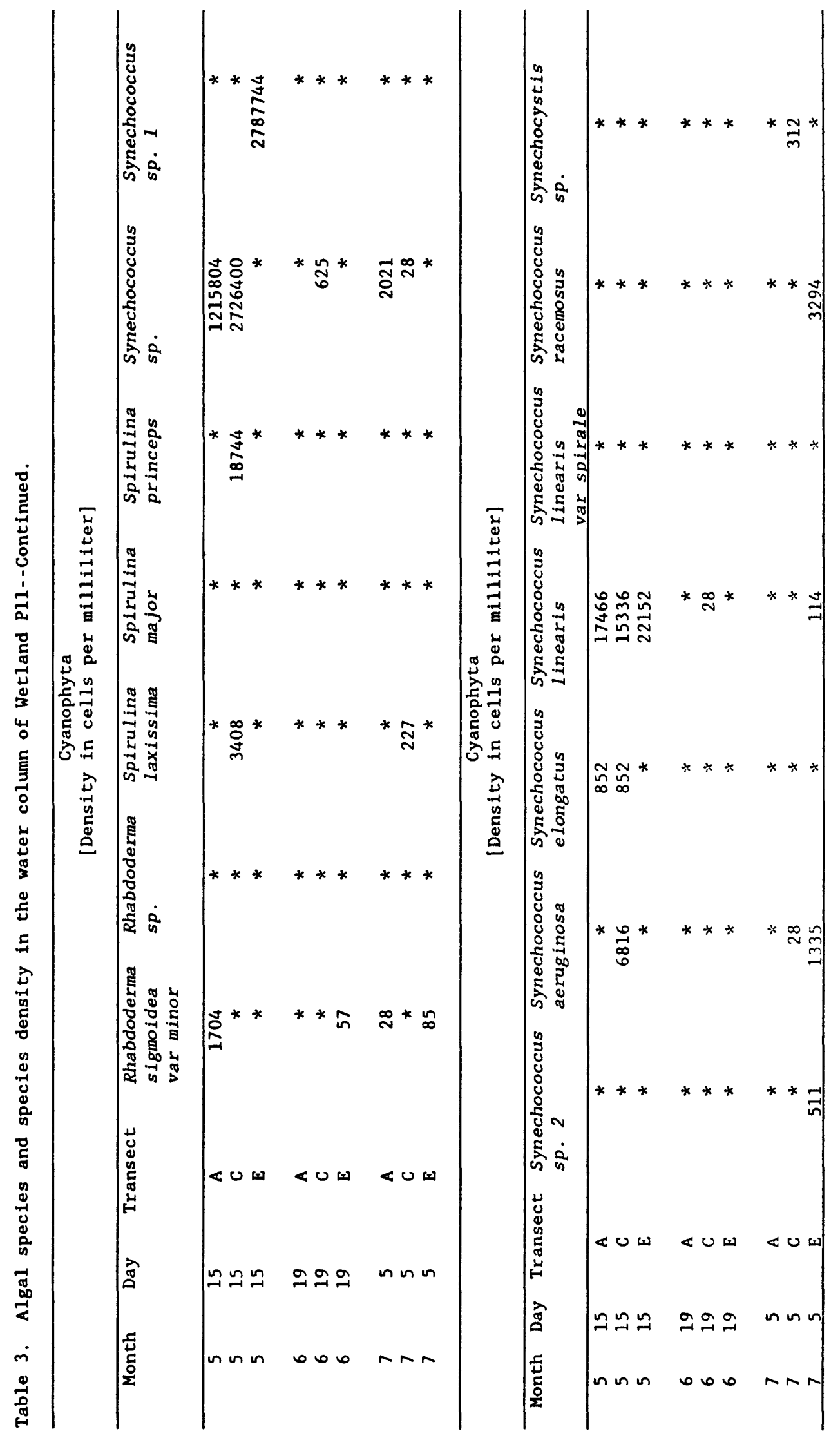




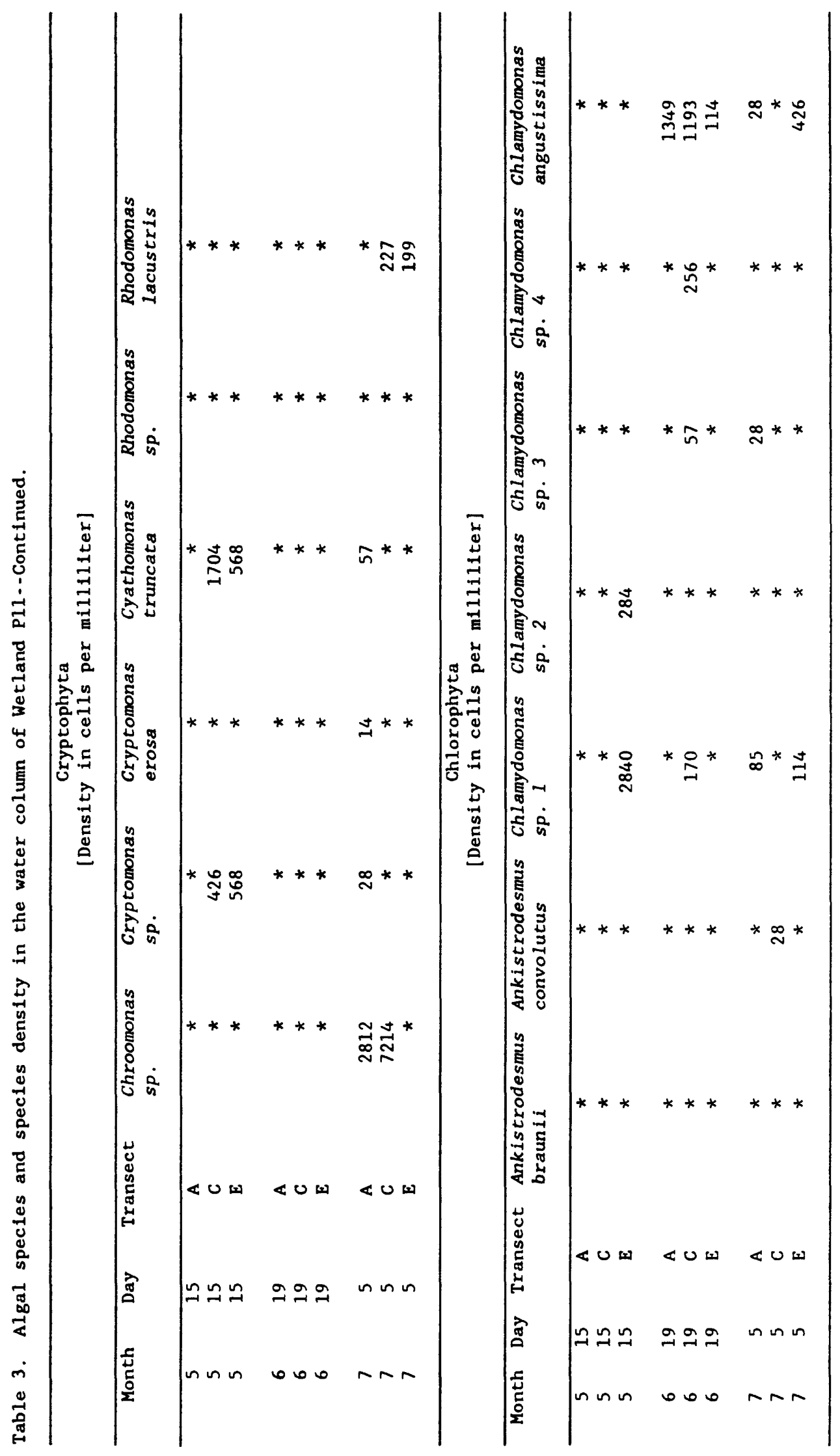




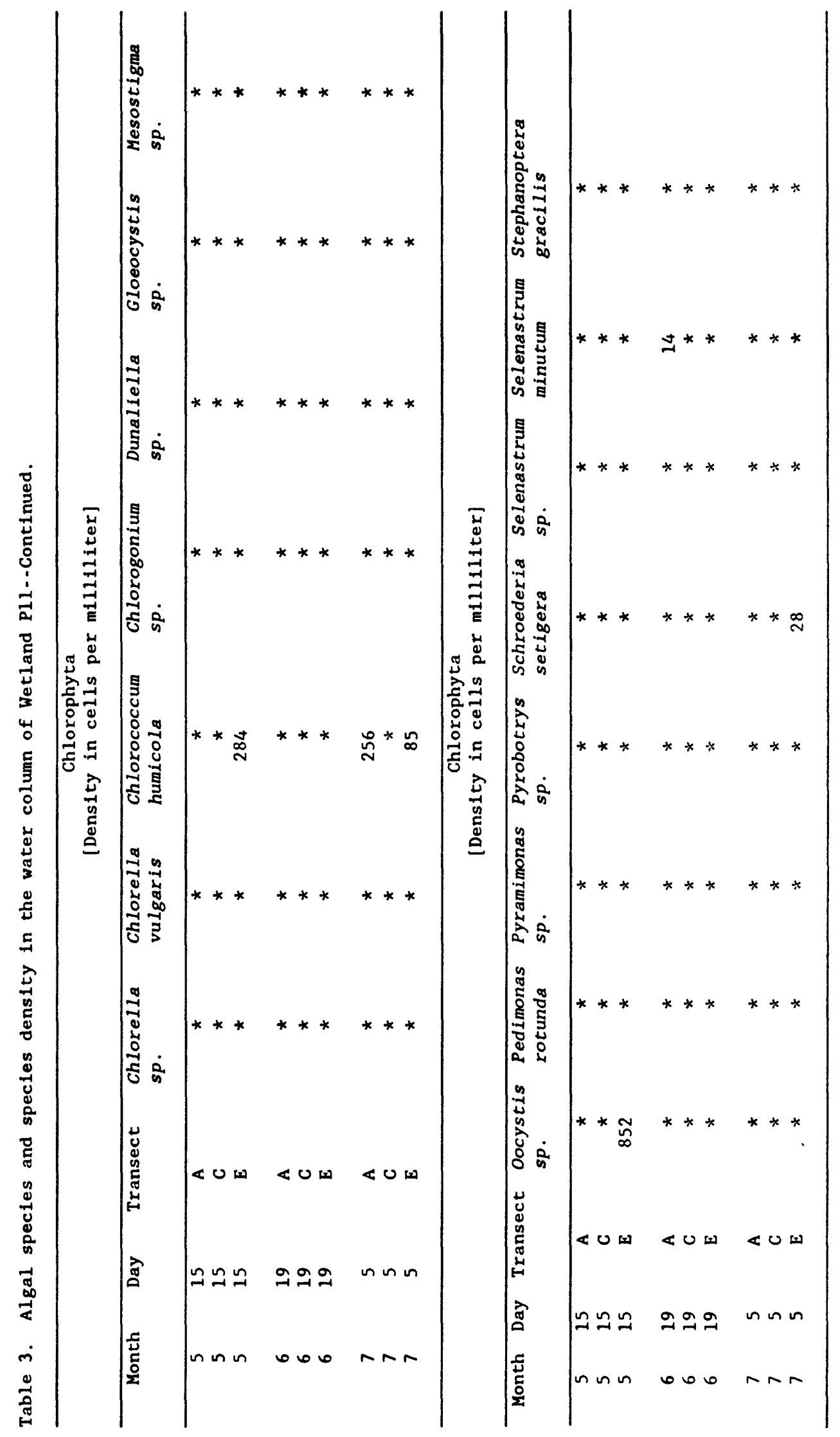









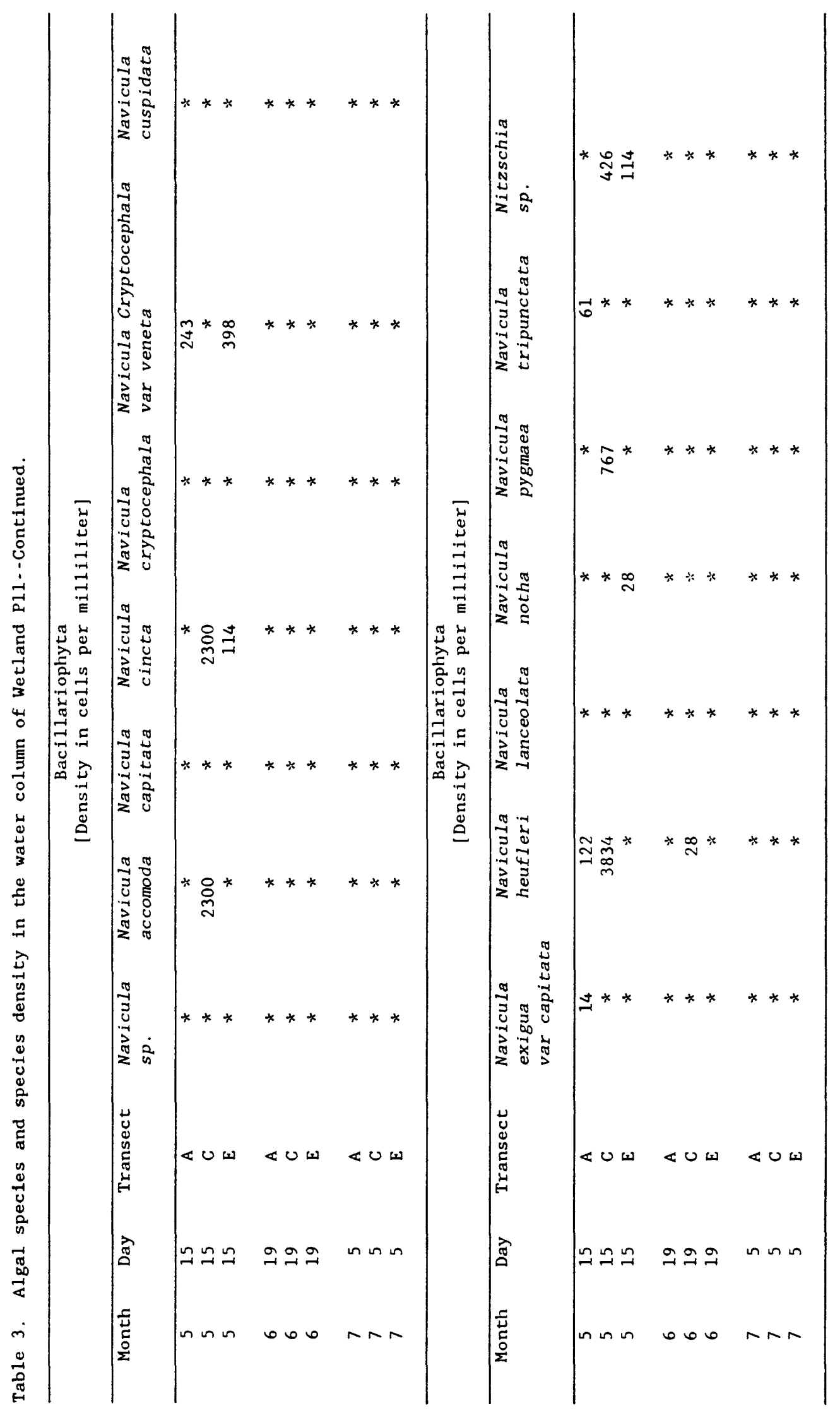




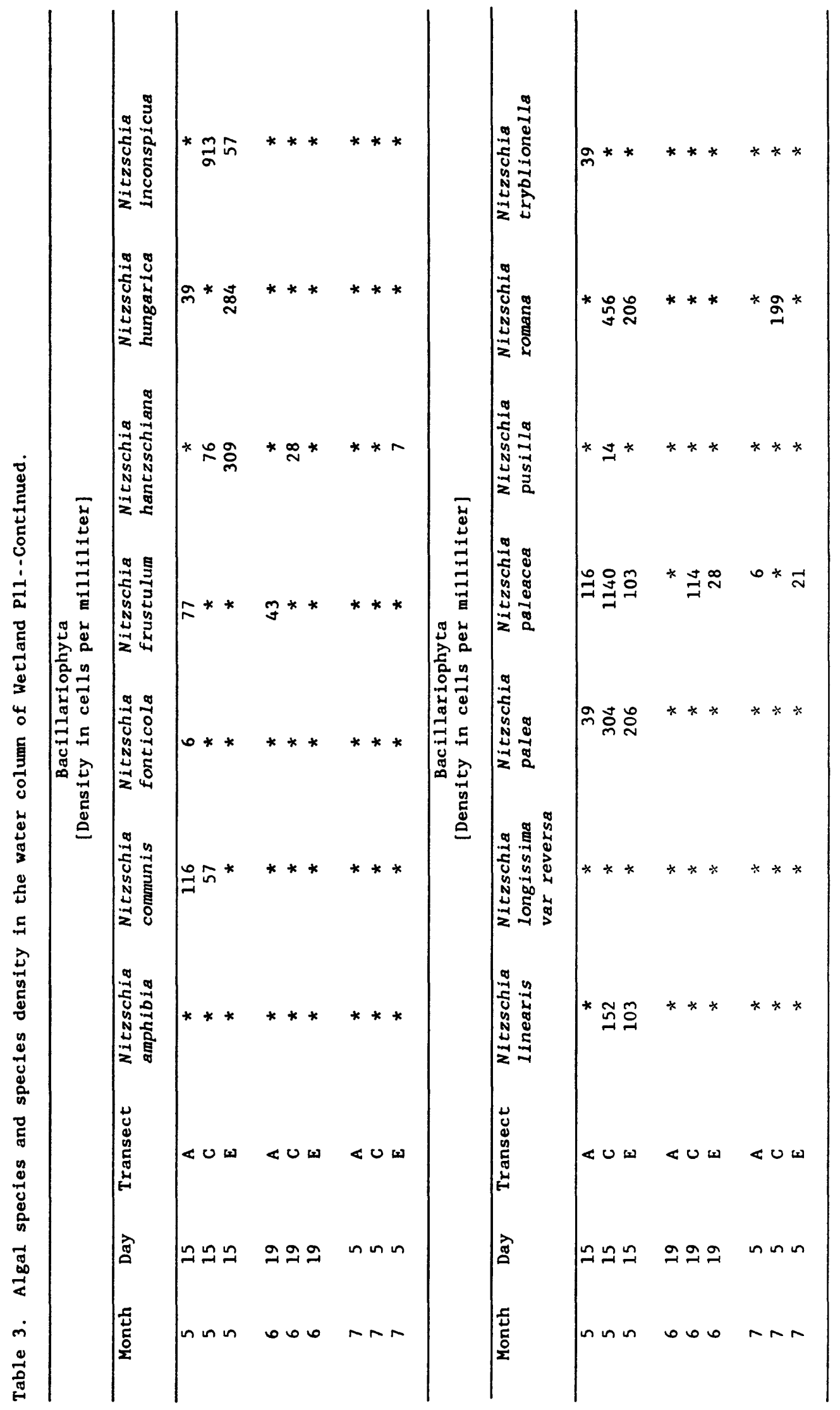




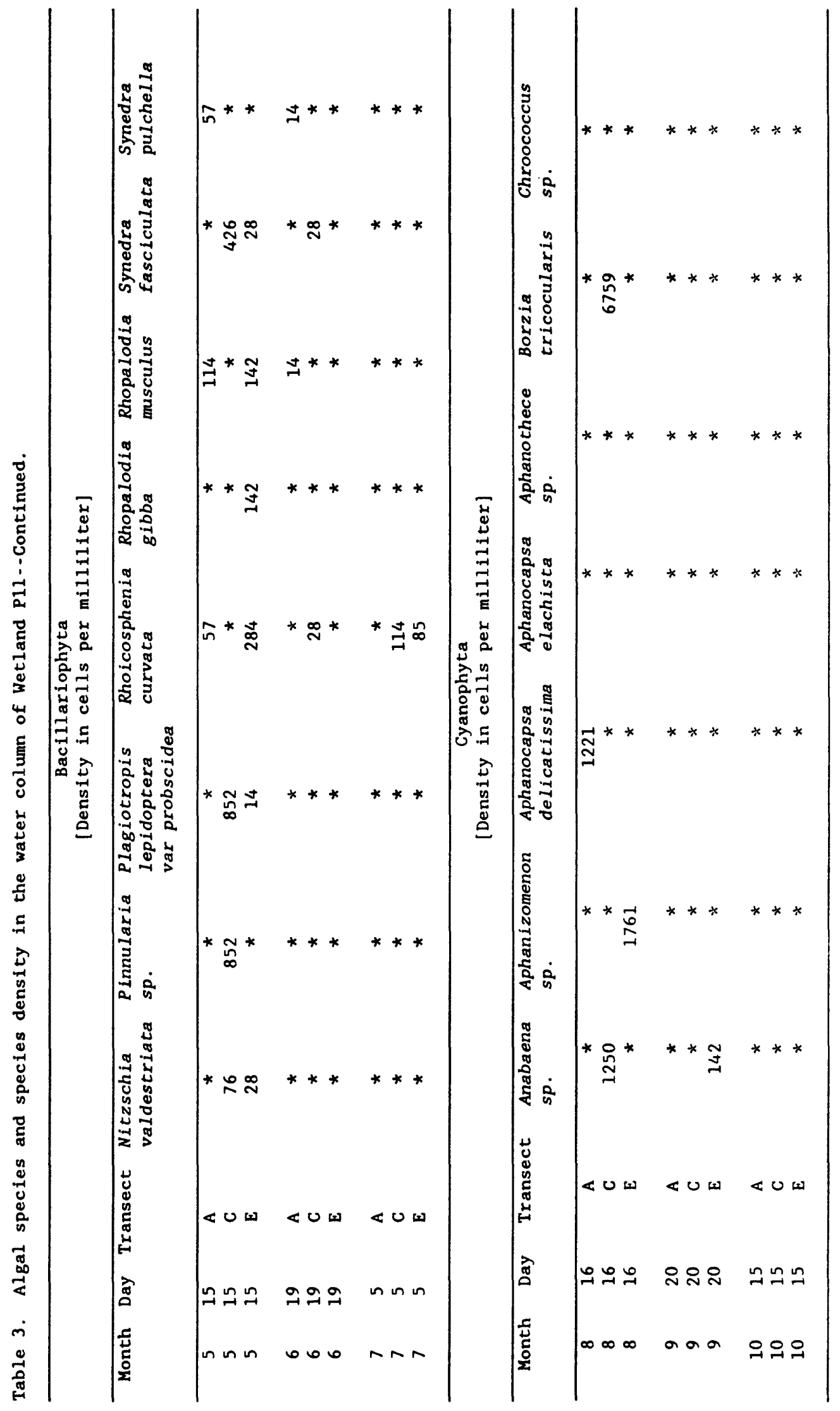




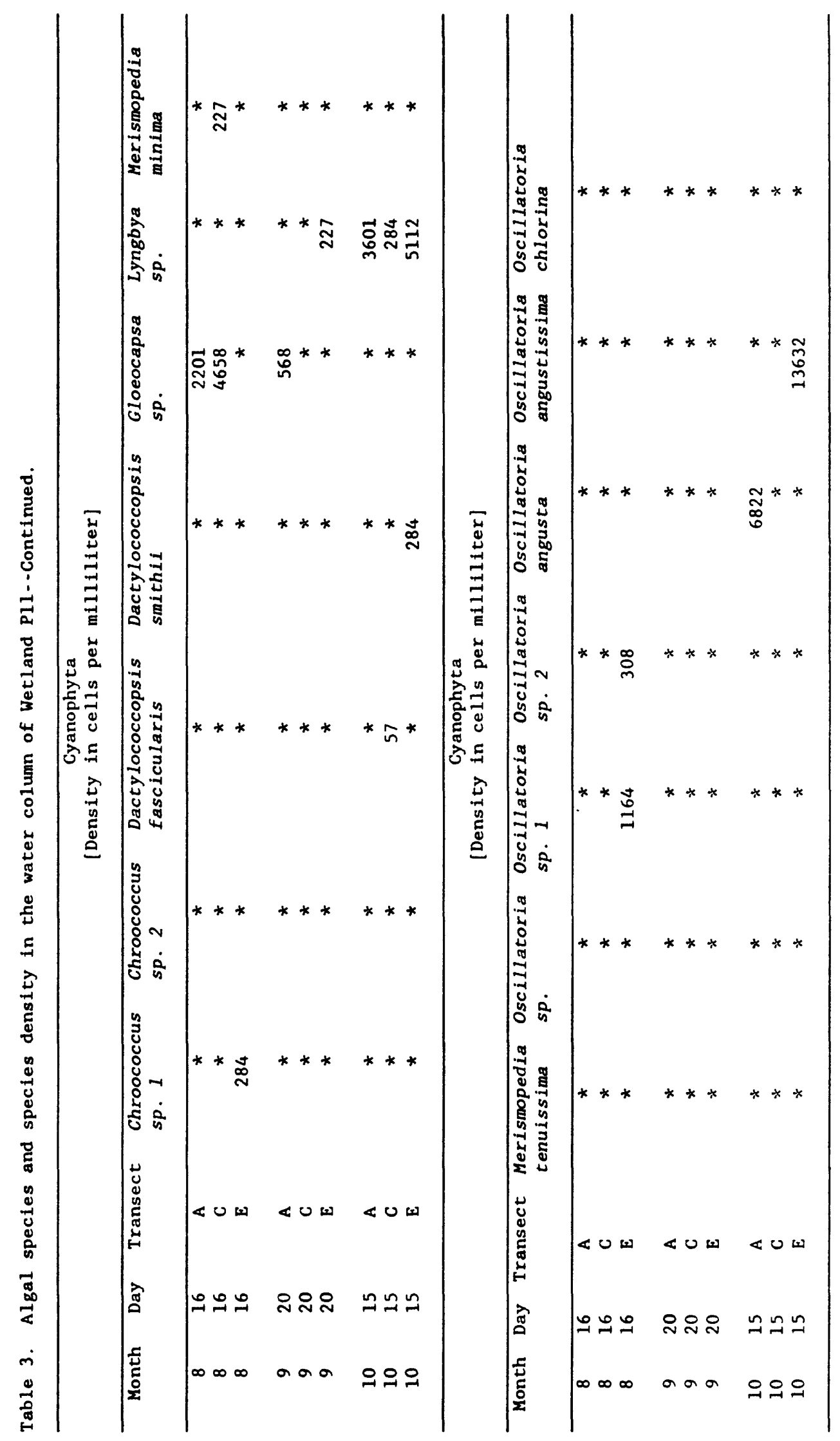




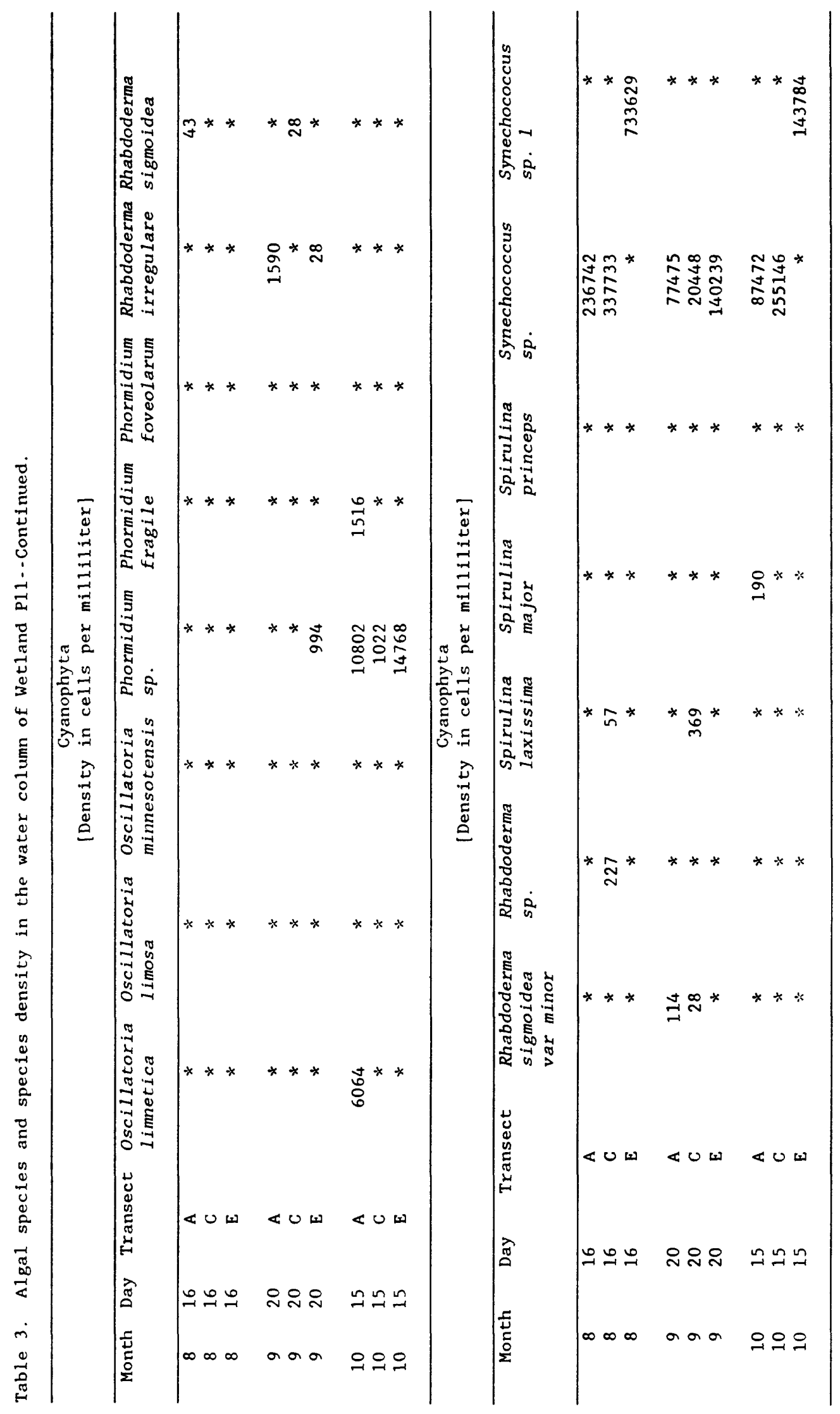




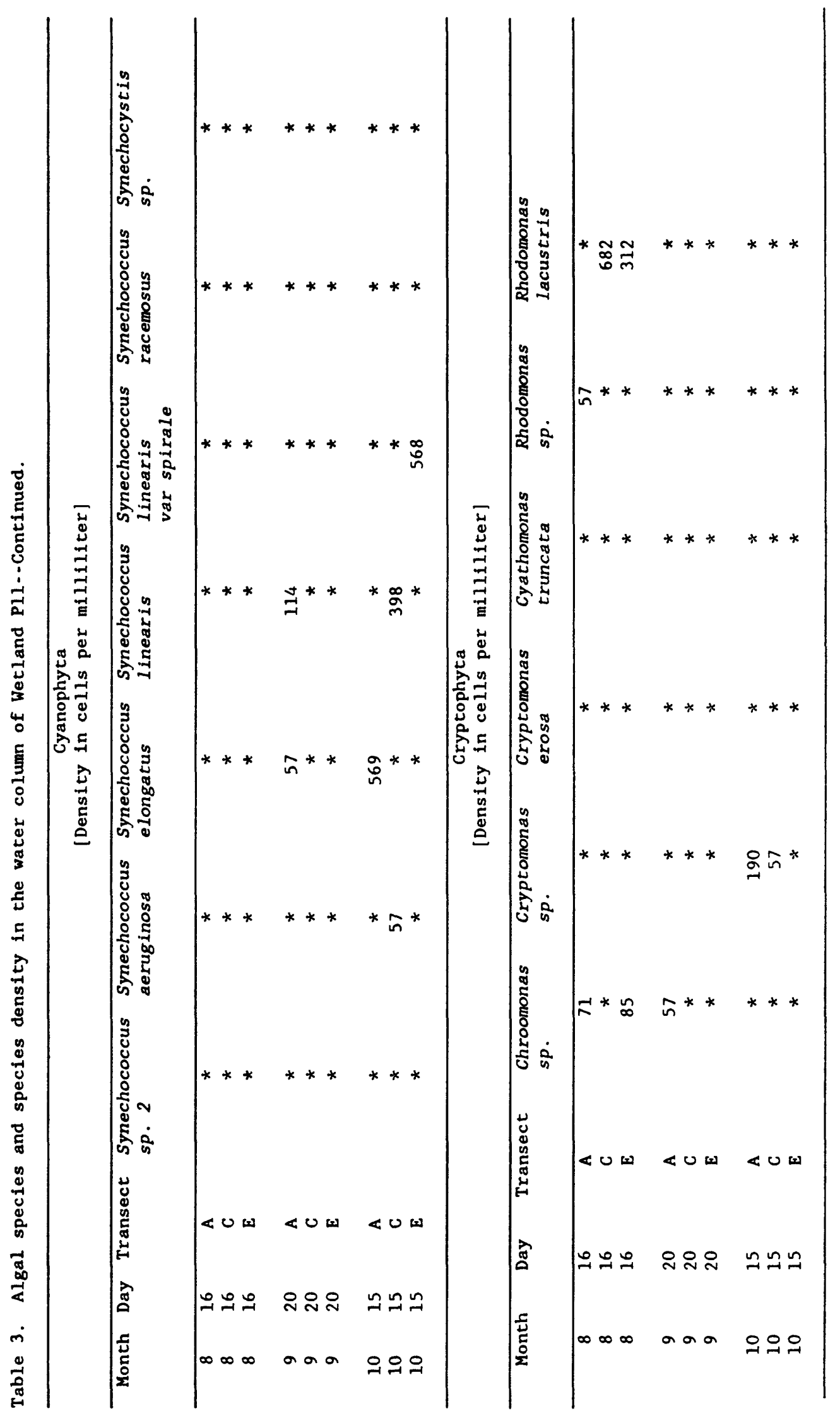




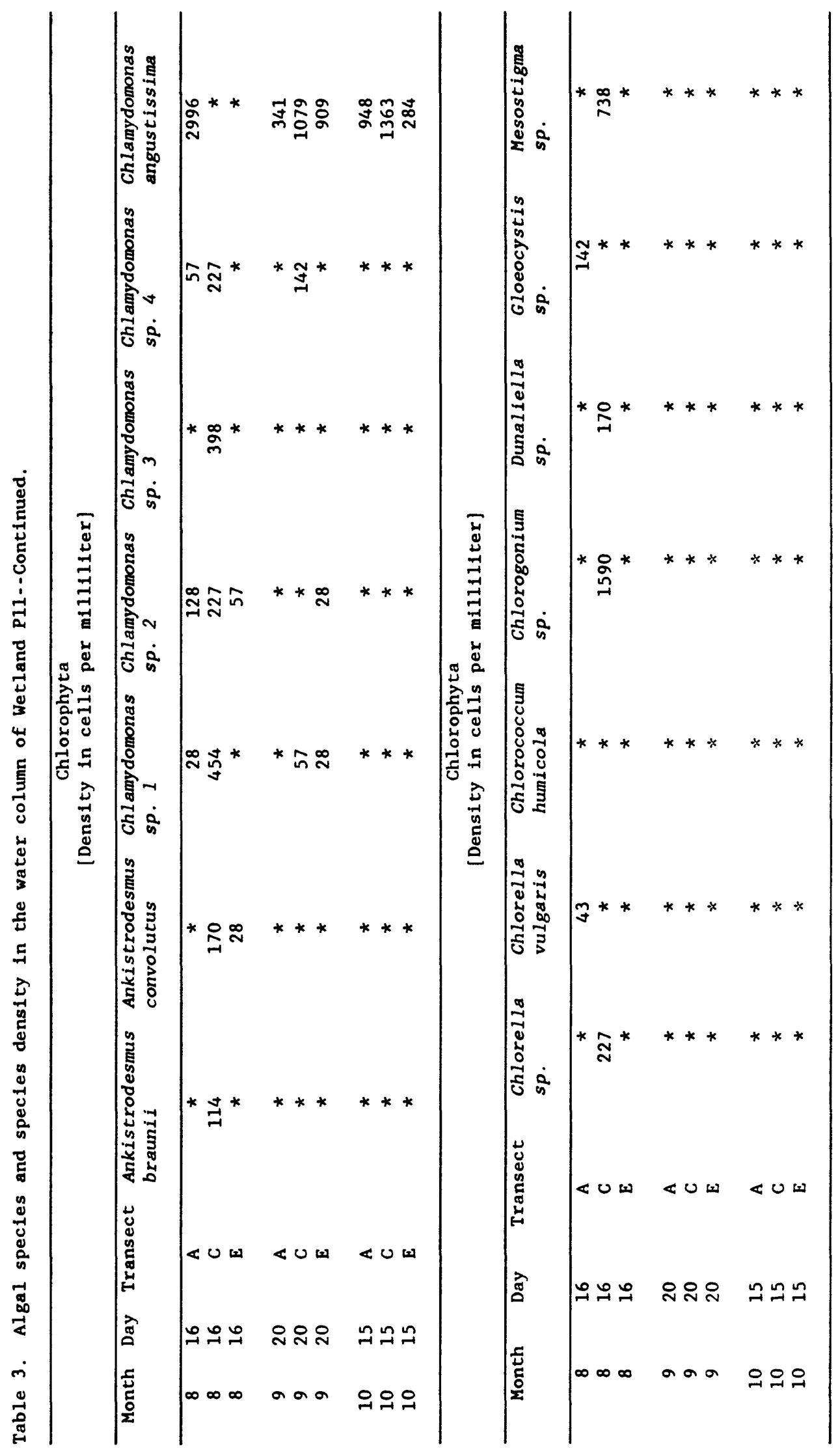




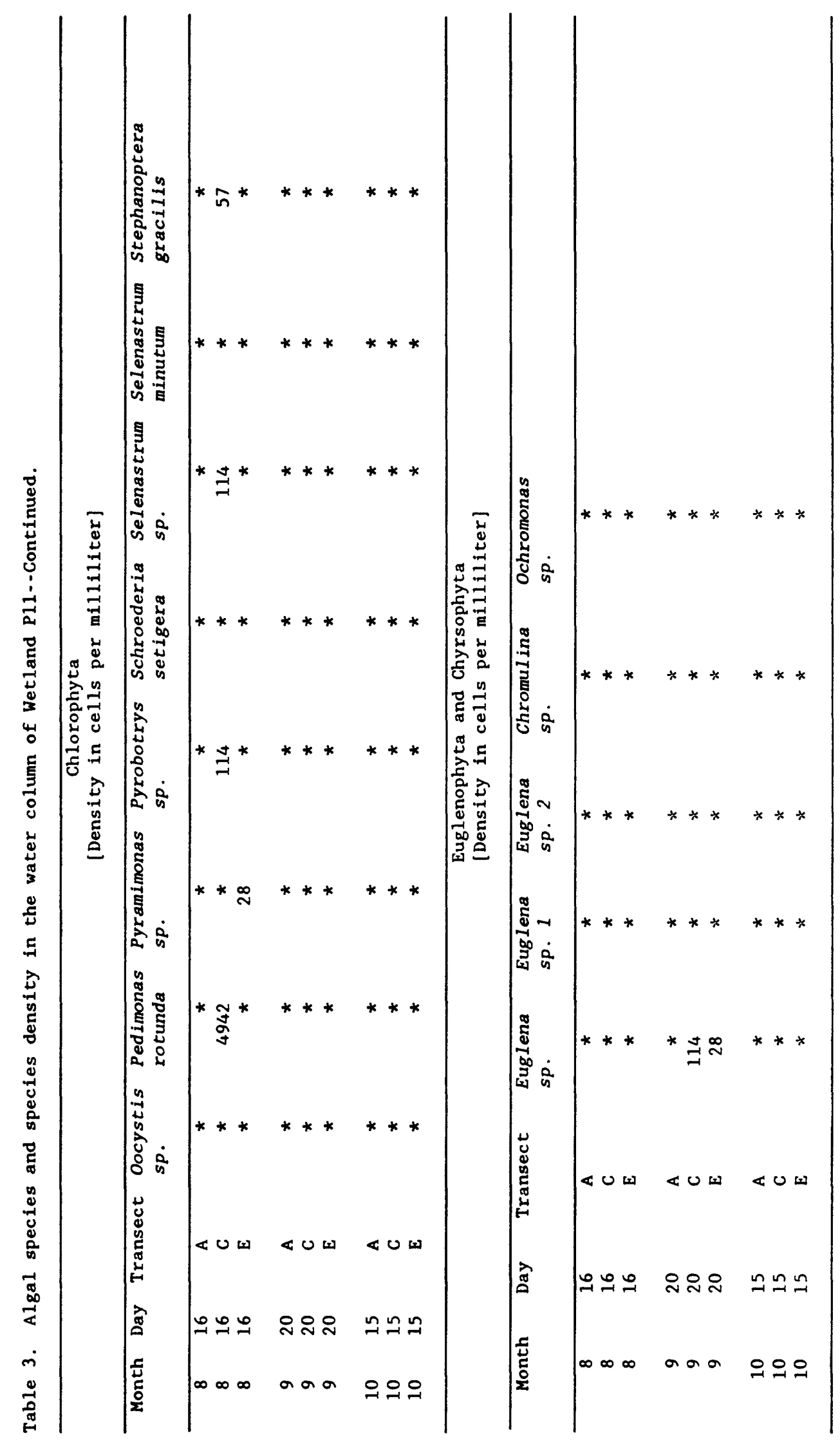




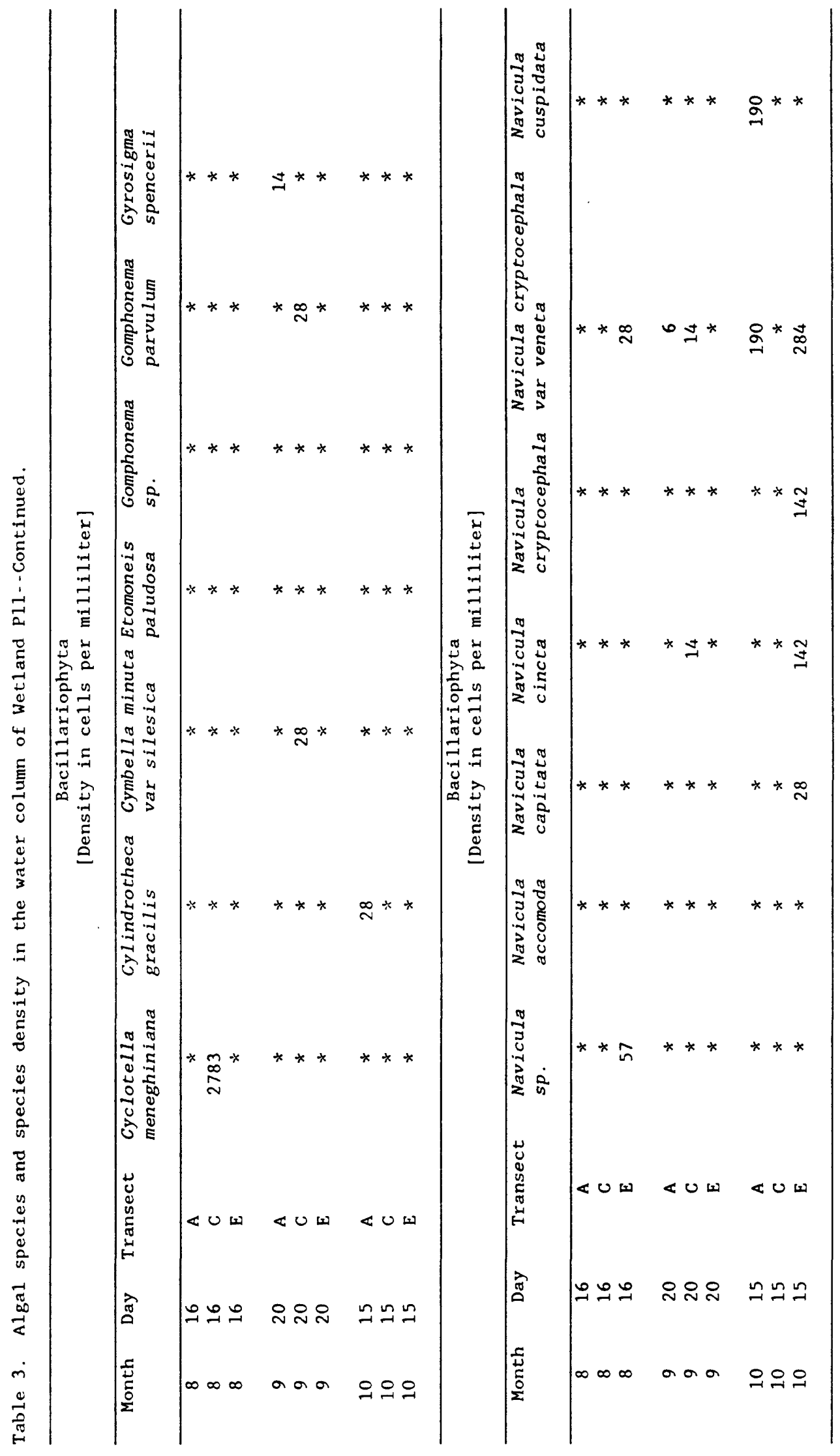




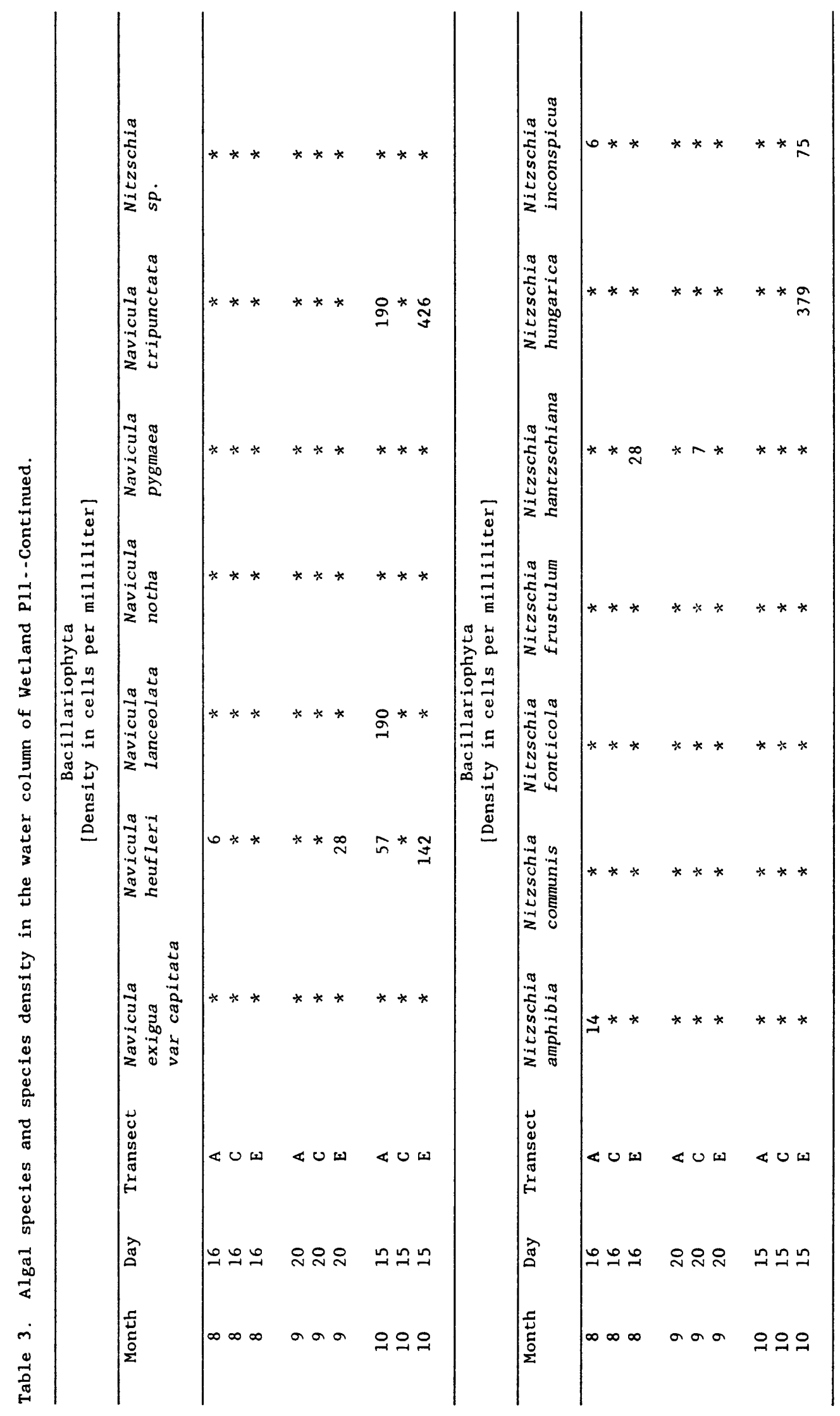




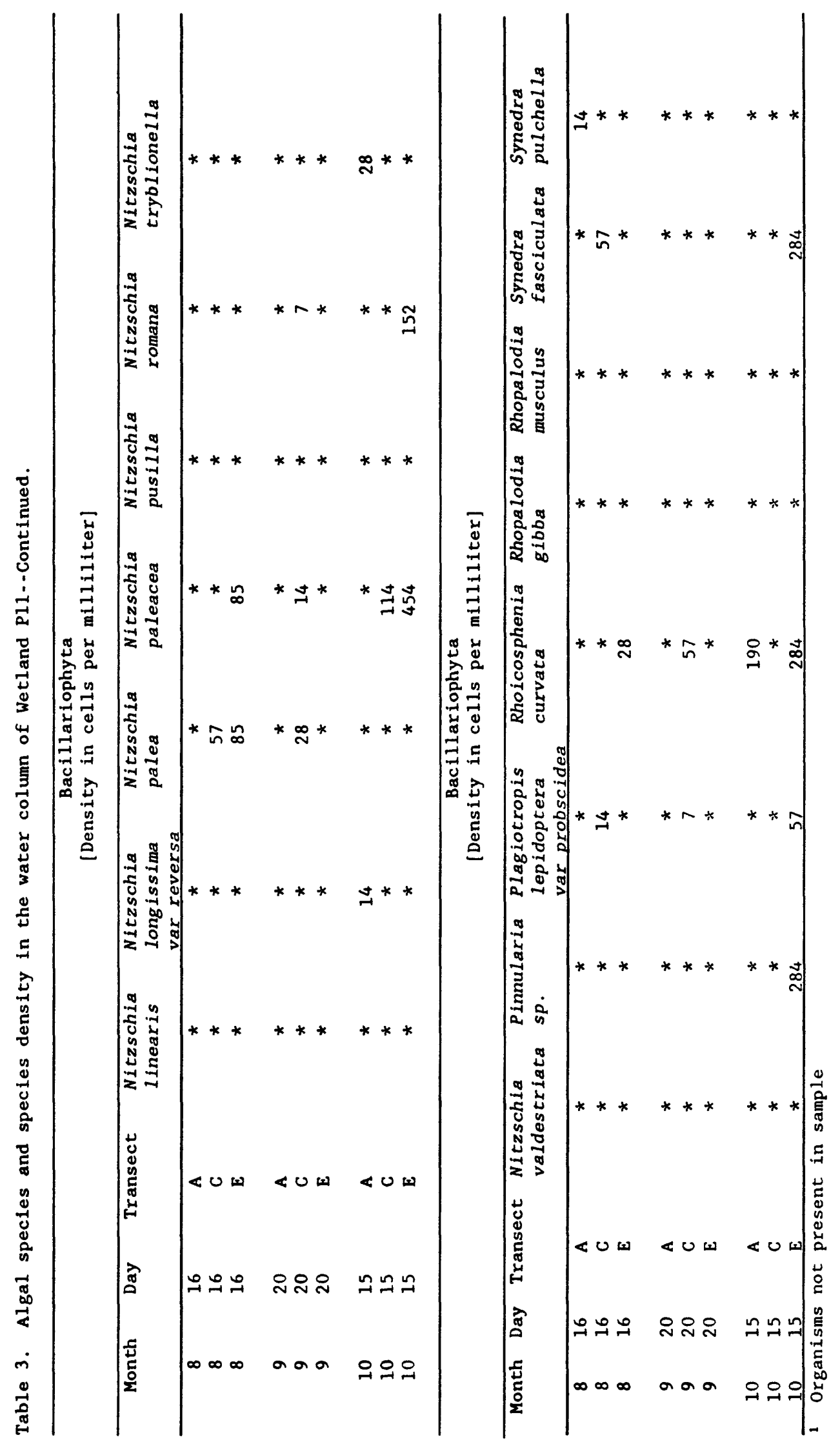




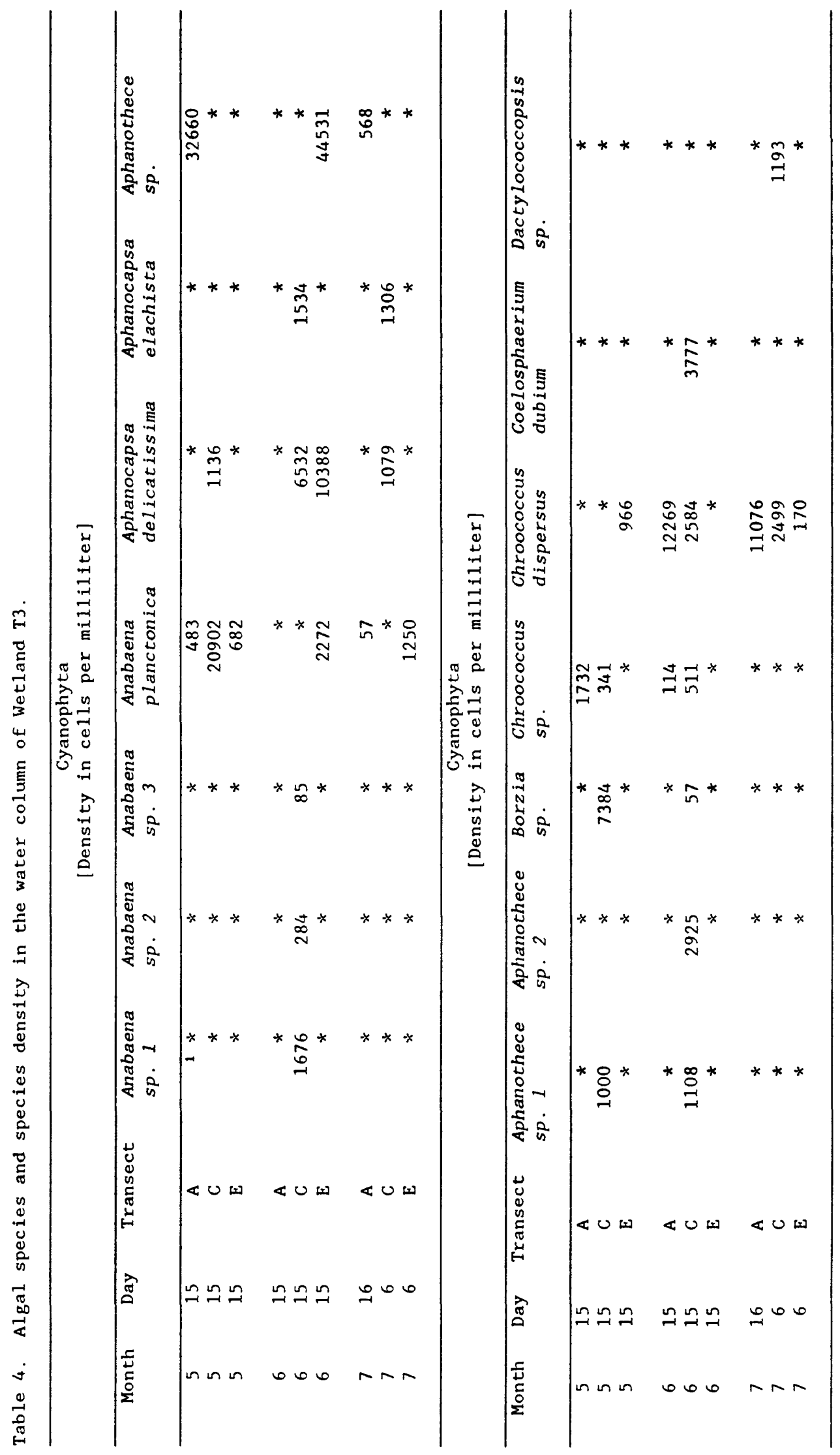



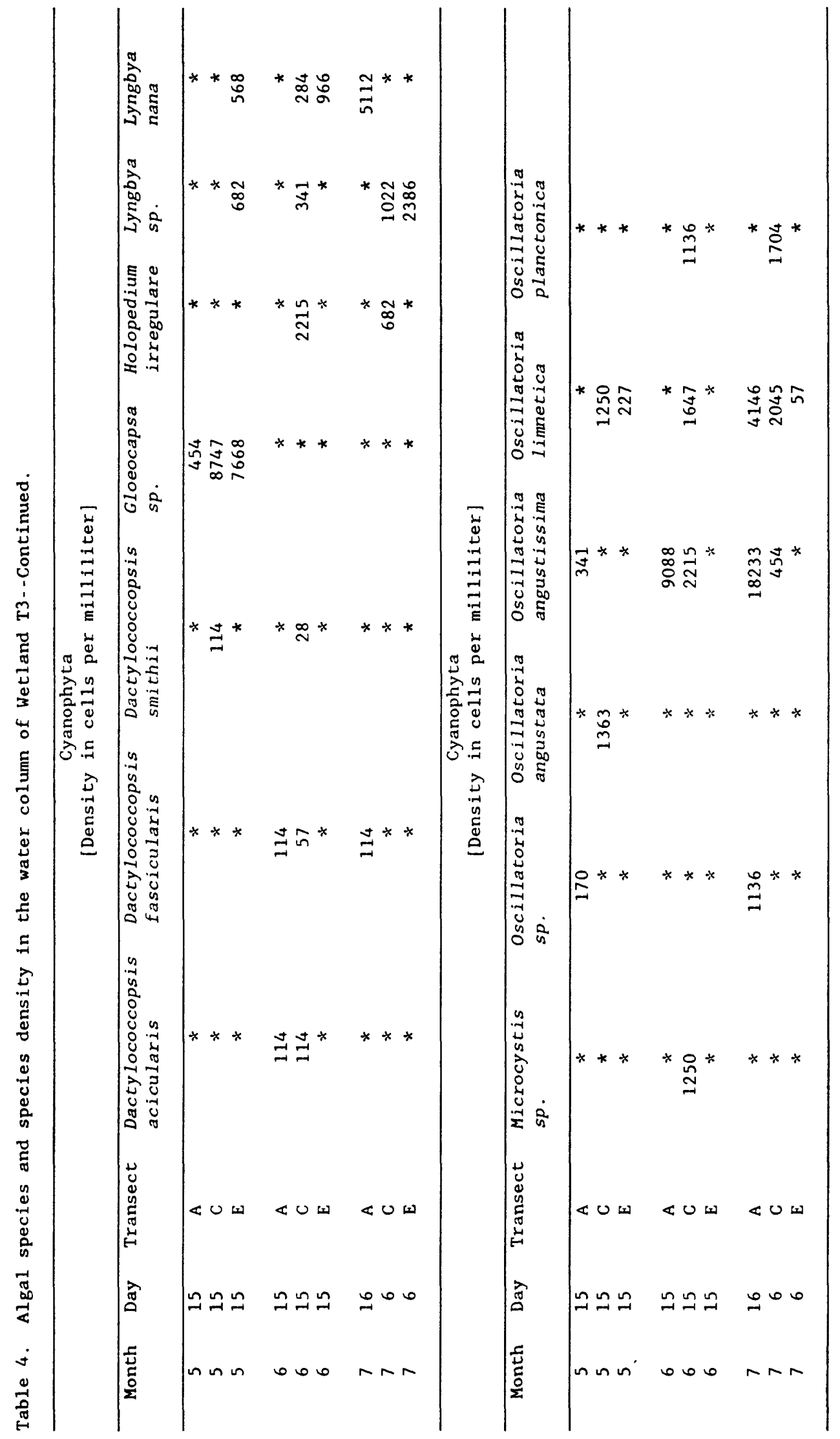


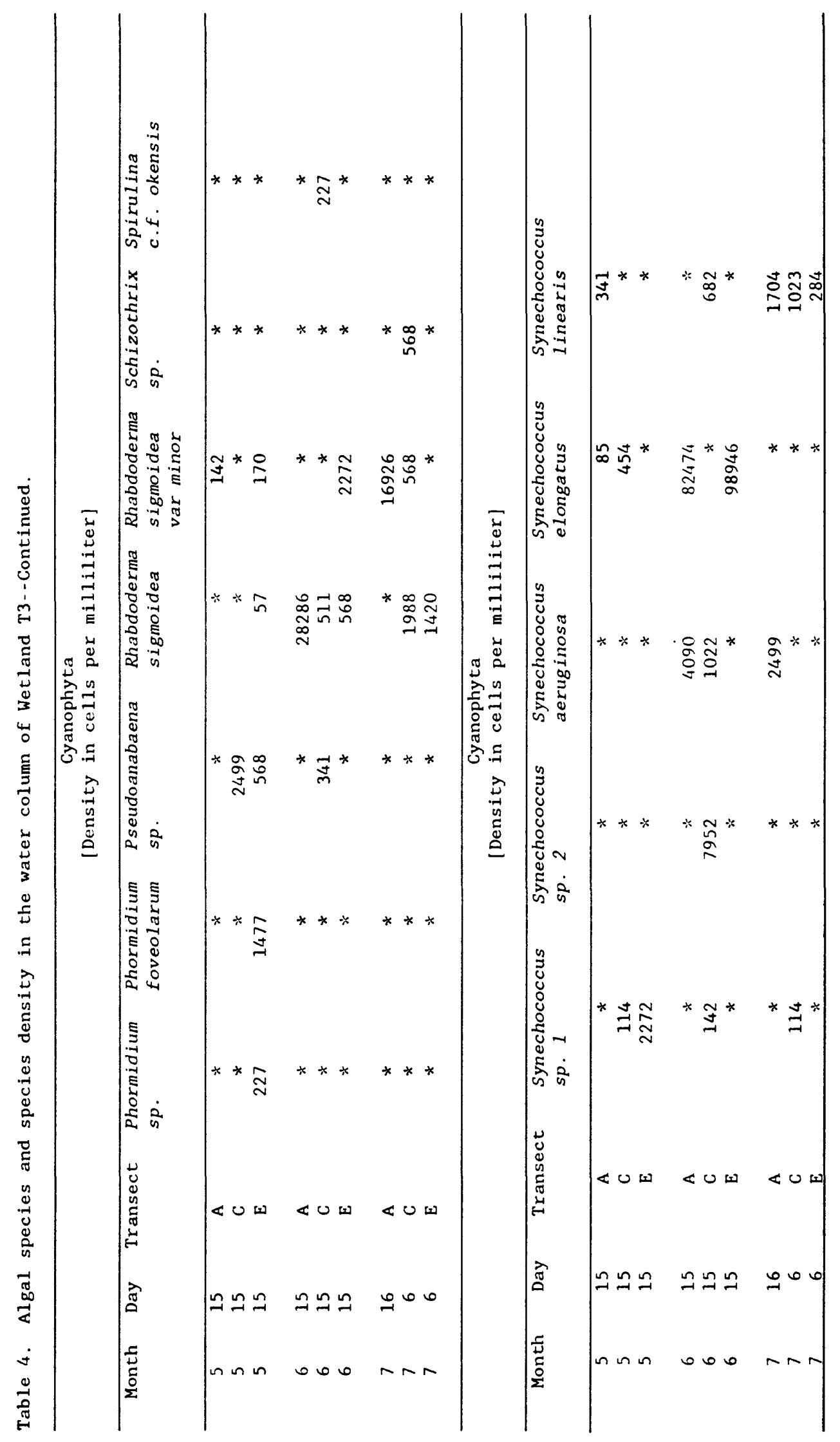




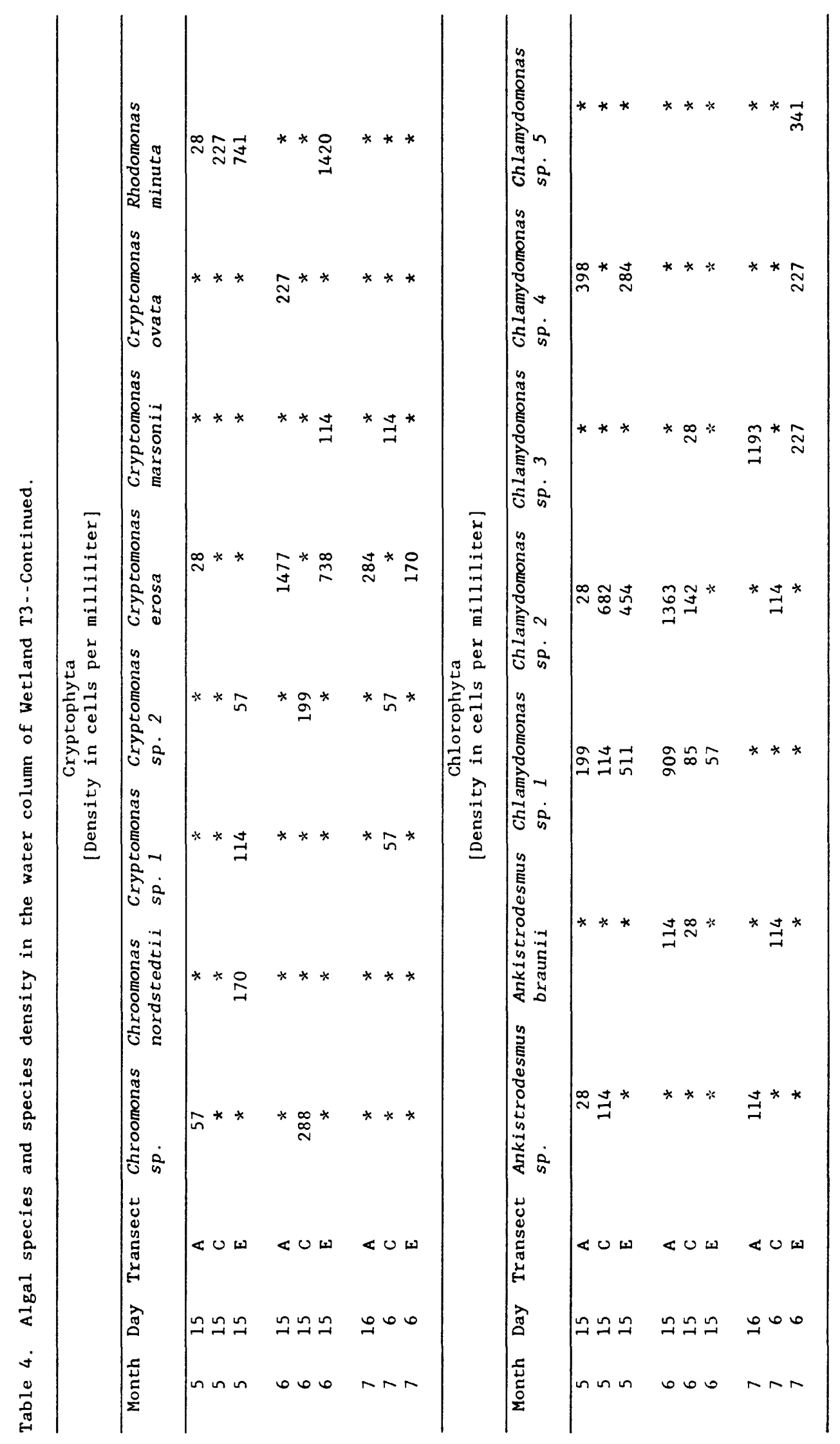




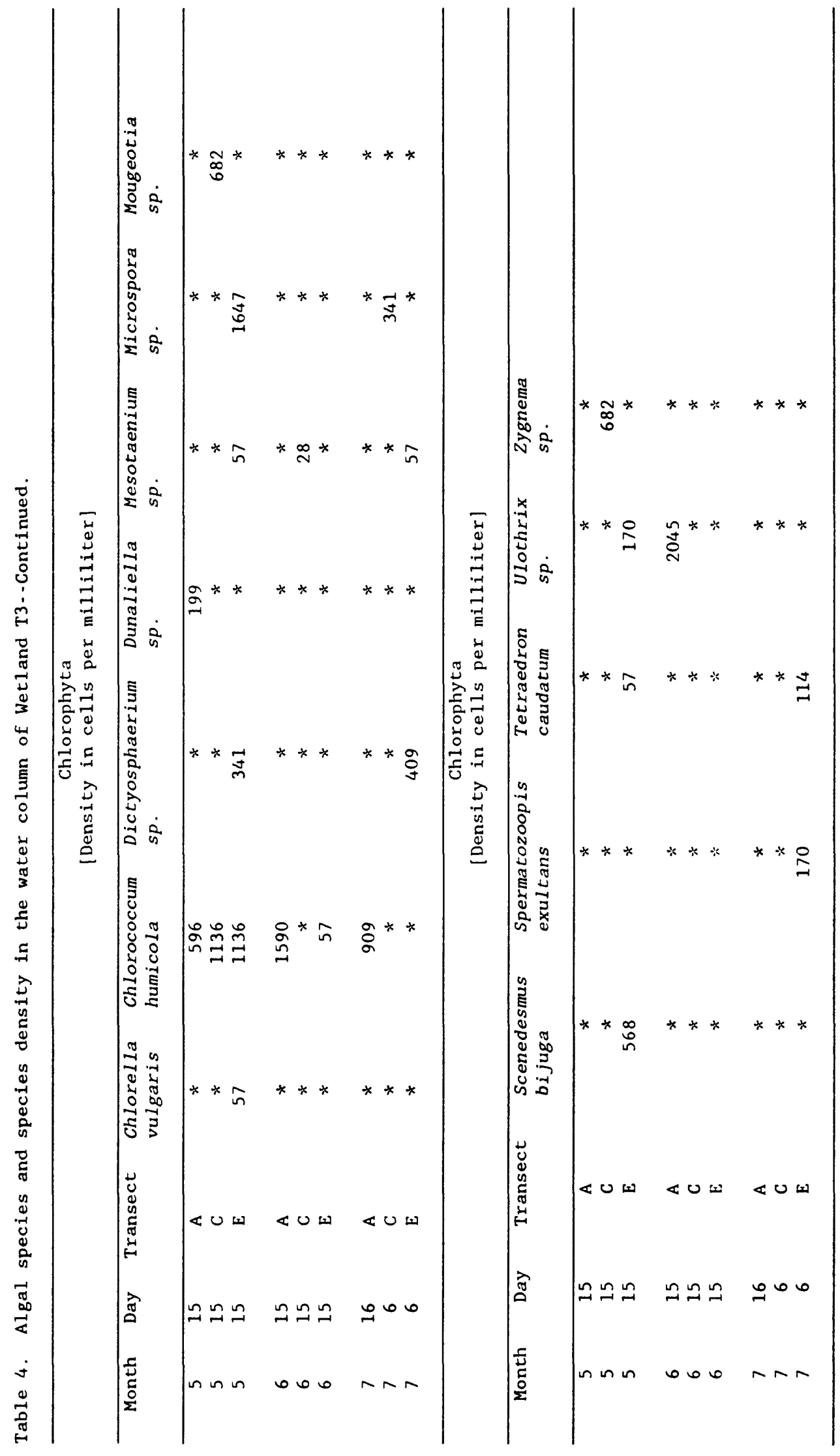



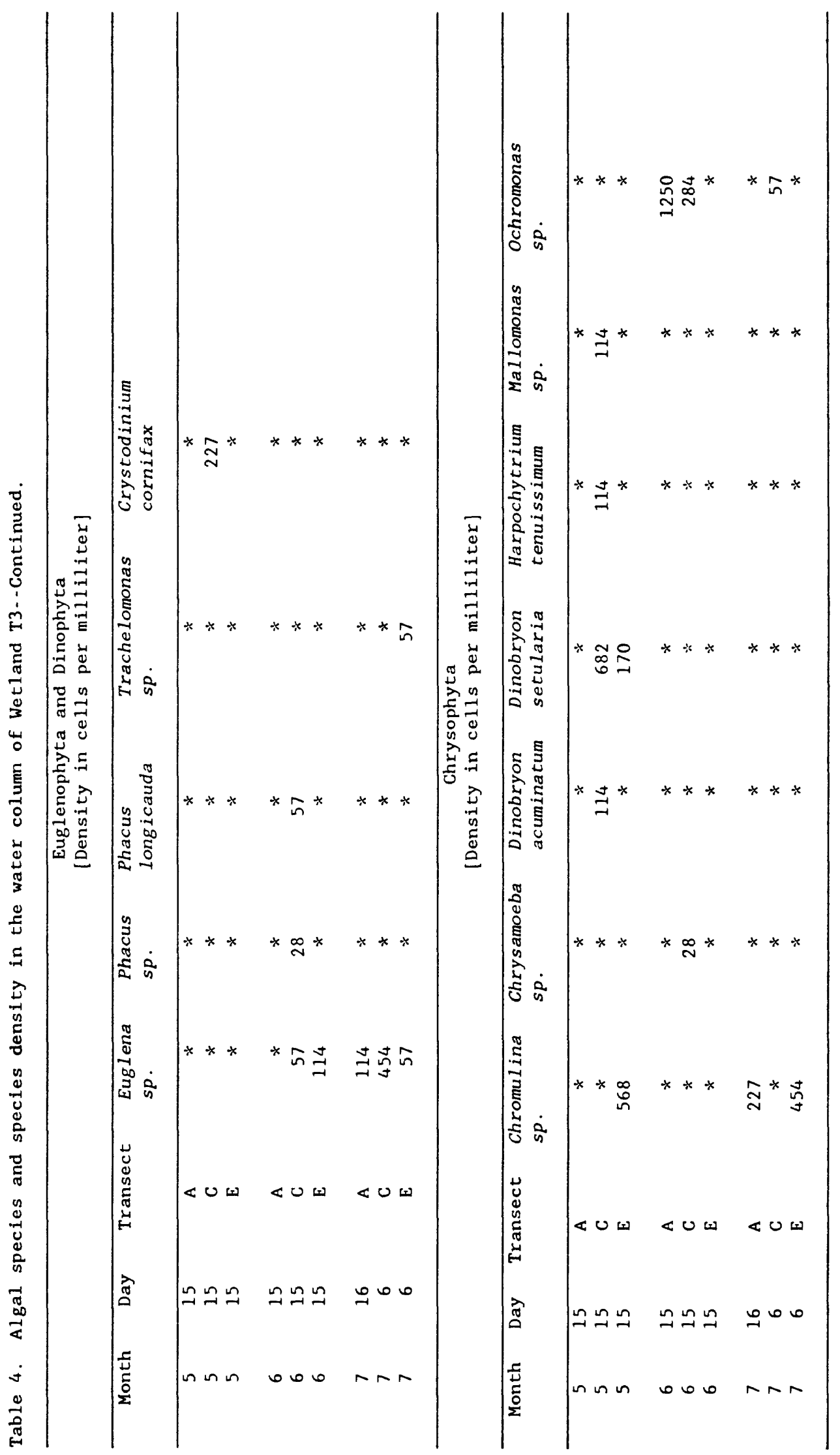







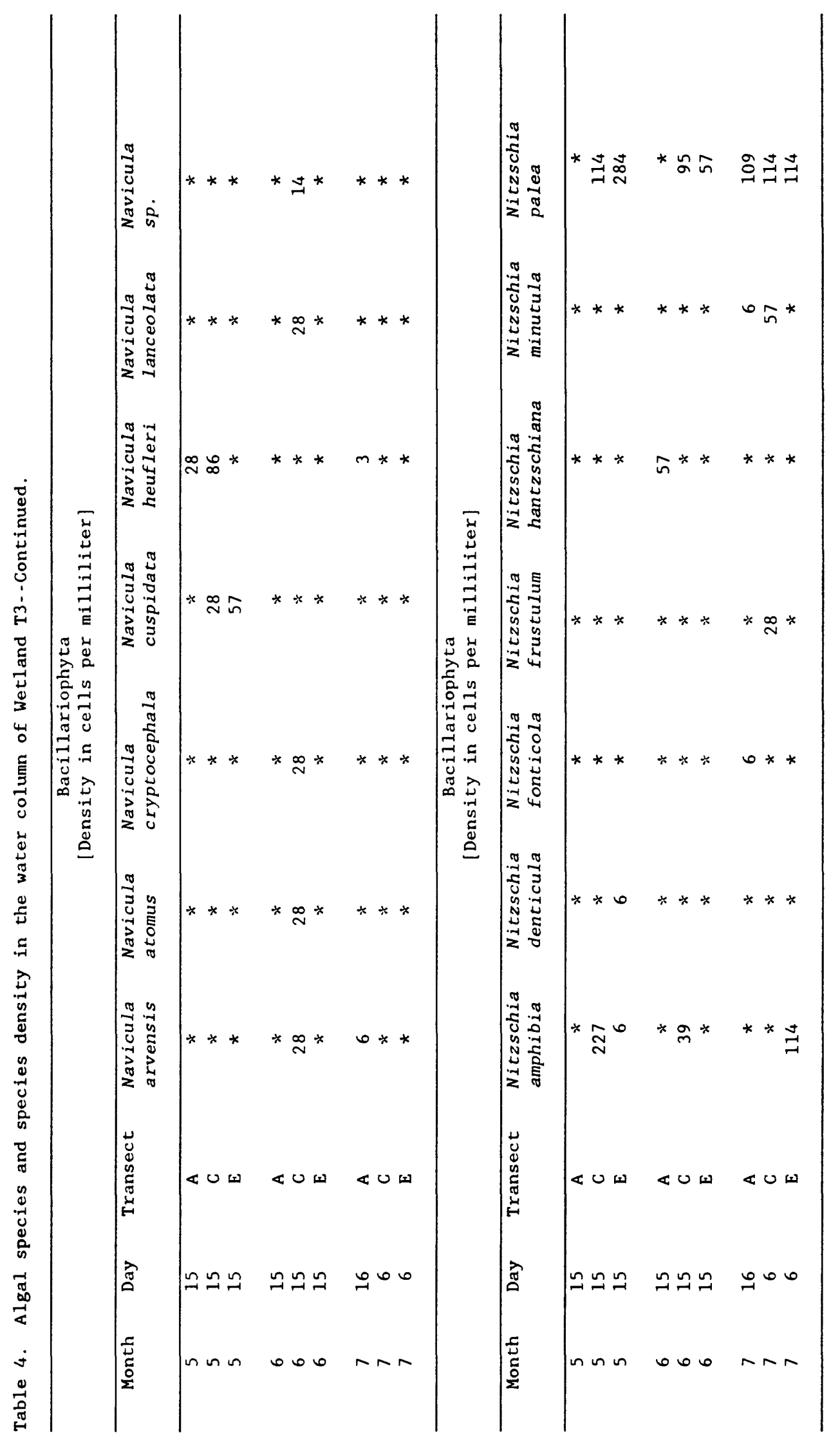




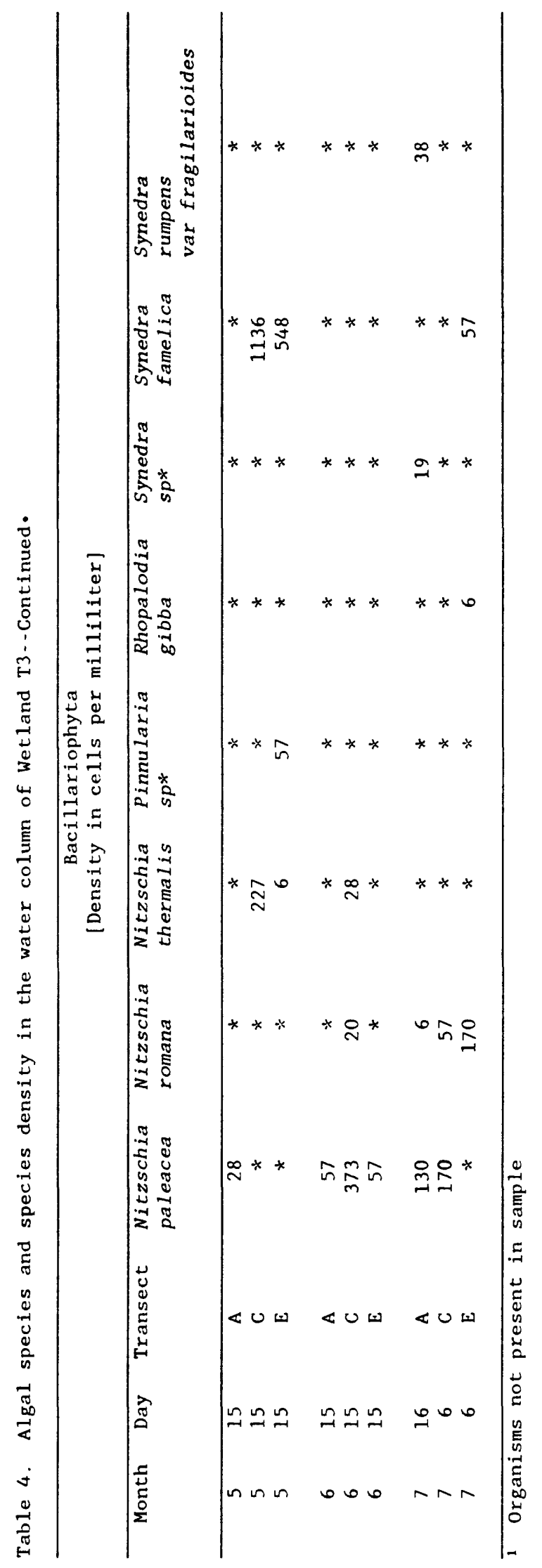




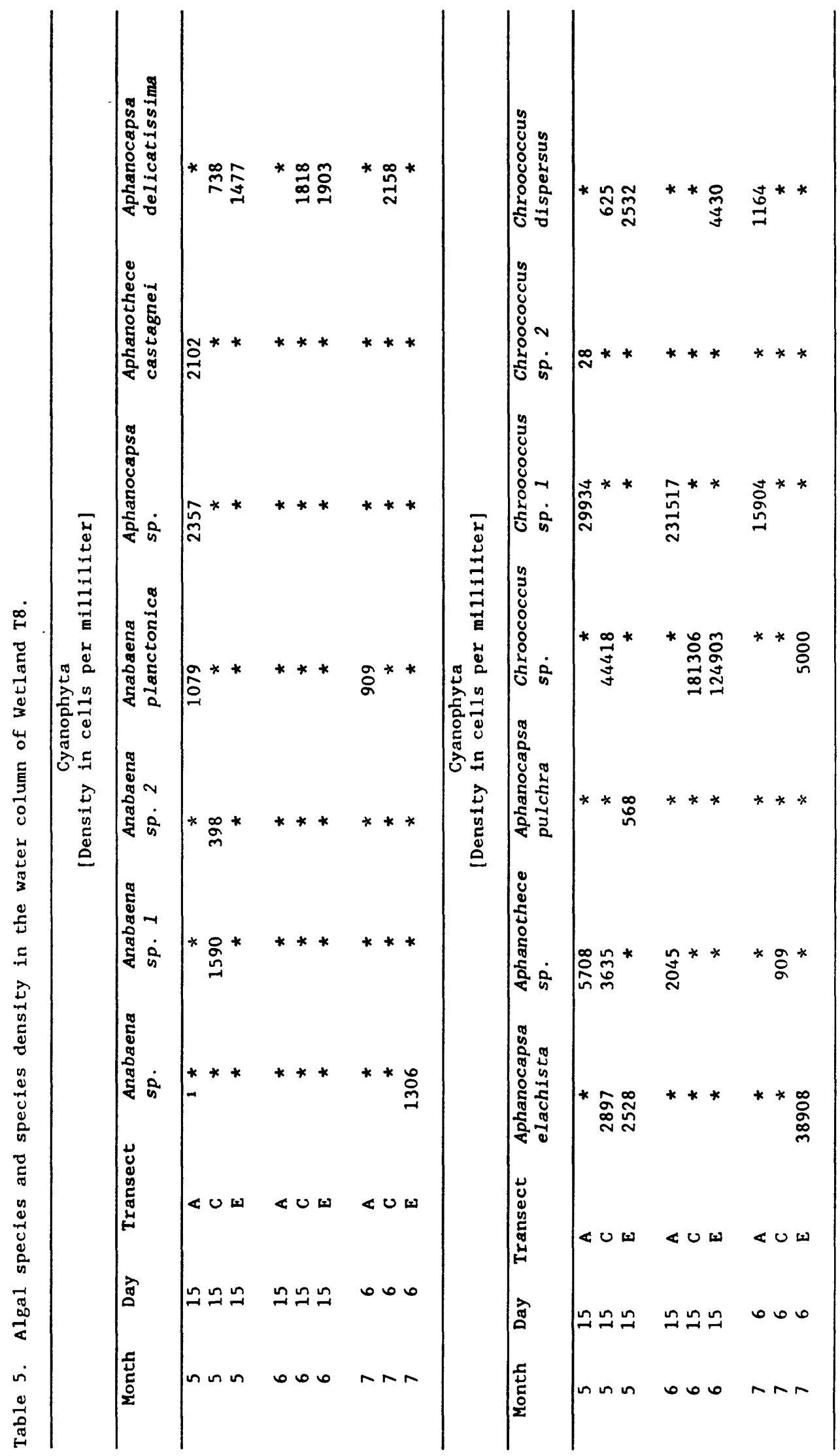




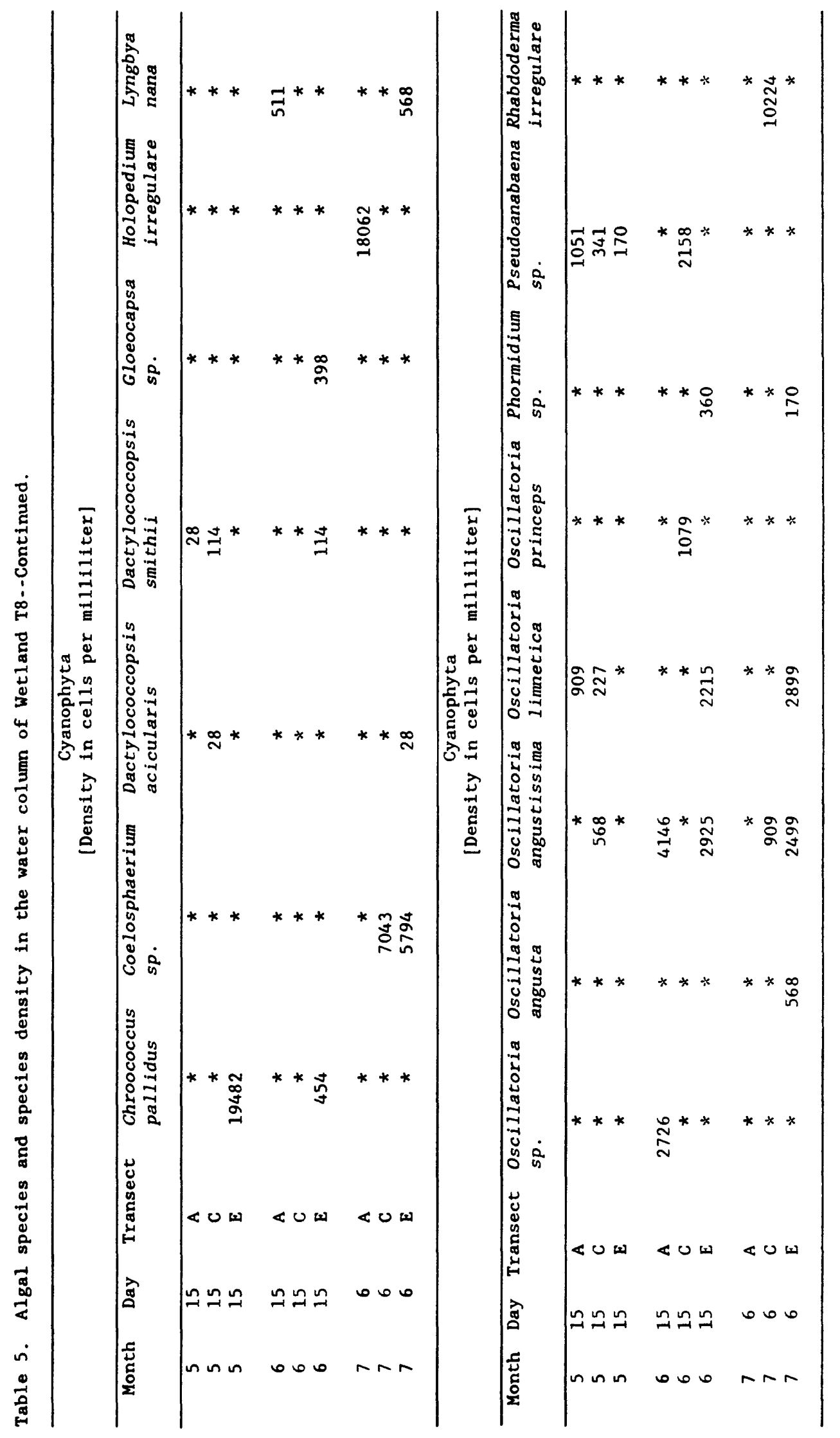









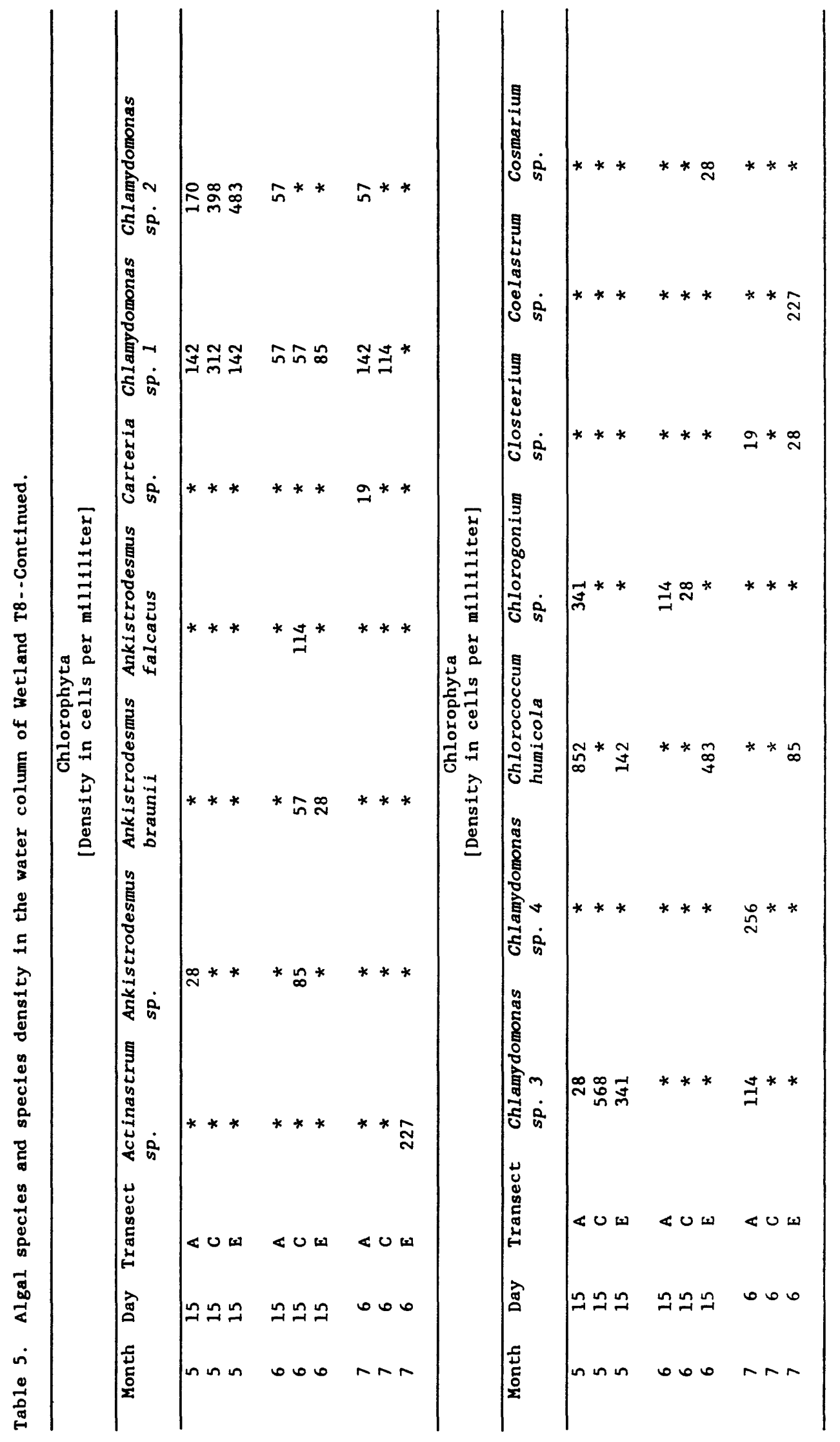




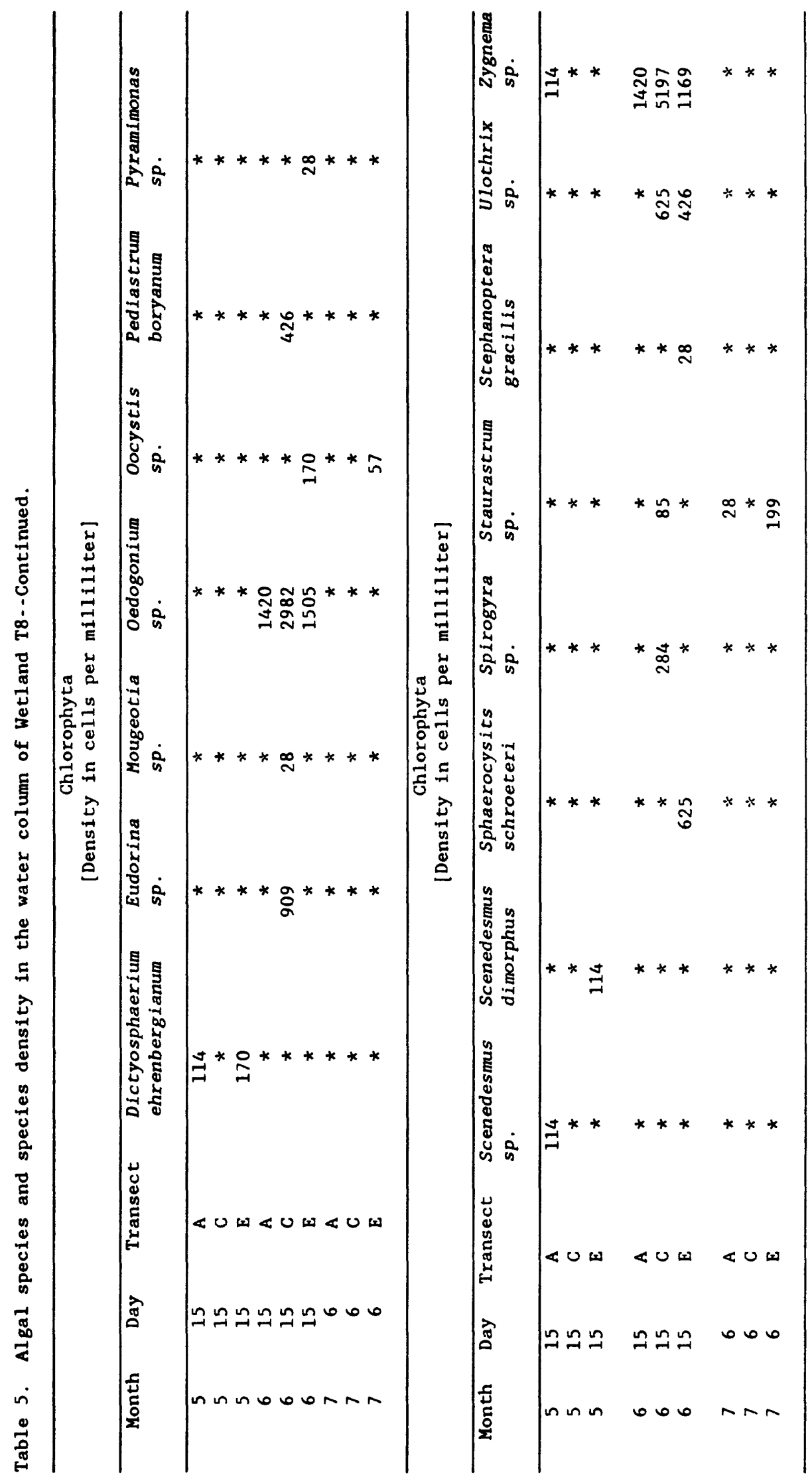




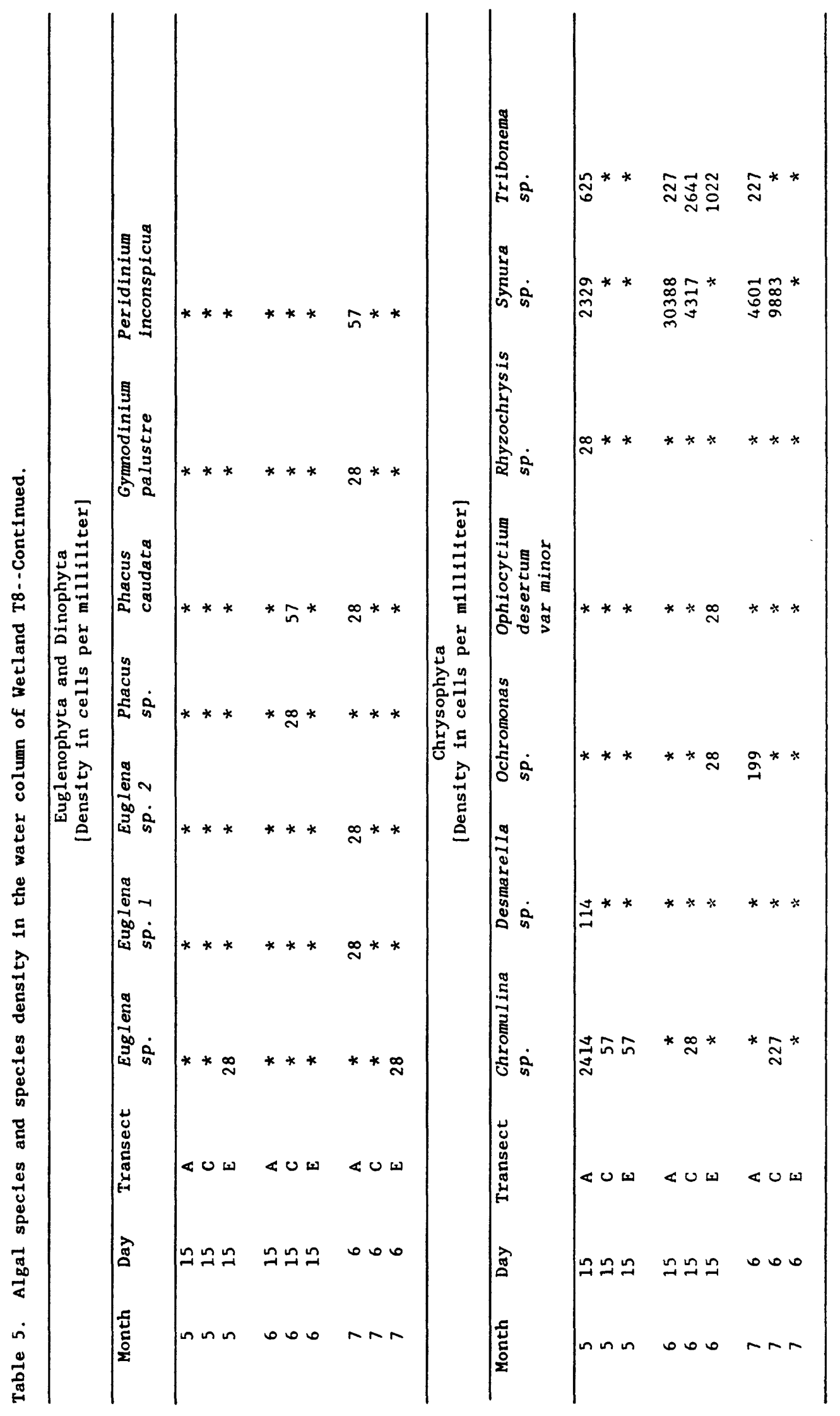




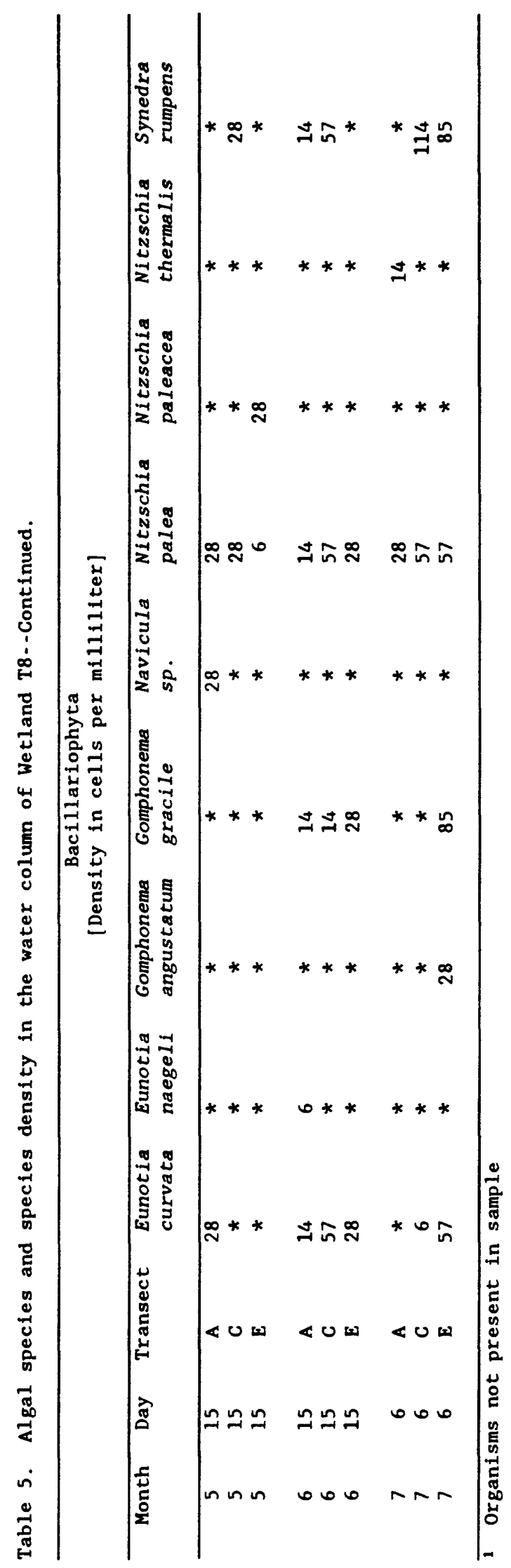




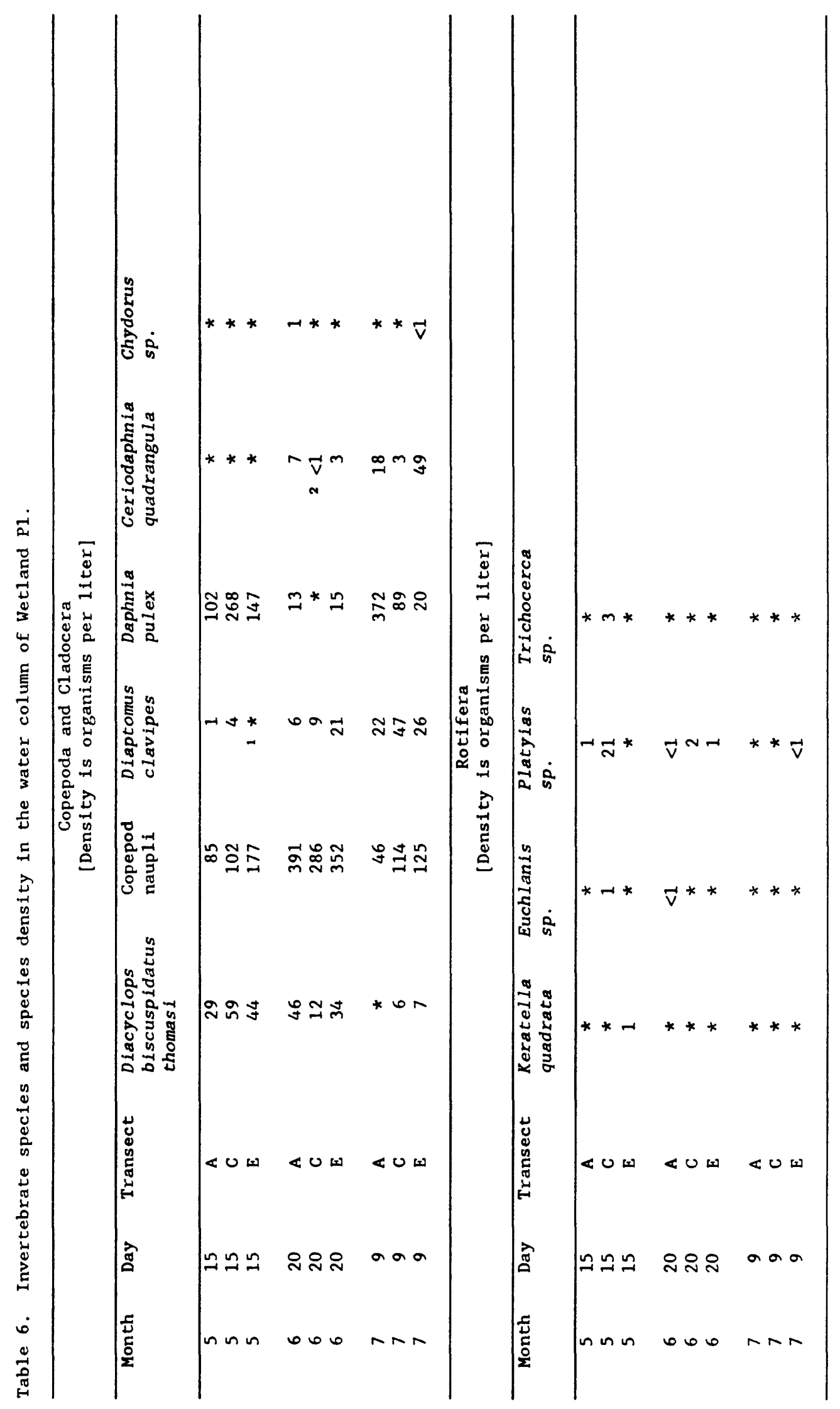




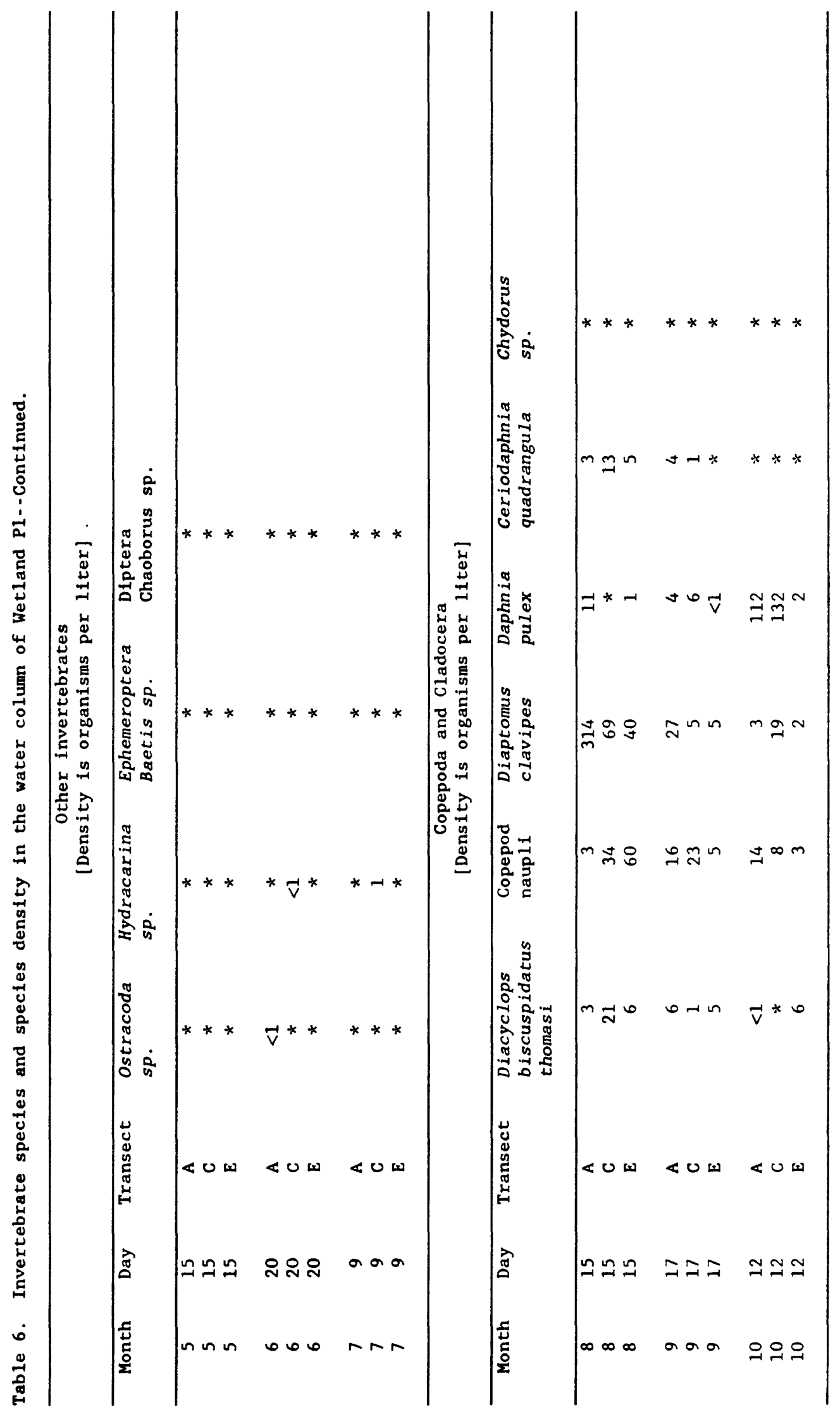




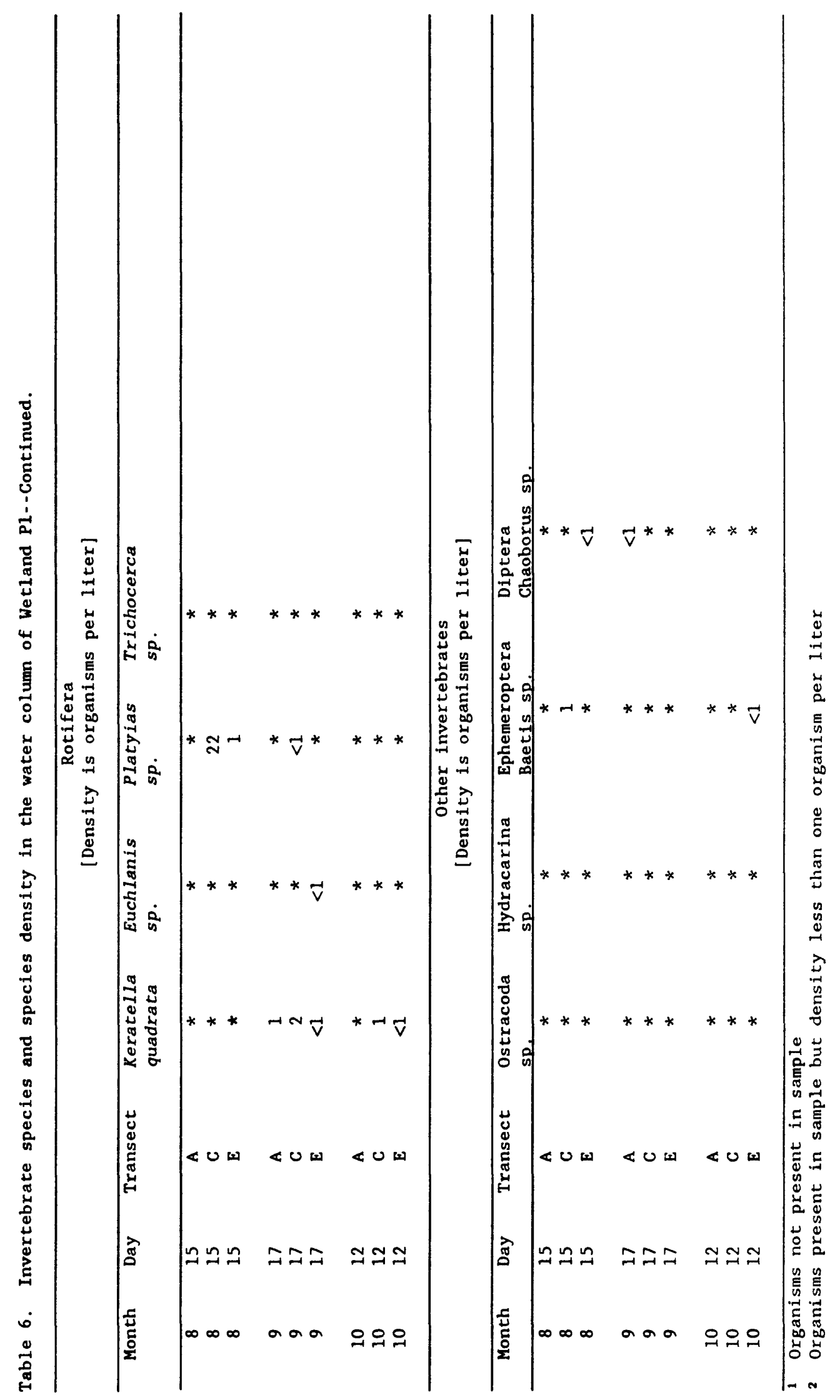




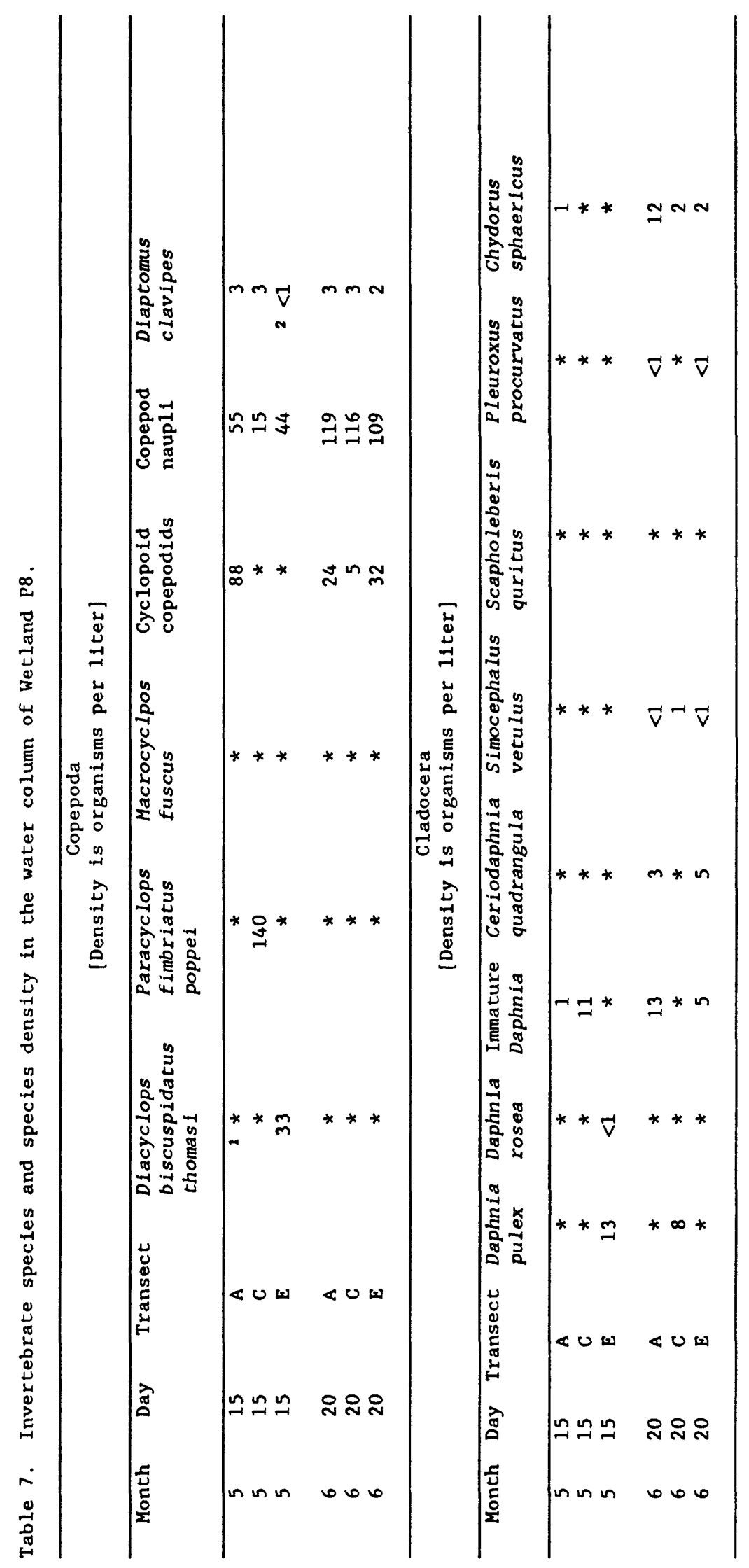




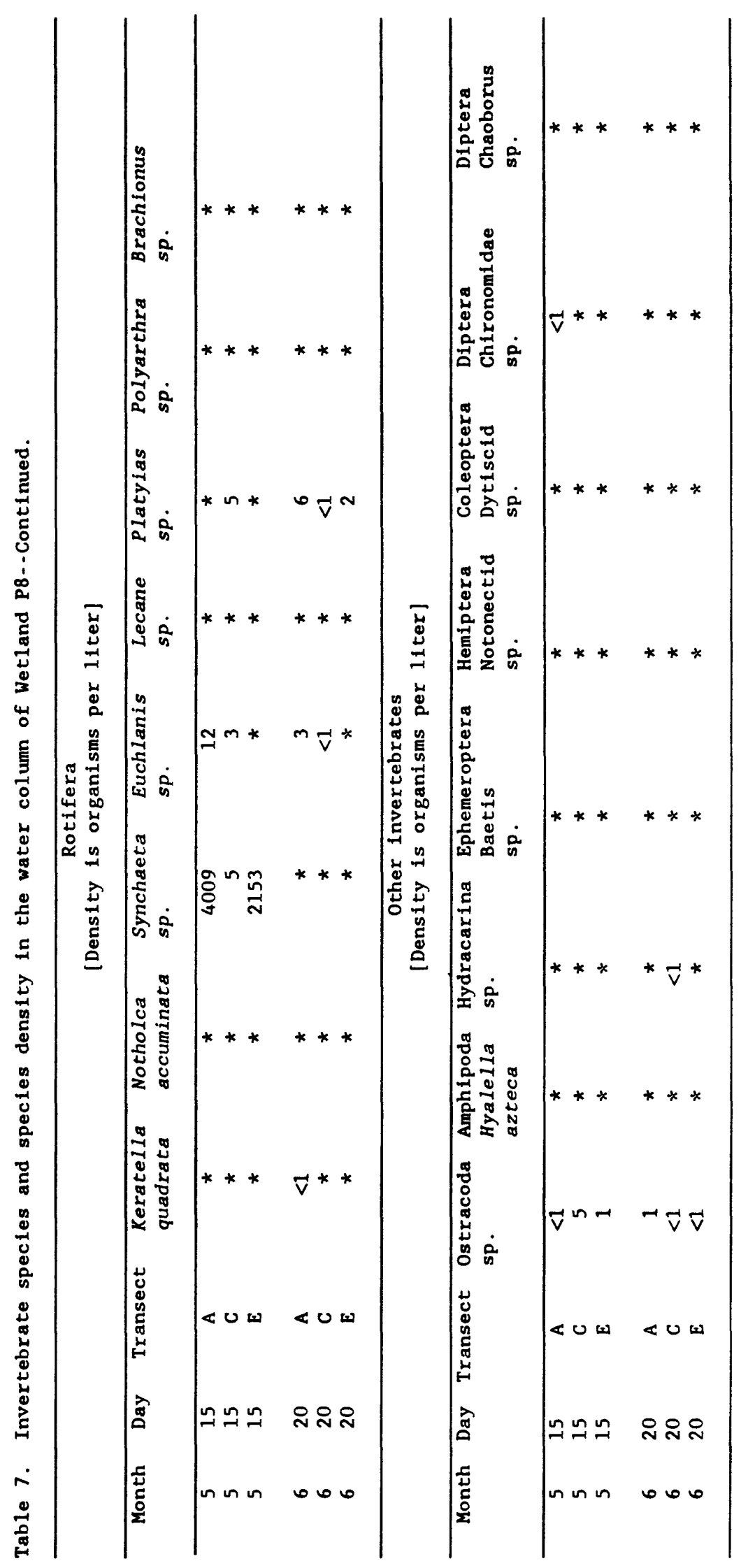




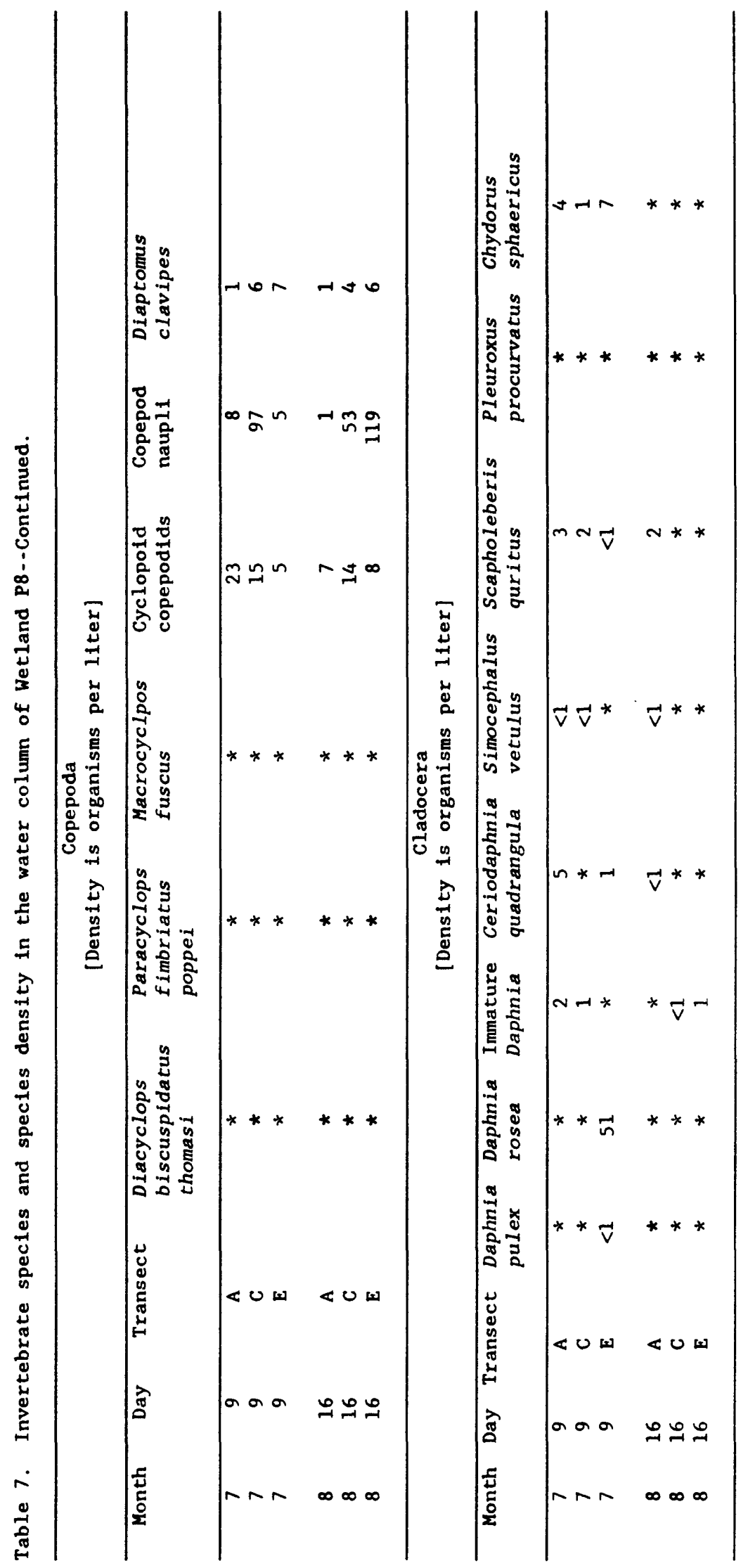




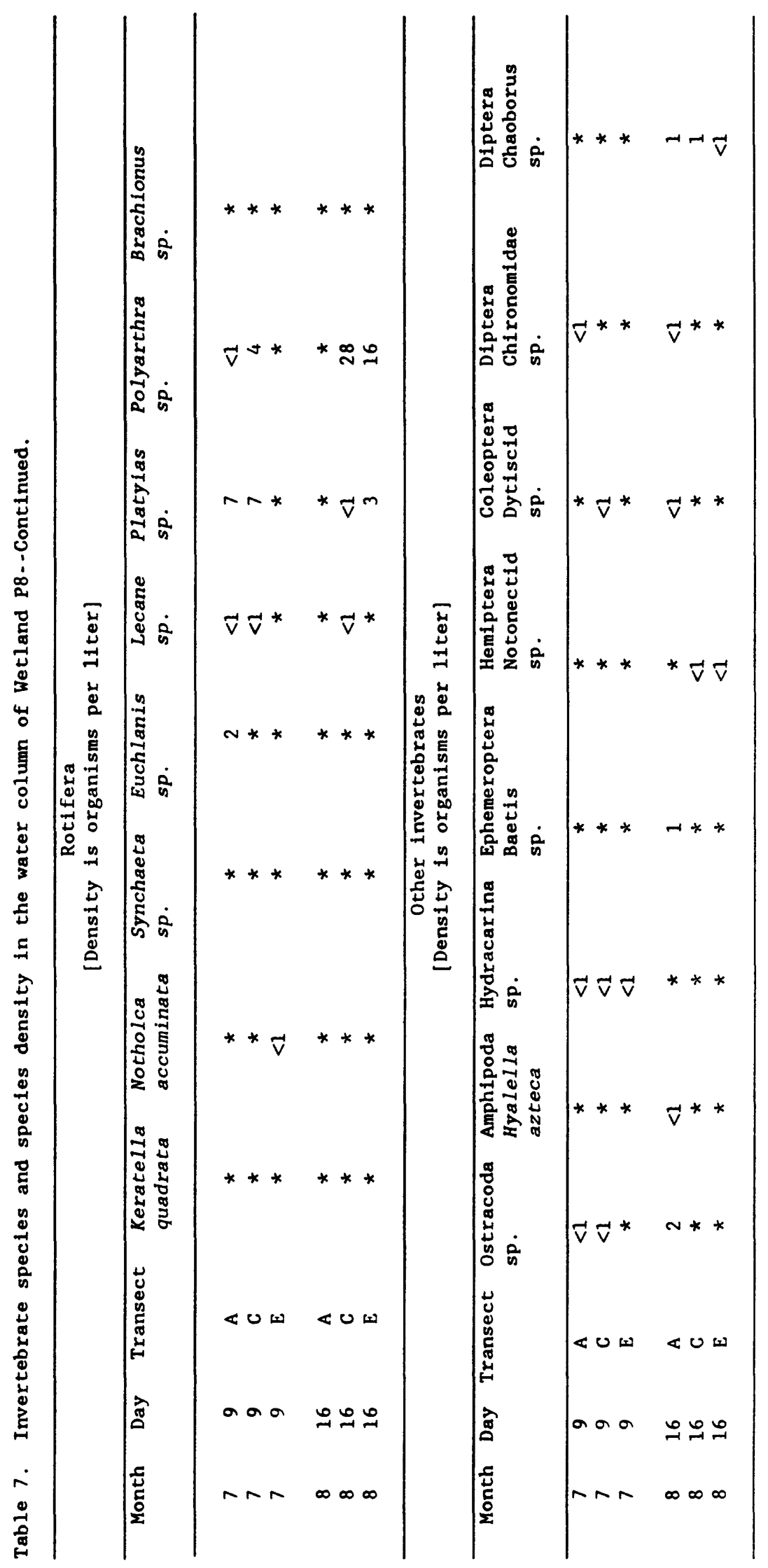




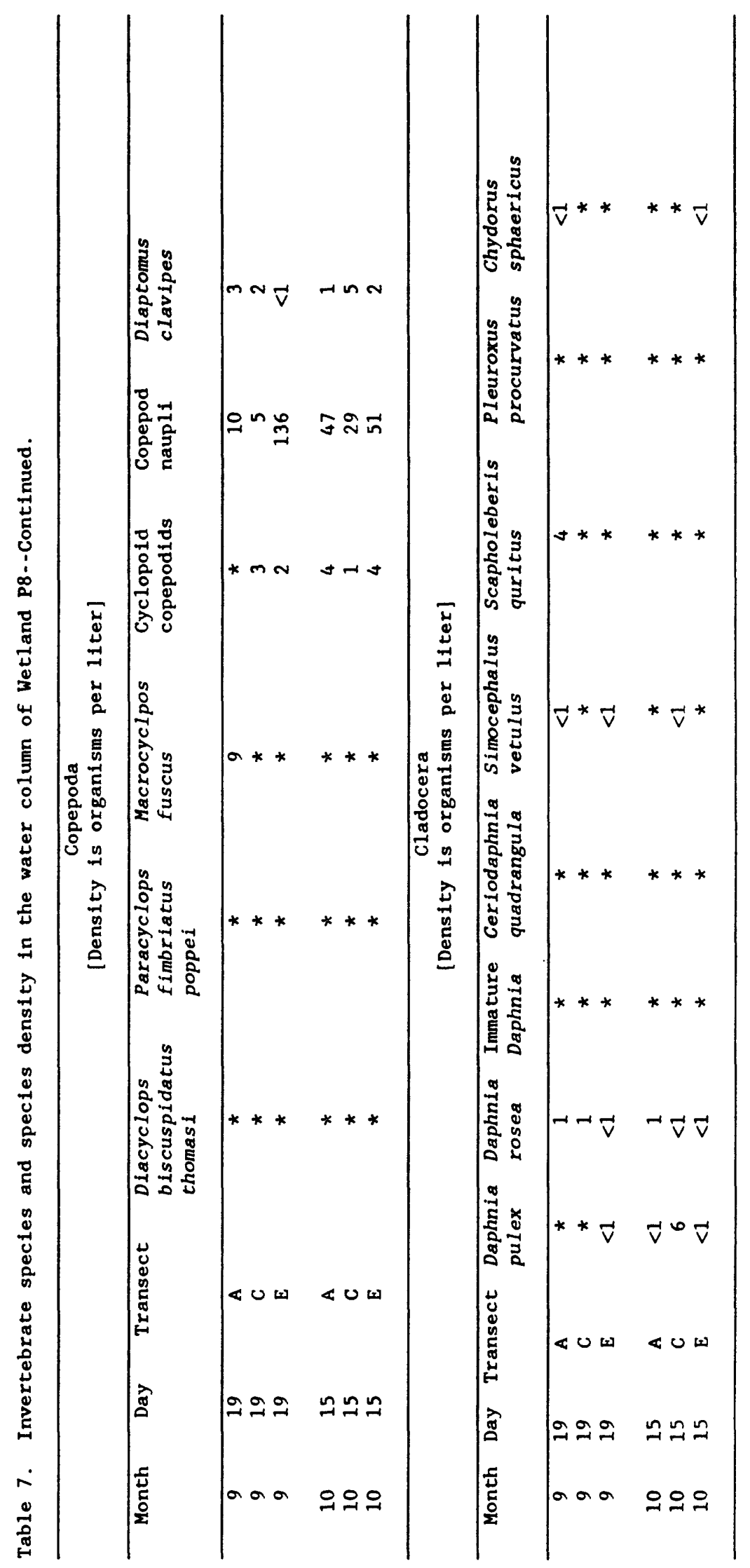




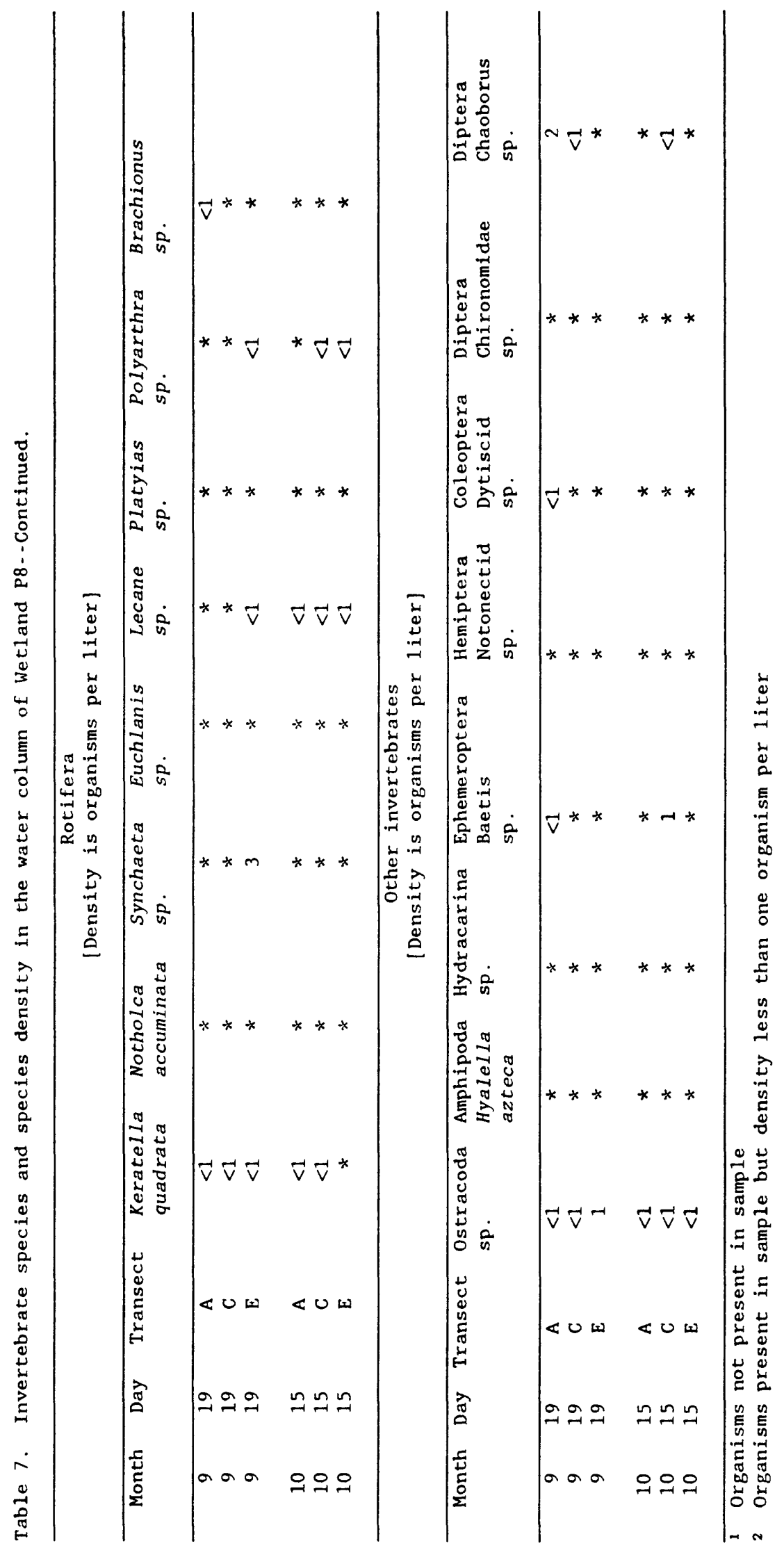




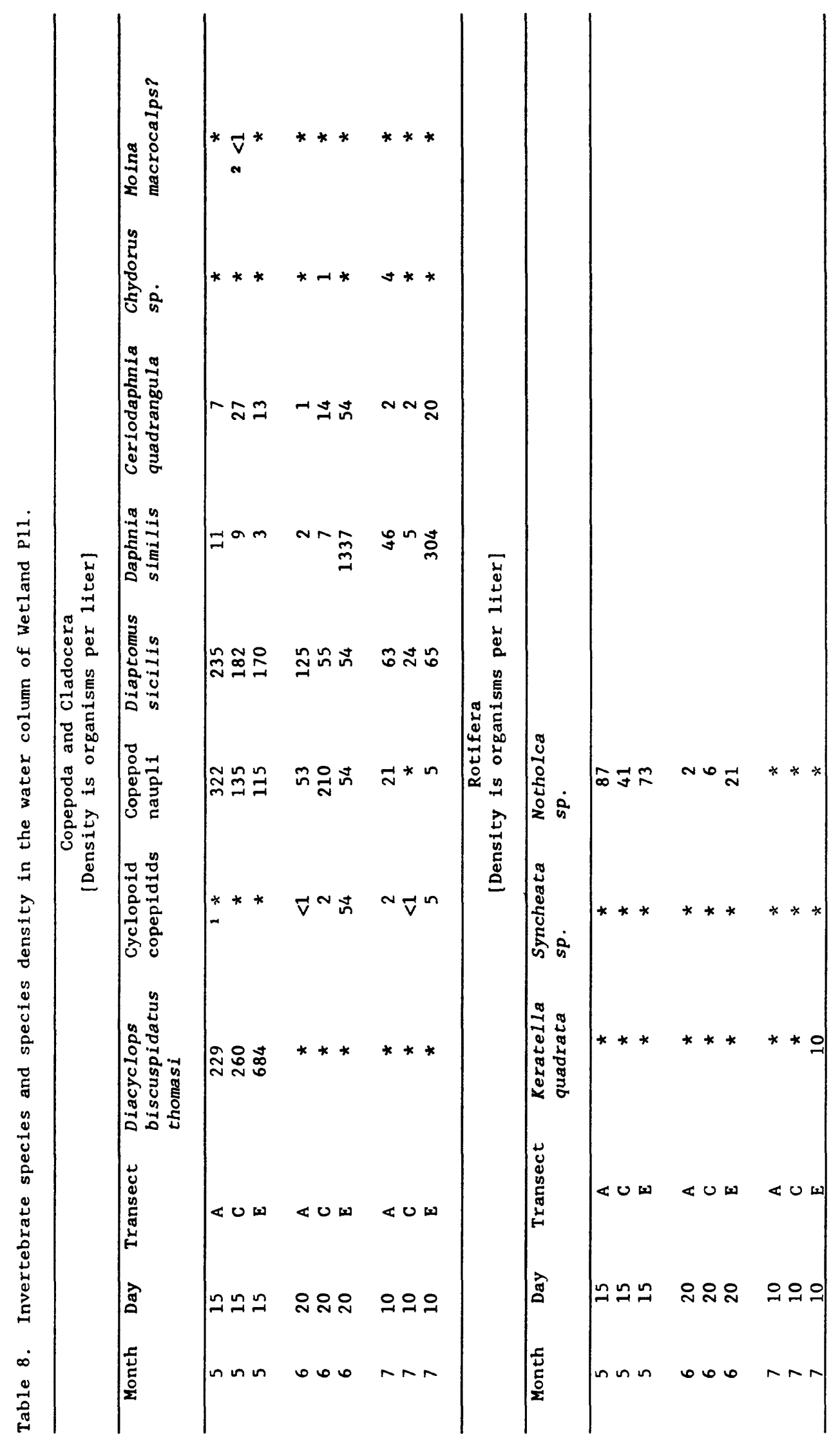









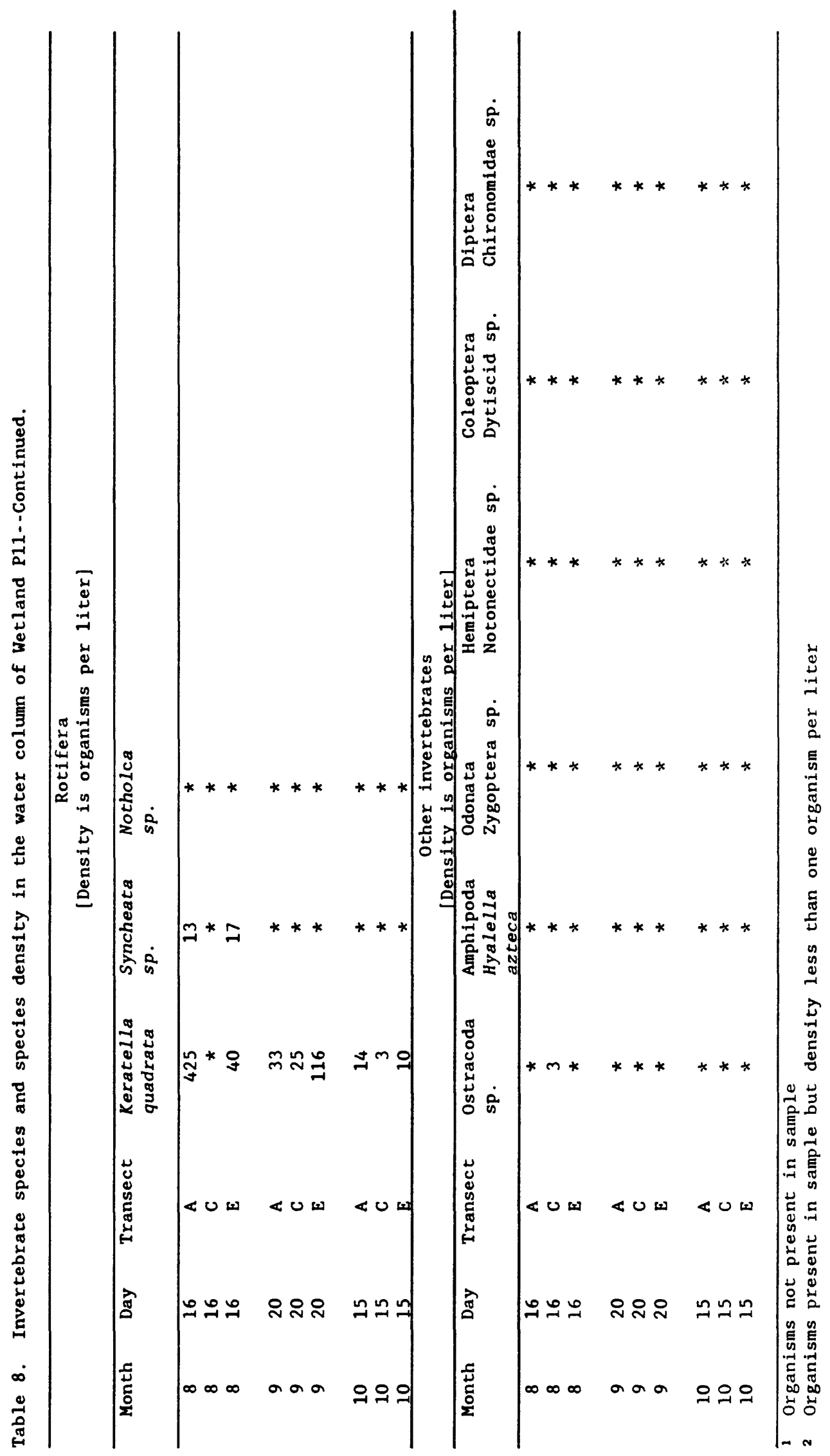




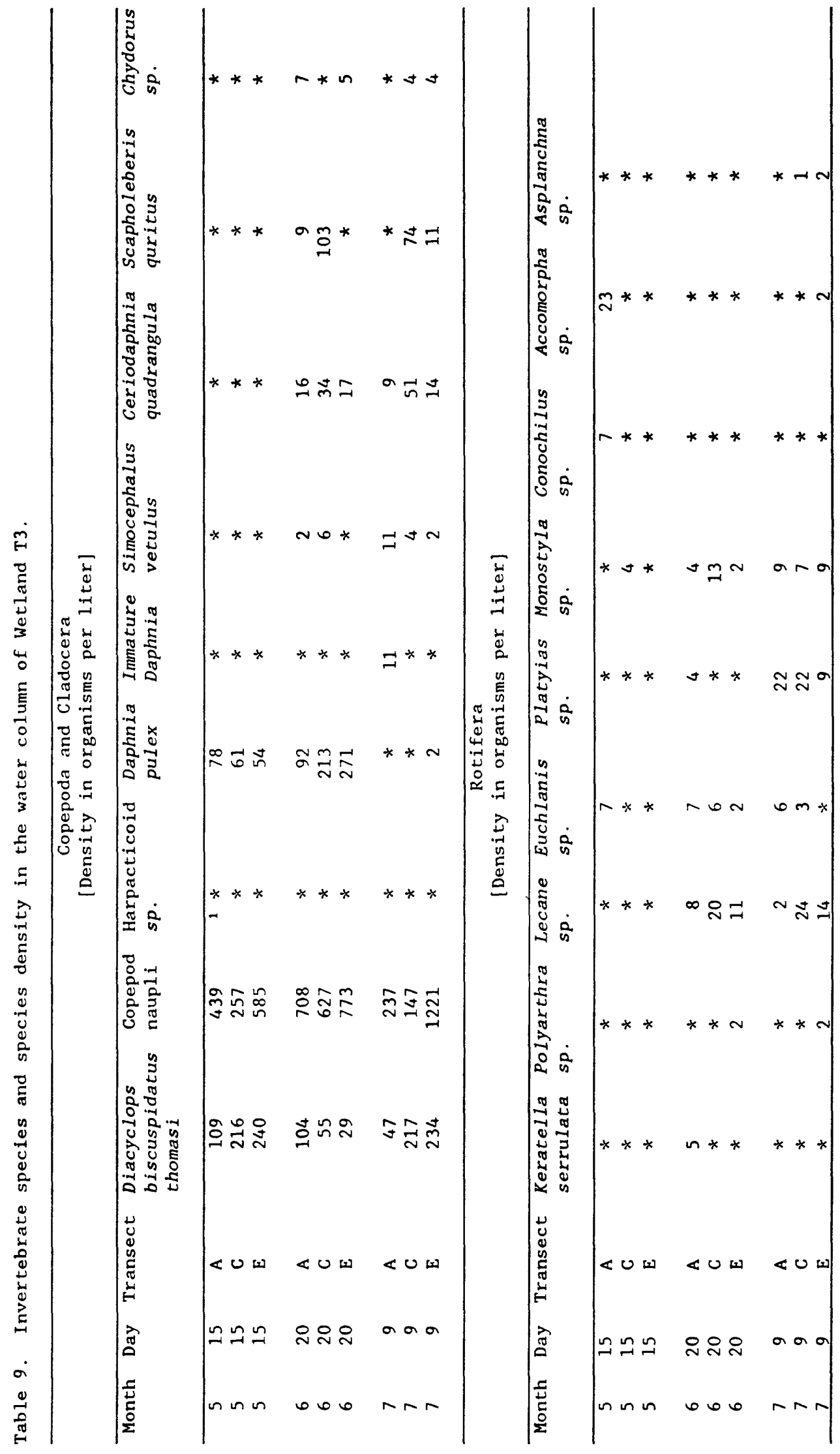




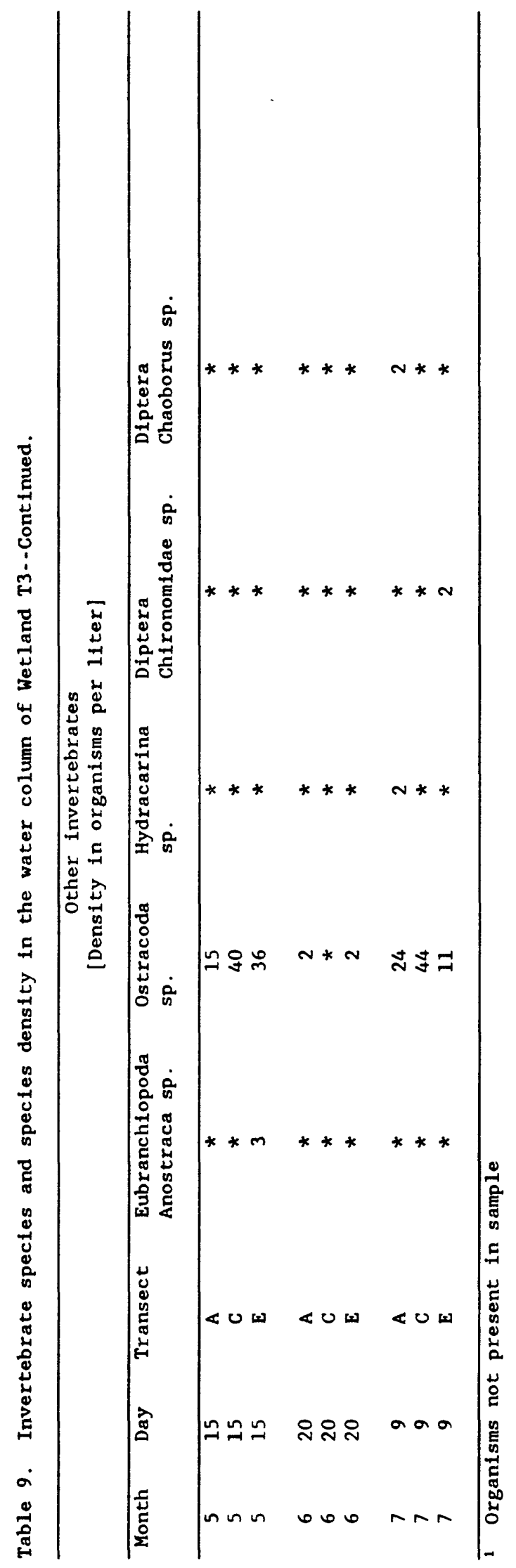




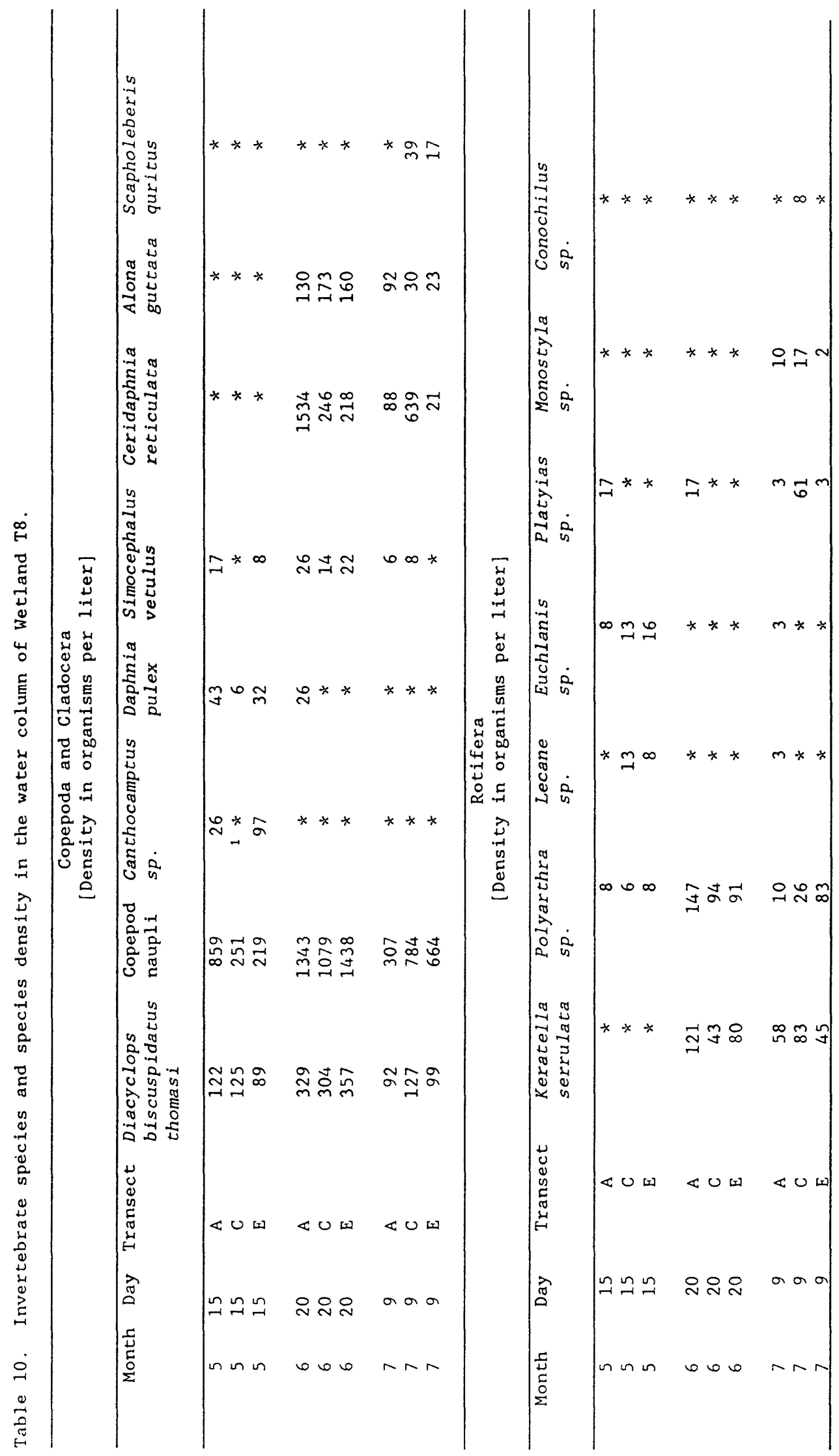




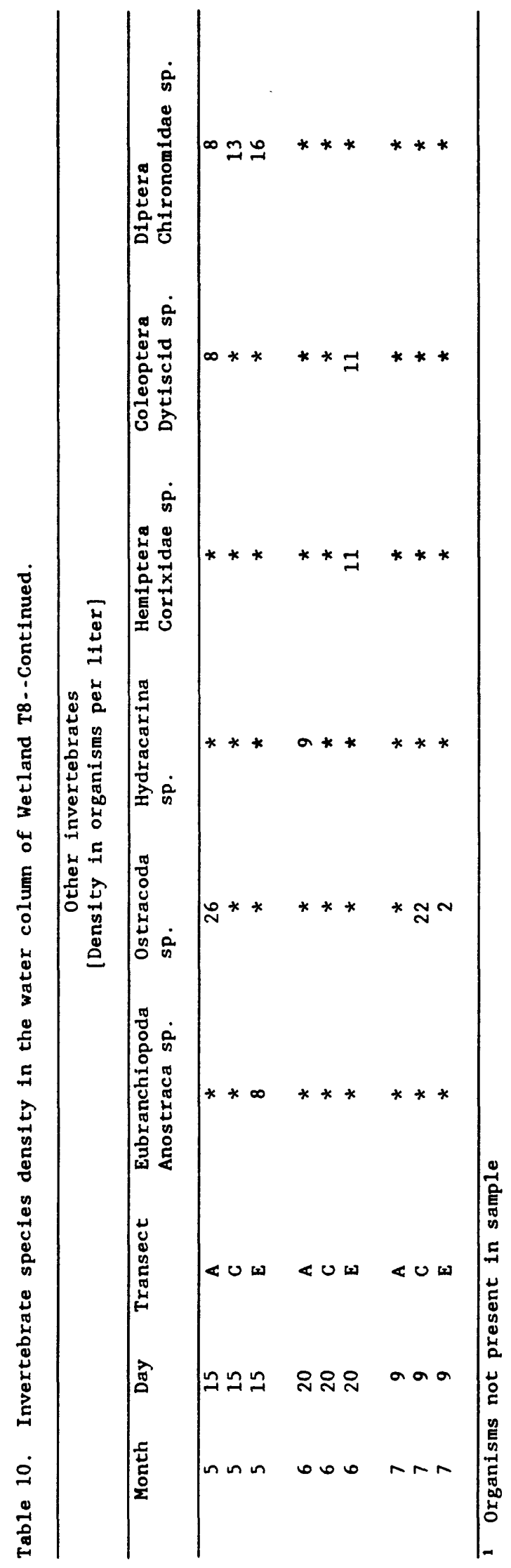

